\title{
Study of the Mn-Binding Sites in Photosystem II Using Antibodies Raised Against Lumenal Regions of the D1 and D2 Reaction Center Proteins
}

Enrique Agustin Dalmasso

(Ph.D. Thesis)

Department of Chemistry

University of Califormia

and

Chemical Biodynamics Division

Lawrence Berkeley Laboratory

University of California

Berkeley, California 94720

April, 1992

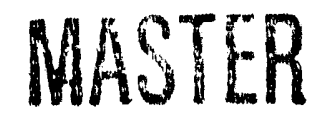

This work was supported by the Director, Division of Energy Biosciences, Office of Basic Energy Sciences, U. S. Department of Energ, inder contract DE-AC03-76SF00098 


\title{
Study of the Min-Binding Sites in Photosystem II \\ Using Antibodies Raised Against Lumenal Regions \\ of the D1 and D2 Reaction Center Proteins
}

by

Enrique Agustin Dalmasso

\begin{abstract}
The experiments discussed in this thesis focus on identifying the protein segments or specific amino acids which provide ligands to the Mn cluster of photosystem II (PS II). This Mn cluster plays a central role in the oxygen-evolving complex (OEC) of PS II. The Mn cluster is thought to be bound by lumenal regions of the PS II reaction center proteins known as D1 and D2. First, several peptides were synthesized which correspond to specific lumenal segments of the D1 and D2 proteins. Next, polyclonal antibodies were successfully elicited using three of these peptides. The peptides recognized by these antibodies correspond to protein segments of the spinach reaction center proteins: lle-321 to Ala-344 of D1 (D1-a), Asp-319 to Arg-334 of D1 (D1-b), and Val-300 to Asn-319 of D2 (D2-a). These antibodies were then used in assays which were developed to structurally or functionally probe the potential Mn-binding regions of the D1 and D2 proteins.

The two assays yielding structural information were western blotting and solution binding experiments. Western blotting identified the denatured proteins of spinach PS II membrane preparations to which the antibodies bound. The solution antibody binding assay was used to confirm antibody binding to native PS II mernbranes. Three assays which examined functional aspects of PS III were measurement of oxygen evolution. yield of photoactivation, and $\mathrm{MnCl}_{2}$ inhibition of diphenylcarbazide (DPC) to 2,6 -
\end{abstract}


dichlorophenol indophenol (DCIP) photoreduction. Assays of oxygen evolution tested the ability of antibodies to affect the naturally bound Mn of PS II. The yield of photoar-ivation assays investigated the ability of antibody to block the binding and subsequent photoligation of Mn to PS II membranes lacking the endogenous Mn cluster. Finally, experiments which assayed the $\mathrm{MnCl}_{2}$ inhibition of DPC to DCIP photoreduction addressed whether bound antibody could block any of the four components of the highaffinity Mn-binding site that become available in the presence of DPC.

The results of these experiments include the following: All three antibodies reacted with their corresponding denatured protein (D1 or D2) on western blots. In solution binding assays, the binding of the three antiborlies to several PS II preparations was demonstrated and characterized. The first antibodies available, those against D1-a, were used in initial experiments to examine effects on oxygen evolution. Using PS II membrane preparations of varying extrinsic protein composition, no adverse effects of these antibodies were observed on oxygen evolution. All three antibodies were then used to test for possible effects on the ability to photoactivate the Mn cluster of the OEC. These assays showed no effect for the antibodies recognizing the D1-b or D2-a peptide and some decrease in yield for the antibodies recognizing the D1-a peptide. Finally, incubation of Tris-treated PS II membrane preparations with antibodies to the D1-a peptide resulted in an inhibition of one component of the high-affinity $\mathrm{Mn}$-binding site as measured by the $\mathrm{MnCl}_{2}$ inhibition of DPC to DCIP photoreduction. This did not occur with antibodies raised against the D1-b or the D2-a peptides. This suggests that the carboxyl end of the D1 protein may provide a ligand for the high-affinity binding of Mn in PS II. Additionally, the inability of the other two antibodies to block any of the high-affinity, Mn-binding sites is an indication that their epitopes are in regions of D1 and D2 which do not contain Mn-binding residues detectable by the $\mathrm{Mn}^{2}+/ \mathrm{DPC}$ assay. 
To those who face challenges, struggle against adversity and surmount seemingly impossible obstacles.

They are the ones who survive the difficult times and truly appreciate the good. 


\section{TABLE OF CONTENTS}

$\begin{array}{ll}\text { Abstract } & 1\end{array}$

Table of contents iii

Acknowledgements iv

Chapter 1: Introduction 1

$\begin{array}{lll}\text { Chapter 2: } & \text { Peptides }\end{array}$

Chapter 3: Antibodies $\quad 63$

$\begin{array}{lll}\text { Chapter 4: } & \text { Western blotting assays } & 68\end{array}$

$\begin{array}{lll}\text { Chapter 5: } & \text { Oxygen evolution assays } & 96\end{array}$

$\begin{array}{lll}\text { Chapter 6: } & \text { Solution binding assays } & 111\end{array}$

$\begin{array}{lll}\text { Chapter 7: } & \text { Photoactivation assays } & 121\end{array}$

$\begin{array}{lll}\text { Chapter 8: } & \text { Assay of high-affinity Mn-binding sites } & 149\end{array}$

$\begin{array}{lll}\text { Appendix 1: } & \text { List of Abbreviations. } & 176\end{array}$

Appendix 2: $\quad$ List of Amino Acid 3 and 1 Letter Codes 179

$\begin{array}{lll}\text { Appendix 3: } & \text { List of Figures } & 180\end{array}$

$\begin{array}{ll}\text { References } & 182\end{array}$ 


\section{Acknowledgements}

Finally, the "acknowledgements." This seems to be the section of a thesis that the author saves for last, but most readers look at first. It is the place where one is allowed to be formal or friendly, and to express gratitude to those people that have enriched one's graduate years. I greatly appreciate the opportunity to do so on paper. But, whether specifically named here or not I hope that my appreciation is not silent and that I have personally demonstrated my gratitude to everyone involved.

Educationally, I would like to especially thank J. Michel and J. Jaglo at RHS, who sparked and fanned my early interests in science; Profs. Carlin, Mohrig, Rammette and Buffington at Carleton, who gave me the foundations of Chemistry within the "confines" of a liberal arts education; John Hearst, my advisor at Berkeley, whose patience, understanding and encouragement have gotten me to where I am today; and Ken Sauer, an outstanding teacher and educator, who served as an advisor and provided the motivation behind my interest in teaching.

During my years in graduate school, several individuals have directly affected and encouraged my progress. Peter Sandusky, Jeff Gingrich and Jean-Luc Zimmermann taught me the basics of research in photosynthesis. Gary Smith and Phil Eggers maintained the computers and electronics at LCB in excellent fashion. Anita Hong (formerly at Applied Biosystems), Joe Pease and David Koh were extremely helpfal with the synthesis and purification of peptides. Joe and David were also involved in numerous lunch and cappuccino runs. And, the technicians and veterinarians at the UCB Office of Laboratory Animal Care were invaluable during antibody production.

Michael Seibert and Chris Preston at the Solar Energy Research Institute in Golden, Colorado were important collaborators in the experiments involving the assay of highaffinity Mn-binding sites in photosystem II. John Hearst, Nacho Tinoco and Taso Melis had the unenviable opportunity to officially read and critique this thesis. Of more importance to the accuracy of the thesis were Ken Sauer, Yvonne Gindt, Vittal Yachandra 
and Mike Seibert, who provided very useful and thorough comments and insights during its preparation.

The entire Hearst group at Hildebrand, to which I am now known as the "Last of the Hildebrand's," has been a special "extended family." I shared many important occasions with this group, which has included Sam, Yun-Bo, Suzanne, Pete and Susie, Jason and Effie, Joe and Tracy, John Hubbard and John Tessman. I have benefitted from the variety of scientific and personal interests of the Hearst group at LCB, namely Greg A., Dave, David O', Don, Marie, Zack and Bhupinder. In addition to Ken and Mel, the members of the Sauer-Klein group at LCB, especially Xvonne, Martin, Wen, Matthew, Ishita, Dave, Warren, Vickie and Vittal, have provided a fruitful learning environment.

Several other friends deserve special mention. David and Martin were challenging skiing partners. The instructors and students of the UCB Underwater Scientific Research Prograrn, especially Jen, Shivaun, Ken, Chris, Skip, Bob, Tiff, Jenni, Johnny, Kyler, Dorothy, Lisa, Katie, Jon, Jim, Bruce, Jack, Paul, Scott, Charles, Lloyd and Doris are reliable buddies and good friends. My friends in Davis, especially Ashley, Pat, Thom and Joy have treated me as part of the family. And, the Husky Siberian scholar, Nanook Poochinski, has been constantly at my side during the past two years.

Finally, the end of this section was reserved for the most special people in my life. Ken and Susan, who encouraged the yearly pilgrimage to Seattle, are genuinely good friends. My brothers, Luis and Horacio, continue to become better friends as time progresses. The unending love, support and encouragement from my parents, Maria and Agustin, have shown me that they often understand me better than I do myself. Most importantly, Jen Koeber and I have grown as individuals and learned so much together in the past five years that I simply cannot thank her enough.

This work was supported by the Director, Division of Energy Biosciences, Office of Basic Energy Sciences, U. S. Department of Energy under contract DE-AC03-76SF00098. 


\section{INTRODUCTION}

The general theme of the topics discussed in this thesis focuses on the identification of the location of the Mn cluster of the oxygen-evolving complex (OEC) of photosystem II (PS II). Specifically, the development and use of several assays using antibodies raised against synthetic peptides corresponding to specific lumenal segments of the D1 and D2 proteins are discussed. The D1 and D2 proteins are thought to constitute the reaction center of PS II and to be the location of the OEC. The assays were used to identify protein segments or specific amino acids which may provide ligands to the OEC Mn (Chapters 4 8). The choice of peptides, their synthesis and the production of antibodies are also discussed (Chapters 2 and 3). This chapter (Chapter 1) is divided into several sections which provide the basic conceptual framework and background necessary to understand the relevance of the assays which are discussed in the chapters that follow. The first two sections present a brief general discussion of photosynthesis and PS II. The next section addresses the relevance of the D1 and D2 proteins. For further details on these topics, refer to publications referenced in the corresponding section. The characteristics of the oxygenevolving complex are dealt with in greater detail in the next section, with emphasis on current chemical and structural proposals for the Mn cluster of the OEC. The identification of the D1 and D2 proteins as the proteins which provide the most likely sites for binding of the OEC Mn is discussed in the next two sections. The initial genetic and biochemical evidence for this proposal is presented first. The second of these two sections concentrates on the more recent, chemical and spectroscopic, evidence supporting the same proposal. After that, a selection of recent publications where antibody effects on enzymatic functions were used to investigate the structure and function of several other enzyme systems are reviewed. Finally, the specific goals of the work presented in this thesis are outlined. 


\section{Photosynthesis}

Photosynthetic organisms that have evolved on earth can be classified as either oxygenic or anoxygenic. Anoxygenic photosynthetic organisms include both sulfur and non-sulfur green and purple bacteria. These bacteria are thought to be the evolutionary precursors to chloroplasts and mitochondria. Photosynthetic organisms which evolve oxygen are called oxygenic and include the prokaryotic cyanobacteria, algae and higher pl unts. The organisms of this group use solar energy to drive the fixation of $\mathrm{CO}_{2}$ to carbohydrates. Water is used as the terminal electron donor for these reactions and its oxidation produces oxygen as a by-product. All of the respiring organisms are indebted to the oxygenic photosynthetic organisms because they provide the reduced carbon compounds and oxygen necessary to sustain non-photosynthetic life.

The conversion of light energy to chemical energy takes place on internal membranes of the photosynthetic organisms. For oxygenic organisms, these processes take place on the thylakoid membranes. Higher plants contain these thylakoid membranes within organelles known as chloroplasts. Imbedded within the thylakoid membranes are several protein complexes which function to capture light energy, create proton and charge gradients, and convert the potential energy of these gradients into chemical energy. Two of these protein complexes function in the trapping of light energy and are schematically shown in the Z-scheme (Blankenship and Prince, 1985) presented in Figure 1-1. This Zscheme positions the chromophores and electron transfer components of Photosystem II (PS II) and photosystem I (PS I) on a vertical axis of increasing, reduction potential. The light energy is used in the pumping of electrons across the thylakoid membrane from the lumenal to the stromal side. PS II uses photon energy to oxidize two molecules of water producing molecular oxygen on the oxidizing (lumenal) side of the membrane. On the reducing (stromal) side of the membrane, PS II reduces plastoquinone to form a 


\section{Figure 1-1: Photosynthetic Z-scheme}

Z-scheme representing non-cyclic electron flow in oxygenic photosynthesis (adapted from Blankenship and Prince, 1985). Redox active chromophores and electron transfer components of PS II and PS I are positioned on a vertical axis of increasing reduction potential. Dark dashed arrows indicate the absorption of a photon by a primary donor, small solid arrows indicate electron transfer steps, light dashed arrows indicate the direction of proton flow and solid lines represent the thylakoid membrane boundaries. 


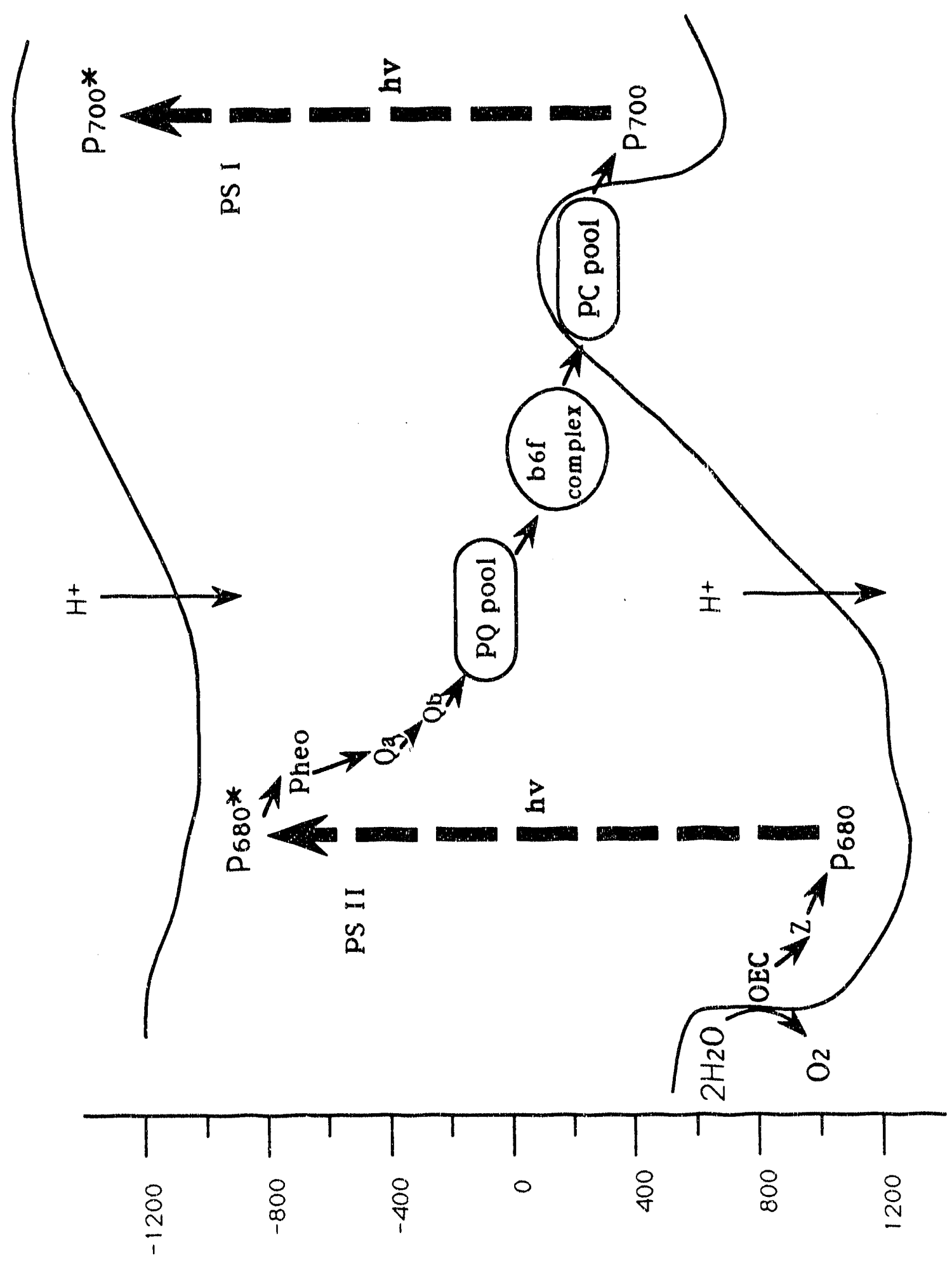

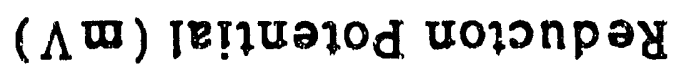


plastoquinol. This plastoquinol is released from PS II and transfers electrons to a plastocyanin pool via the Cyt $66 f$ complex (another integral membrone protein complex). Plastocyanin then transports electrons to PS I, which serves as an electron donor to bound ferrodoxin. Reduced ferrodoxin then transfers electrons to NADP+ (nicotinamide-adenine dinucleotide phosphate) to form NADPH. The combined action of the two photosystems establishes a proton gradient which is used to synthesize ATP (adenosine triphosphate). NADPH and ATP are used by the organism in the fixation of carbon dioxide to synthesize carbohydrates.

The two photosystems capture photon energy by the excitation of chlorophyll molecules in associated light-harvesting complexes. This excitation is then transferred to the reaction center of the appropriate photosystem, where charge separation takes place. This charge separation is a one electron process which is linked to multiple electron processes by charge accumulation. The details of charge separation and charge stabilization by PS II and the oxygen-evolving complex (OEC), whose localization is the focus of the work presented in this thesis, are described in the next section.

\section{Photosystem II}

The transfer of excitation from the light-harvesting antenna to the reaction center of PS II results in excitation of a chlorophyll $a$ complex known as P680. The number corresponds to the absorption maximum of this chromophore. Excitation of P680 is indicated by the vertical arrow for PS II in Figure 1-1. This excitation results in a large change in the reduction potential of P680 to form P680* (the excited state of P680). This excited electron is transferred to an intermediate pheophytin a molecule. A quinone molecule $\left(\mathrm{Qa}_{\mathrm{a}}\right.$ accepts one electron from this intermediate pheophytin $a$ and transfers it to a 
second quinone molecule $\left(Q_{b}\right)$. $Q_{b}$ acts as a two-electron gate in that it receives a second electron from $\mathrm{Q}_{a}$ after a second excitation of $\mathrm{P} 680$. This doubly reduced $\mathrm{Q}_{b}$ binds two protons and is released by PS II as a plastoquinol. The membrane-soluble plastoquinol then transfers electrons to PS I as described earlier.

The transfer of an electron away from P680 towards the reducing side of the thylakoid niemtrane produces an electron deficiency, or "hole," in P680. This "hole" is filled by electron donation from a nearby tyrosine residue called $Y_{Z} Z$ (previously known as $Z$ ). This oxidized species, $\mathrm{YZ}^{+}$, then extracts an electron from the OEC. The OEC acts as a four-electron gate on the oxidizing (lumenal) side of the thylakoid membrane. These four oxidizing equivalents are created by four separate excitations of P680 and transferred sequentially to the OEC through $Y_{Z}$. The OEC was proposed to cycle through four intermediates which accumulate these four oxidizing equivalents. It was proposed to involve the four Mn ions found tightly bound to PS II which are required for oxygen evolution. The OEC is discussed in greater detail in the section titled "oxygen-evolving center" later in this chapter.

All of the chromophores and electron-transfer components of PS II are bound by the protein components of PS II. A schematic of the oxygen-evolving core proteins of PS II is presented in Figure 1-2. This diagram depicts the proteins necessary for oxygen evolution under physiological conditions. The majority of light-harvesting proteins, which are present in PS II memhrane preparations, are not shown. The two largest proteins shown, $\mathrm{CP} 43$ and $\mathrm{CP} 47$, ane tightly associated light-harvesting proteins. The functions of CP43 and CP47 are not well understood, but they are present in all of the PS II preparations that evolve oxygen. The $\mathrm{D} 1$ and $\mathrm{D} 2$ proteins have been shown to function as the reaction center of PS II and bind the electron-transfer components of PS II as well as the Mn of the OEC. These two proteins, their amino acid sequences and their functions will be discussed in depth in sections that follow. The function of Cyt b-559 is also 


\section{Figure 1-2: Schematic of PS II proteins}

This schematic of the oxygen-evolving core proteins of PS II depicts the proteins necessary for oxygen evolution under physiological conditions. The D1 and D2 proteins have been shown to function as the reaction center of PS II and bind the electron-transfer components of PS II as well as the Mn of the OEC. In addition to the four $\mathrm{Mn}$ per reaction center, $\mathrm{Cl}^{-}$ and $\mathrm{Ca}^{2+}$ are cofactors required for oxygen evolution. Dashed lines represent the thylakoid membrane bouncaries. 


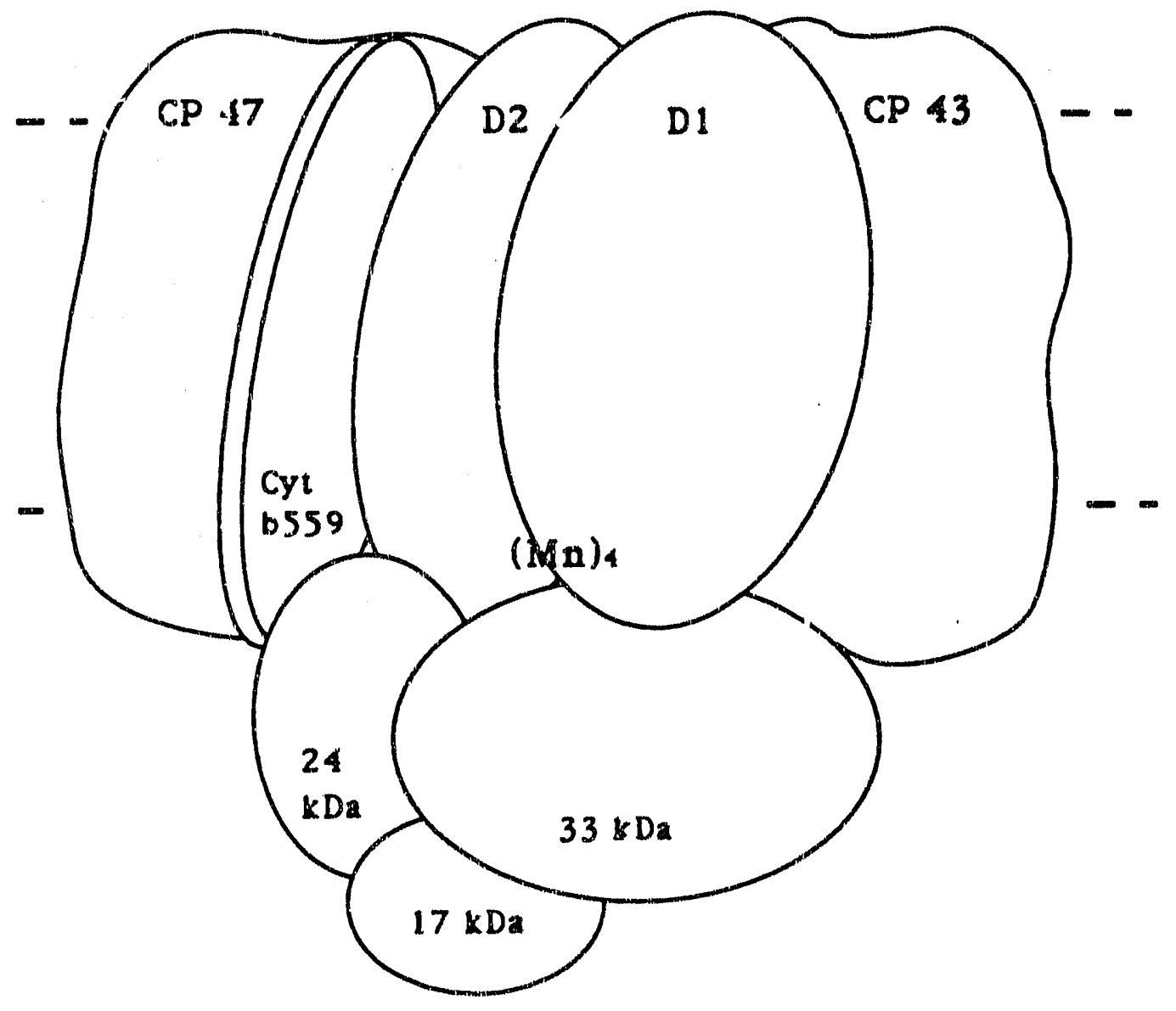


unclear, but it is always found tightly associated with the D1 and D2 proteins. There is one copy of Cyt b-559 per reaction center and it spans the thylakoid membrane. Each Cyt b559 contains a $5 \mathrm{kDa}$ polypeptide, a $9 \mathrm{kDa}$ polypeptide and a bridging heme group.

Finally, there are three extrinsic polypeptides of 17,24 and $33 \mathrm{kDa}$. The $17 \mathrm{kDa}$ protein is thought to provide or create tight $\mathrm{Cl}^{-}$-binding sites. The $24 \mathrm{kDa}$ protein is thought to provide or create tight $\mathrm{Ca}^{2+}$-binding sites. These two proteins are not essential for oxygen evolution and can be replaced by increasing the concentrations of $\mathrm{Cl}^{-}$and $\mathrm{Ca}^{2+}$, respectively. The $33 \mathrm{kDa}$ protein is not absolutely essential, but is necessary for full oxygen-evolving activity and protects the OEC Mn from reductants in the medium. The 33 $\mathrm{kDa}$ protein provides few, if any, ligands to this $\mathrm{Mn}$. Additionally, a $20 \mathrm{kDa}$ polypeptide and several small polypeptides of $<5 \mathrm{kDa}$ with unknown functions have been shown to be associated with various PS II preparations and have been omitted from this figure for clarity.

\section{Reaction center of PS II}

The assignment of the specific proteins which function as the reaction center of PS II has been a source of controversy until recently. One of the proposed models focussed on the protein known as CP47 (Nakatani et al., 1984). The issue was clarified when a strong sequence homology between the herbicide-binding protein of PS II from higher plants and blue-green algae (also known as the $\mathrm{Qb}_{b}$-binding protein or the D1 protein) and the $\mathrm{L}$ subunit of the reaction center of the photosynthetic, but non-oxygen evolving, purple, non-sulfur bacteria Rhodobacter capsulatus was demonstrated by Hearst and Sauer (1983, 1984). Hearst (1986) also described the homology of the D2 protein of PS II with the M subunit of the reaction center of $R b$. capsulatus (deduced from nucleotide sequence of its gene) published by Youvan et al. (1984). There was also a much stronger homology 
present between the two proteins of the same reaction center, that is between the $L$ and $M$ subunits of $R b$. capsulatus as well as between the D1 and D2 proteins of PS II. Based on these sequence homologies, Hearst (1986) suggested that the DI and D2 proteins (encoded by chloroplast genes $p s b A$ and $p s b D$, respectively) function as the reaction center proteins of PS II in analogy to the $L$ and M subunits of purpie bacteria. Based on affinity-labeling of the L subunit of Rhodopseladomonas viridis and the Dl protein of PS II by the reactive herbicide azidoatrazine in combination with sequence homologies of the D1 and D2 proteins with the $\mathrm{L}$ and $\mathrm{M}$ subunits of Rps. viridis, respectively, Michel and Deisenhofer (1986) independently came to the same conclusion.

The assignment of the D1 and D2 proteins as the core of the PS II reaction center was strengthened by the high resolution ( $3 \AA$ ) X-ray crystal structure of the photosynthetic bacterial reaction center of Rps. viridis. This structure has been published along with detailed discussions of the chromophore locations (Deisenhofer et al., 1984) and the arrangement of protein subunits (Deisenhofer et al., 1985). This work was recognized in 1988 by the award of the Nobel Prize in Chemistry to Drs. Johann Deisenhofer, Robert Huber and Hartmut Michel. Their research provided the first high-resolution X-ray crystal structure of an integral membrane protein and was a significant contribution to the photosynthesis field. Of overall importance in the structure are the near-symmetry of the two highly homologous bacterial reaction center proteins $\mathrm{L}$ and $\mathrm{M}$. This observation is consistent with the proposal that the homologous D1 and D2 proteins constitute the PS II reaction center. Also, the $L$ and $M$ proteins bind the reaction center pigments involved in electron translocation across the membrane. An analogous role for binding of pigments by the D1 and D2 proteins within the PS II reaction center can be proposed based on similarity of the chromophores identified to be active in electron transport through the bacterial and PS II reaction centers. It should be noted that the crystal structure (Deisenhofer et al., 1985) shows much intertwining of all 3 bacterial reaction center proteins (the $L$ and $M$ 
subunits discussed above, and the $H$ subunit, for which no clearly analogous PS II protein has been identified, although several have been proposed). The extent of intertwining appears to be greatest in the loop regions on the lumenal and stromal sides of the membrane and implies that no PS II reaction center protein which is required for full oxygen-evolving activity can be completely dismissed as providing at least a few ligands to the Mn cluster of the OEC. The identification of the proteins and specific amino acids which provide these ligands to the active $\mathrm{Mn}$ is of great interest.

More recently, Nanba and Satoh (1987) isolated a PS II complex consisting of the D1 and D2 proteins and Cyt b-559. They propose this complex to be the reaction center of PS II. The pigment composition of this complex was reported to be 5 chlorophyll $a, 2$ pheophytin $a$ and 1 B-carotene. This is quite similar to the 4 bacteriochlorophyll $a, 2$ bacteriopheophytin $a$ and 1 carotene composition of the purple bacterial reaction center. The complex, however, has no bound quinones or $\mathrm{Mn}$ and does not evolve oxygen. They also describe that "this complex is highly active in the photoreversible accumulation of reduced pheophytin $a$ exhibiting the characteristic kinetics and spectrum of the photosystem II reaction center." In addition to the D1 protein, the D2 protein, the large and small protein subunits of Cyt $b-559$, this reaction center preparation was shown to contain a polypeptide with apparent molecular weight of 4.5-4.8 kDa (lkeuchi and Inoue, 1988; Webber et al., 1989). This small protein is encoded by the chloroplast genome ( $\mathrm{psbl}$ gene, $4.2 \mathrm{kDa}$ calculated molecular weight of the gene product) as are the other 4 proteins of the isolated reaction center. Ikeuchi and Inoue (1988) found a sioichiometry for the $4.2 \mathrm{kDa}$ protein relative to the 2 subunits of Cyt $b-559$ of approximately $1: 1: 1$, indicating that there is one copy of the $4.2 \mathrm{kDa}$ protein per reaction center complex based on the recent assignment of one Cyt b-559 per copy of D1 or D2 protein in the isolated reaction center preparation.

The reaction center complex preparation described by Nanba and Satoh (1987) has been the focus of many recent investigations, all of which are consistent with the 
assignment of the D1 and D2 proteins as binding the PS II reaction center pigments. The reaction center complex was characterized by absorption, linear dichroism and circular dichroism spectroscopy (Newell et al., 1988), from which a perpendicular orientation of the reaction center long axis to the membrane plane was postulated (by comparison to the larger oxygen-evolving PS II core complex). These authors also give evidence indicating exciton coupling between chlorophyll molecules, consistent with the primary donor P680 being an exciton-coupled $\mathrm{Chl}$ dimer. The spectral properties of these preparations were studied further and are discussed by Tetenkin et al. (1989). The structured radical signal which accumulates after illumination at low temperature in the presence of sodium dithionite was assigned to the anion radical of pheophytin $a$ by EPR and absorption spectroscopies (Frank et al., 1989). The presence of a spin-polarized triplet EPR signal after illumination at low temperature was reported as evidence for charge separation in the reaction center complex (Telfer et al., 1988; Ghanotakis et al., 1989). Using time-resolved fluorescence, Mimuro et al. (1988) calculated rate constants for the charge separation and charge recombination events, which differ only slightly from the rates measured for other PS II preparations. Study of the electron-transport properties (Chapman et al., 1988) indicates that silicomolybdate, but not artificial quinones, can function as an electron acceptor in these preparations. They also showed that $\mathrm{MnCl}_{2}, \mathrm{NH}_{2} \mathrm{OH}, \mathrm{KI}$ and diphenylcarbazide (DPC) can act as electron donors to the reaction center complex. These exogenous electron acceptors and electron donors facilitate the study of electron transfer through the reaction center complex. Finally, Seibert et al. (1989) demonstrated that the full high-affinity $\mathrm{Mn}$-binding site as measured by the $\mathrm{Mn}^{2+}$ inhibition of DPC-stimulated DCIP photoreduction described by Hsu et al. (1987) is present in the isolated reaction center complex. They also attempted to photoactivate this preparation using the procedures described by Tamura and Cheniae (1987) without success. These studies provide further evidence that the reaction center of PS II is largely limited to the proteins present in this preparation and provide strong support for the central role of the D1 and D2 proteins within 
this structure. Although the results are also consistent with the binding of active Mn, there has been no demonstration of any oxygen-evolving activity by this complex. This lack of oxygen evolution indicates a possible requirement fo: additional proteins or cofactors to confer full activity.

\section{Oxygen-Evolving Complex}

The structural characterization and specific location of the OEC Mn cluster of PS II have been areas of intense research and controversy. Early evidence located the $\mathrm{Mn}$ to the interior of the thylakoid membranes within the chloroplast, meaning the lumenal side of these thylakoid membranes. The OEC Mn cluster has been shown to be associated with the PS II complex, released in the inhibition caused by several chemical treatments, involved in the in vivo reconstitution of oxygen evolution and necessary for the photoactivation of $\mathrm{Mn}$ depleted PS II preparations in vitro. All of these developments have been reviewed by Brudvig et al. (1989). The genetic and biochemical explanations for the location of the Mn cluster are discussed in the next section of this chapter. More recent chemical evidence for assignment of the D1 and D2 proteins as providing the ligands that actually bind the OEC $\mathrm{Mn}$, and some evidence as to the actual physical location of the Mn cluster, are discussed following that section. The spectroscopic evidence for $\mathrm{Mn}$ involvement is reviewed by Dismukes (1988), Brudvig et al. (1989) and others, and is described below with relevance to the structure and oxidation states of the Mn cluster within the OEC.

The early phenomenological description of the OEC was mainly based on observations and theoretical proposals by Joliot and Kok. The cyclical nature of maxima in oxygen evolution upon excitation with short flashes of light was described by Joliot et al. (1969). The maximum amount of oxygen evolved for dark-adapted spinach chloroplasts or algae samples occurred after the third flash. Thereafter, the maxima were spaced every 
fourth flash and eventually damped out to a censtant level. Kok et al. (1970) interpreted these results using a kinetic model of charge accumulation within an oxygen-evolving complex. This complex was proposed to involve the intrinsic $\mathrm{Mn}$ found to be required for oxygen evolution. The OEC was proposed to cycle through the accumulation of oxidizing equivalents and the oxidation of water as depicted in the S-state scheme (Figure 1-3). The S-state scheme describes the accumulation of one oxidizing equivalent during each of the transitions from $S_{0}$ to $S_{4}$ with a spcntaneous decay from $S_{4}$ to $S_{0}$, at which point the $\mathrm{O}_{2}$ molecule is released.

Evidence for $\mathrm{Mn}$ involvement in charge accumulation has been obtained using several different techniques, including EPR and X-ray absorption spectroscopies. The earliest EPR evidence was found by Dismukes and Siderer (1981) who described a "multiline" EPR signal of approximately $19 \mathrm{Mn}$ hyperf ne lines which was formed after a single flash of ligh:. This signal was similar to the 16-line EPR spectrum described for an antiferromagnetically coupled Mn dimer previously diescribed by Cooper et al. (1978) and was evidence for a change in the magnetic properties of the Mn complex upon illumination. This signal was assigned to the $S_{2}$ state of the Kok S-state scheme based on the assumption that dark-adapted samples reside mainly in the $S_{1}$ state because of the three flashes required for the first maxima in oxygen evolution during flash kinetic measurements. It was also shown that the Mn cluster actually changes oxidation state during the $S_{1}$ to $S_{2}$ transition as ciscribed by Goodin et al. (1984). They showed high resolution $\mathrm{Mn} X$-ray edge spectra for samples poised in the $S_{1}$ and $S_{2}$ states and compared them to edge spectra of model compounds. The change in edge position from $S_{1}$ to $S_{2}$ for PS II samples correlated well with the change observed for model compounds having an increase in oxidation state of one unit.

Other spectroscopic evidence, mainly from EXAFS, has been useful in proposing structural models of the OEC Mn cluster. In addition, ultraviolet difference spectra taken 


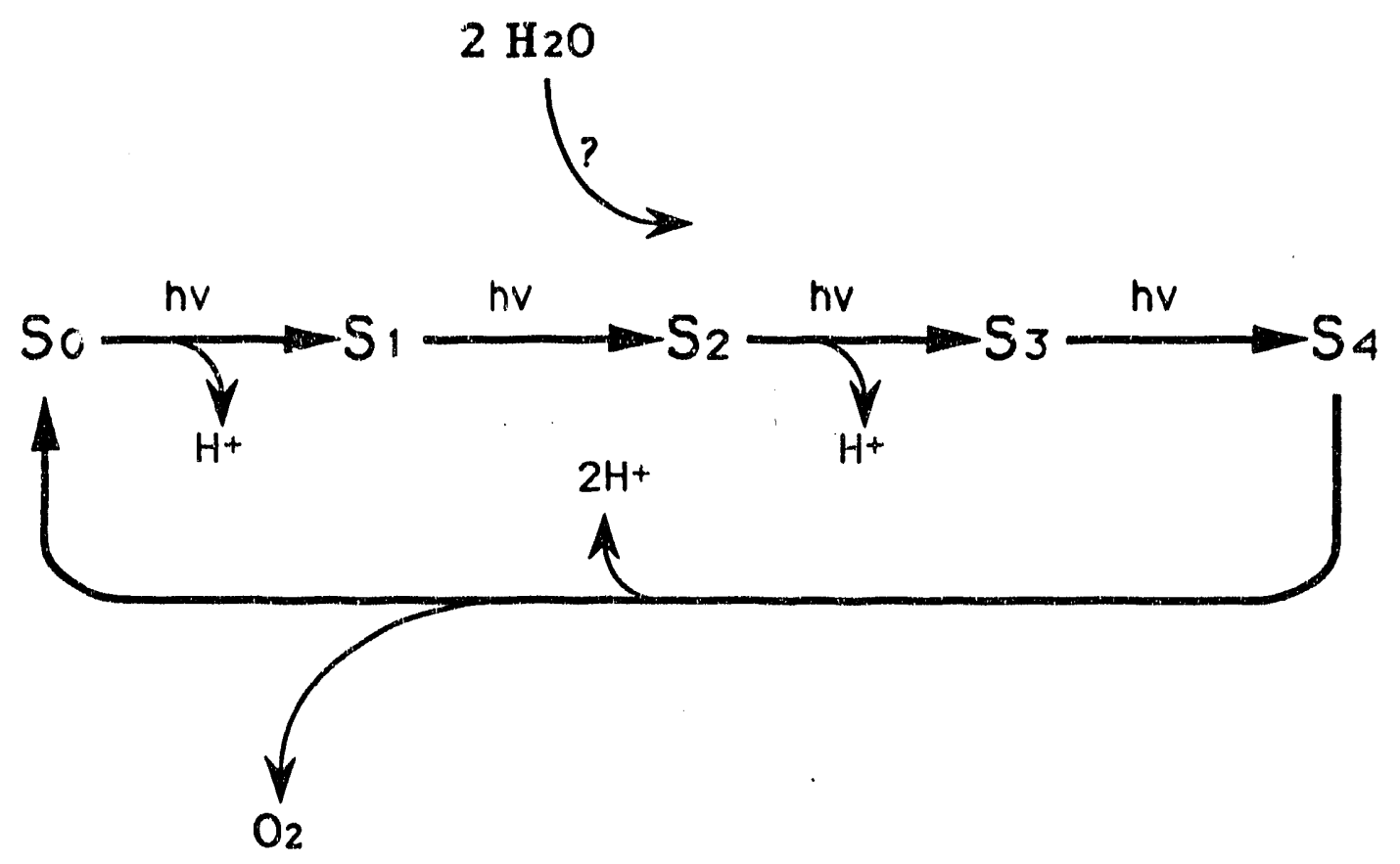

Figure 1-3: S-state scheme

Scheme proposed by Kok et al. (1970) using a kinetic model of charge accumulation within the oxygen-evolving complex. The S-state scheme describes the accumulation of one oxidizing equivalent (corresponding to the absorption of a photon by the primary donor) during each of the transitions from $\mathrm{S}_{0}$ to $\mathrm{S}_{4}$. A spontaneous decay occurs from $\mathrm{S}_{4}$ to $\mathrm{S}_{0}$, at which point the $\mathrm{O}_{2}$ molecule is released. The proton release pattern and the binding of two water molecules are also shown. 
during flash-induced S-state transitions have been used to formulate models of the oxidation states of the Mn within the OEC (Dekker et al., 1984; Kenger and Weiss, 1986; Saygin and Witt, 1987). These experiments are apparently very difficult, and the results and their interpretations are neither clear cut nor consistent and will, therefore, not be further discussed here. Results of EXAFS using PS II membrane preparations were reported by Yachandra et al. (1986). This study showed a Mn cluster containing at least two Mn separated by $2.7 \AA$, which is consistent with di- $\mu$-oxo bridging. The same distance was obtained from EXAFS of PS II preparations poised in the $S_{1}$ and $S_{2}$ states (Yachandra et al., 1987). More recently, Guiles et al. (1990b) have compared Mn XAS of PS II preparations in the S3 state to those in the $S_{2}$ state. They concluded that a $\mathrm{Mn}$ oxidation does not take place during the $S_{2}$ to $S_{3}$ transition. They proposed a redox active ligand, possibly a histidine residue, to store this oxidizing equivalent and be located near the Mn cluster. In a study comparing the Mn XAS of PS II preparations prepared in a modified So state (by hydroxylamine treatment) to those in the $S_{1}$ state, Guiles et al. (1990a) concluded that a Mn oxidation is likely during the So to $S_{1}$ transition. These reports, along with recent EXAFS and Mn K-edge data, are reviewed (Sauer et al., 1991) and are most consistent with the four Mn oxidation states as: So state (II, III, IV, IV), S1 state (III, III, IV, IV), S2 state (III, IV, IV, IV) and S3 state (III, IV, IV, IV).

More recently, results from EPR and ESEEM have added information useful in modeling possible structures for the Mn cluster and describing ligands to the OEC Mn. Originally, one of the proposals for the source of the broad, featureless, $g=4$.1 EPR signal associated with the $S_{2}$ state was a mononuclear Mn(IV) ion (Hansson et al., 1986). This proposal has been dismissed based on Mn-hyperfine structure observed on the $g=4.1 \mathrm{EPR}$ signal of oriented PS II preparations (Kim et al., 1990). This structure indicates that more than one Mn ion must be magnetically coupled to produce this signal. This result is consistent with proposals assigning both the multiline and the $g=4.1 \mathrm{EPR}$ signals to 
different conformations of the same multinuclear Mn cluster. Additionally, DeRose et al. (1991) have provided evidence for at least one histidine ligand to the EPR-active Mn. They applied ESEEM techniques to PS II preparations isolated from thermophilic cyanobacteria grown on [ $\left.15_{N}\right]$. These samples showed a change in nitrogen modulation from [ $\left.{ }^{14} \mathrm{~N}\right]-$ grown cyanobacterial preparations.

Studies of the power saturation and relaxation properties of signal II EPR signals have indicated a close spatial relationship between the radicals responsible for signal II $\left(\mathrm{YD}^{+}\right.$and $\left.\mathrm{YZ}^{+}\right)$and the $\mathrm{Mn}$ cluster of PS II. These radicals have been recently identified by site-specific mutations of PS II membrane proteins using the unicellular cyanobacterium Synechocystis 6803. This organism is a facultative photoheterotroph which can grow on glucose without the presence of functional PS II. Debus et al. (1988a) changed Tyr-160 of the $\mathrm{D} 2$ protein to phenylalanine by site-directed mutagenesis of a $p s b D$ gene in Synechocystis. This mutant assembles a functional PS II complex as demonstrated by the ability to grow photosynthetically and evolve oxygen, but it lacks the stable EPR signal assigned to the $\mathrm{D}^{+}$radical. They concluded that $\mathrm{D}$ is Tyr-160 of the $\mathrm{D} 2$ protein and renamed it YD. They also suggested, based on a continuation of the $C_{2}$ symmetry of the PS II reaction center pigments towards the oxidizing side of P680, that the intermediate electron donor from $\mathrm{Mn}$ to $\mathrm{P} 680^{+}$, known as $\mathrm{Z}$, is Tyr-161 of the D1 protein. To test this hypothesis, Debus et al. (1988b) changed Tyr-161 of D1 to phenylalanine by site-directed mutagenesis of a psbA gene in Synechocystis. The mutant assembles PS II as shown by its ability to produce the EPR signal assigned to the $\mathrm{D}^{+}$radical discussed above. It is unable to grow photosynthetically or evolve oxygen and has altered fluorescence properties. The altered fluorescence properties can be interpreted as a disruption in the forward electron transfer to $\mathrm{P} 680^{+}$(the transfer rate is slowed by several orders of magnitude compared to wild-type). These data provide strong support for the the assignment of Tyr-161 of the D1 protein as Z (now called $\mathrm{YZ}_{\mathrm{Z}}$ ), the intermediate electron 
donor from the Mn complex to $\mathrm{P} 680^{+}$. Studies of the spectroscopic properties of the $\mathrm{YD}^{+}$ and $\mathrm{YZ}^{+}$radical species, their interactions with the $\mathrm{Mn}$ cluster and possible oxidation states of the Mn cluster are discussed below.

The power saturation and relaxation properties of the EPR signals indicated a close spatial relationship between the radicals responsible for signal II ( $\mathrm{YD}^{+}$and $\left.\mathrm{YZ}^{+}\right)$and the Mn cluster of PS II and have also provided insight into the structure and possible valence of the ions of the Mn cluster. Styring and Rutherford (1988) described the changes in low temperature power saturation of $\mathrm{D}^{+}$caused by the S-state transitions of the Mn cluster. They observed that the $\mathrm{D}^{+}$signal is easier to saturate after Mn-removal by Tris washing. This observation indicates a cross relaxation between $\mathrm{D}^{+}$and an efficient relaxer in the presence of $\mathrm{Mn}$, which they suggest to be the OEC Mn cluster. They prepared samples in various S-states by illumination with a series of flashes and measured the microwave power for half-saturation of the $\mathrm{D}^{+}$signal. This power for half-saturation varied with flash number and was most consistent with a description of the Mn cluster as mixed-valent and paramagnetic for $S_{0}$ and $S_{3}$ (in addition to $S_{2}$ ) while the $M n$ in $S_{1}$ is more diamagnetic. They proposed the simplest reasonable model for the ions responsible for $\mathrm{YD}^{+}$relaxation to be $\mathrm{S}_{0}[\mathrm{Mn}(\mathrm{II})-\mathrm{Mn}(\mathrm{III})], \mathrm{S}_{1}$ [Mn(III)-Mn(III)], $\mathrm{S}_{2}$ [Mn(III)-Mn(IV)] and $\mathrm{S}_{3}[\mathrm{Mn}$ (III)$\mathrm{Mn}(\mathrm{IV})]$, and suggested that more complex models are possible for a tetrameric Mn cluster.

Evelo et al. (1989) used electron spin echo spectroscopy to study the spin-lattice relaxation time of the EPR signal attributed to $\mathrm{D}^{+}$, the stable tyrosine radical of PS II reaction centers. They studied the temperature dependence and average relaxation time for PS II preparations with the intact OEC poised at various S-states by illumination with a series of flashes. They found the spin-lattice relaxation curves to be biphasic, indicating a bi-exponential relaxation of $\mathrm{D}^{+}$. They attributed this behavior to structural heterogeneity distinguished by two, magnetically non- or weakly coupled Mn ions that differ in relaxation time. The average relaxation time depends strongly on the S-state of the OEC, being 
slowest for $S_{0}$, fastest for $S_{1}$ and intermediate for $S_{2}$ and $S_{3}$ (which are approximately equal). The temperature dependence in the range of 5-30 $\mathrm{K}$ for the relaxation of $\mathrm{D}^{+}$ indicates that there are oxidations of $\mathrm{Mn}$ in the OEC in going from $S_{0}$ to $S_{1}$ and $S_{1}$ to $S_{2}$, but not for the $S_{2}$ to $S_{3}$ transition (consistent with the XAS data discussed earlier). They observed a strong dipolar contribution to the relaxation of only the SO-state, indicating a paramagnetic species (different from the $S=1 / 2$ species in the $S_{2}$-state) which couples strongly to $\mathrm{D}^{+}$and is a much faster relaxer than the Mn cluster of the $\mathrm{S}_{2}$-state. Finally, they proposed oxidation states for the 4 OEC Mn based on their data where: A) Two of the four $\mathrm{Mn}$ ions form a binuclear cluster which is antiferromagnetically coupled and are $\left(2^{+}\right.$, $\left.3^{+}, S=1 / 2\right)$ in $S_{0},\left(3^{+}, 3^{+}, S=0\right)$ in $S_{1},\left(3^{+}, 4^{+}, S=1 / 2\right)$ in $S_{2}$ and $\left(3^{+}, 4^{+}, S=1 / 2\right)$ in $S_{3}$. Their interpretation is consistent with conclusions reached from X-ray spectroscopy (Sauer et al., 1991) and cw EPR (Styring and Rutherford, 1988) data. B) The other two Mn ions have oxidation states which differ by one unit (based on different relaxation properties) but do not change during any of the S-states from $S_{0}$ to $S_{3}$. Either $\left(2^{+}, 3^{+}\right)$or $\left(3^{+}, 4^{+}\right)$would agree with their results, but $\left(4^{+}, 4^{+}\right)$is favored by the $\mathrm{X}$-ray spectroscopy data described earlier (Sauer et al., 1991).

\section{Location of Mn-binding: genetic and biochemical evidence}

As previously discussed, the reaction center of PS II has been assigned to the D1 and D2 proteins in analogy to the $L$ and $M$ subunits of purple bacteria (Hearst, 1986; Michel and Deisenhofer, 1986). Electron donation from the Mn cluster of the OEC to the reaction center primary donor (P680) goes through a redox-active tyrosine residue (YZ). In order to have efficient electron transfer, the Mn cluster of the OEC, YZ and P680 must be in close proximity to each other. The most likely location for Mn-binding would therefore be the lumenal side of the D1 and/or D2 reaction center proteins. Notably, if one 
combines information on helical regions with the sequence alignments of the D1 protein with the $L$ subunit and the D2 protein with the $M$ subunit, it is apparent that the lumenal loops of D1 and D2 are significantly longer and contain more amino acids capable of ligating metal ions than the corresponding regions of $L$ and $M$. This is strong support for Mn-binding in these regions of the D1 and D2 proteins.

A second line of evidence for the D1 and D2 proteins as the PS II reaction center canse fror: Metz and Bishop (1980). They identified a low-fluorescent mutant (LF-1) of the green aiga Scenedesmus obliquus containing a PS II reaction center functional in electron transpon which did not evolve oxygen. PS II membranes preparations of this mutant bound only approximately $40 \%$ of the Mn bound by the wild-type (WT) memioranes. Metz et al. (1980) demonstrated that the defective PS II protein had a slower elextrophoretic mobility (higher apparent molecular weight) on LDS-PAGE than the corresponding WT protein. This $36 \mathrm{kDa}$ LF-1 protein was correlated to a $34 \mathrm{kDa} W T$ protein both of which were photoaffinity labeled by the PS II inhibitor azido [ 14 C]atrazine (Metz et al., 1985). The LF-1 PS II had active electrun acceptor functions and contained a reaction center functional in electron 1risporth as characterized by the EPR spectra of radicals formed upon illumination (Rutherford et al., 1988). The defective protein was identified as the DI protein of PS II (Metz et al., 1986; Taylor et al., 1988), while the D2 protein was apparently unchanged from its WT counterpart (Taylor et al., 1988). The D1 protein was shown to function on both the oxidizing and reducing sides of PS II, providing the first experimental evidence that D1 is a reaction center protein (Metzet al., 1986). This D1 protein has been proposed to assemble into PS II without proper processing of the carboxyl end (Metz et al., 1986; Diner et al., 1988; Taylor et al., 1988) which somehow blocks incorporation of the full complement of $\mathrm{Mn}$ required for oxygen evolution. These characteristics of the LF-1 mutant provide further evidence for Mn-binding in the region near the carboxyl end of the Dl protein. 
A final biochemical property which assigns the D1 protein as part of the PS II reaction center is its fast, light-dependent, turnover in vivo (Edtiman and Reisfeld, 1978; Silverthome and Ellis, 1980). The D1 protein was also shown to exhibit rapid lightdependent in vitro degradation (Mattoo et al., 1984; Ohad et al., 1985). In the in vitro system, there was no turnover since protein synthesis is not present in isolated thylakoid membrane preparations. The biochemical reason for the turnover was proposed to be replacement of proteins damaged by the extremely high oxidizing potential of the higher oxidation states of $\mathrm{Mn}$ generated within the $\mathrm{Mn}$-chuster of the OEC. The rapid degradation of the D1 protein, therefore, is consistent with the D1 protein as the primary site for binding of OEC Mn. The D2 protein was also shown to tumover more rapidly than other reaction center proteins, although slower than the Dl protein (Hundal et al., 1990). The pathway of the cleavage leading to D1 turnover was described by Greenberg et al. (1987). They identified the primary in vivo degradation product of the D1 protein as a $23.5 \mathrm{kDa}$ fragment after exposure of Spirodela oligorrhiza cells to photoinhibiting light conditions. They also demonstrated that this $23.5 \mathrm{kDa}$ fragment contained the amino-terminus of the D1 protein, proposed the cleavage site to be near the quinone-binding site of D1 (between helices IV and V, adjacent to a "PEST-like region" as defined by Rogers et al., 1986), and showed that the degradation of this $23.5 \mathrm{kDa}$ fragment was much faster than the initial cleavage of the Dl protein. During photoinhibiting light conditions, a correlation was shown between the release of $4 \mathrm{Mn}$ ions (per D1 protein lost) and the degradation of the D1 protein itself (Virgin et al., 1988). They also explained a correlation between the inhibition of oxygen evolution and loss of EPR multiline signal, both of which were much faster than the D1 protein degradation. Recently, Hundal et al. (1990) have reported the degradation. of the D1 protein in vitro, by using isolated thylakoid membrane preparations, to be consistent with the in vivo degradation. They showed that concomitant with degradation of D1 protein, the 17, 24 and $33 \mathrm{kDa}$ extrinsic proteins were released. Also, they showed that the previously described release of $4 \mathrm{Mn}$ per Dl protein during $\mathrm{Dl}$ degradation occurs in 
parallel with D1 loss even in the absence of the three extrinsic polypeptides. All of these data are consistent with the D1 protein providing the majority, if not all, of the amino acids that act as terminal ligands required to bind the active OEC Mn of PS II.

\section{Location of Mn-binding: chemical and spectroscopic evidence}

Several compounds, including benzidine, DPC, $\mathrm{Mn}^{2+}$ and $\mathrm{I}^{-}$can act as exogenous electron donors to PS II membrane preparations lacking the endogenous OEC Mn complex. Upon illumination of PS II membrane preparations (from which Mn had been removed by Tris treatment) in the presence of $\left[{ }^{125}\right]^{-}$, the D1 protein was shown to be heavily labeled (Ikeuchi and Inoue, 1987). They assigned the D1 protein migration on SDS-PAGE by comparison to azido [ ${ }^{14} \mathrm{C}$ ]atrazine labeling and immunoblotting with anti-D1 and anti-D2 rabbit antisera. Although the D1 protein was consistently the heaviest labeled protein for several different plants and a cyanobacterium, they also note weak labeling of the D2 protein and/or CP47 in some instances. In another study utilizing the same methods to label spinach PS II membranes, Takahashi and Satoh (1989) identified the fragment of the D1 protein that becomes photoaffinity labeled by $\left[^{125}\right.$ ] as Me-143 to Met-172 based on the overlap of labeled fragments identified from different protease digestions. They deduced the specific amino acid labeled to be Tyr-161 on D1, which has been proposed to correspond to $\mathrm{Z}$, the intermediate electron donor to P680 (Debus et al., 1988a). Even more interesting, is the light-dependent labeling of the D1 protein by $\left[{ }^{125}\right]$ when $\mathrm{Cl}^{-}$-depleted PS II membranes retaining the active OEC Mn are incubated with [125I]- (Ikeuchi et al., 1988). They noted preliminary enzymatic mapping, but the specific fragment or amino acid labeled had not been identified. They proposed the labeled amino acid residue would be in a region in close proximity to the OEC Mn. Finally, they concurred with the proposal of 
the $D 1$ protein as the location of $Z$, the OEC Mn-binding site and also the site of $\mathrm{Cl}^{-}$ binding.

Several experiments using [ $14 \mathrm{C}]-D E P C$ have been used to examine the relationship of photoactivation and Mn-binding to specific PS Il polypeptides. Tamura et al. (1989a) showed the connections between photoactivation of PS II meinbranes (by photoligation of Mn as described in Chapter 7), chemical modification by DEPC, the involvement of histidine residues on D1 (and possibly D2) and the $\mathrm{Mn}^{2+} / \mathrm{DPC}$ competition assay developed by Hsu et al. (1987) described in Chapter 8. Tamura et al. (1989a) also showed evidence for specific histidine modification by DEPC under their reaction conditions. Many PS II proteins were radioactively labeled by [14C]-DEPC in their experiments, but labeling of the D1 protein and the D1/D2 protein dimer were suppressed by photoligated $\mathrm{Mn}$ (involvement of the D2 protein was not confirmed or eliminated due to heavy labeling of the light-harvesting proteins in the corresponding region of the gel). Seibert et al. (1989) proposed that the high-affinity $\mathrm{Mn}$-binding site measured by the $\mathrm{Mn}^{2}+$ inhibition of DPC-stimulated DCIP photoreduction can be divided into at least two different components. Using DEPC (the histidine chemical modifier described above) they show that half of the Mn-binding site of WT Scenedesmus (or spinach or wheat) preparations is blocked after modification. Another important result was the demonstration that the full high-affinity Mn-binding site is present in the isolated reaction center complex (D1/D2/Cyt $b$-559/4.2 $\mathrm{kDa}$ proteins), limiting the possible proteins which might provide these ligands to $\mathrm{Mn}$. In their most recent publication, Preston and Seibert (1991b) combined two amino acid chemical modifiers (DEPC, which modifies histidines, and EDC, which modifies carboxyl-containing residues) with protease treatments in order to better define the highaffinity $\mathrm{Mn}$-binding site using the DPC/Mn ${ }^{2+}$ non-competitive inhibition assay for DCIP photoreduction (Preston and Seiberh 1991a). Basically, their data indicate that the DEPCsensitive and EDC-sensitive halves of the high-affinity site can each be divided into two 
components which demonstrate differential sensitivity to the proteases used, therefore indicating four separately identifiable components. Although they propose the four components located by the $\mathrm{Mn}^{2}+\mathrm{DPC}$ assay to be ligands involved in photoligation of $\mathrm{Mn}$ during photoactivation and/or binding the functional OEC $\mathrm{Mn}$, they also provide some alternative explanations (discussed in Chapter 8), all of which are still consistent with the involvement of the D1 protein in Mn-binding.

As discussed earlier, Debus et al. (1988a) showed that the stable EPR signal assigned to the $\mathrm{D}^{+}$radical arises from Tyr-160 of the $\mathrm{D} 2$ protein, and renamed it $\mathrm{YD}^{+}$. Also, Debus et al. (1988b) demonstrated that the intermediate electron donor from $\mathrm{Mn}$ to $\mathrm{P}_{680^{+}}$, known as $\mathrm{Z}^{+}$, is $\mathrm{Tyr}-161$ of the $\mathrm{D} 1$ protein, and renamed it $\mathrm{YZ}^{+}$. Studies of the properties of these two radicals and their spectroscopic interactions with P680 and the Mn cluster of the OEC have provided further evidence on the location of the Mn complex in PS II. Hoganson and Babcock (1989) studied the EPR spectrum of P680+ in PS II membranes at room temperature using repetitive flash excitation. Under their conditions, oxygen evolution was inhibited, which extended the lifetime of the P680 radical into the 150-200 $\mu$ s range, allowing observation of this transient EPR signal. Using different Ureatments, they compared the broadening of the P680+ EPR spectrum in the presence of either the reduced or oxidized forms of $\mathrm{YZ}_{\mathrm{Z}}$. They discussed in depth the assignment of their observed EPR signal to P680+, describing evidence based on narrower EPR line width relative to those of other PS II radical signals and on optical studies of P680+ secay kinetics. Both sets of references support their assignment. They also thoroughly explained various theories used to estimate the distance between the two radicals. They attributed the observed $1 \mathrm{G}$ broadening of the $\mathrm{P} 60^{+}$spectrum by $\mathrm{YZ}^{+}$(relative to the spectrum of P680+ with $\mathrm{YZ}$ in its diamagnetic state) to a magnetic dipole-dipole interaction between the two radicals. Based on their calculations, they estimated the center-to-center distance between $\mathrm{P} 680^{+}$and $\mathrm{YZ}^{+}$to be $10-15 \AA$. 
Several studies of the power saturation and relaxation properties of their EPR signals have indicated the spatial relationship between the radicals responsible for signal II $\left(\mathrm{YD}^{+}\right.$and $\left.\mathrm{YZ}^{+}\right)$and the Mn cluster of PS II. Yocum et al. (1981) demonstrated that the removal of $\mathrm{Mn}$ by Tris washing resulted in slower relaxation of $\mathrm{Z}^{+}$than observed in the presence of the intact Mn cluster. They concluded that the Mn cluster was situated close to $\mathrm{Z}^{+}$and was responsible for the faster relaxation of $\mathrm{Z}^{+}$in its presence. Rutherford et al. (1988) studied the EPR properties of the LF-1 mutant of Scenedesmus obliquus which lacks the $\mathrm{Mn}$ cluster and described a slower $\mathrm{D}+$ EPR signal relaxation relative to the $\mathrm{Mn}$ containing Scenedesmus wild-type. They suggested that $\mathrm{Z}^{+}$and $\mathrm{D}^{+}$may be located more equivalently with respect to the Mn cluster than had previously been proposed. Finally, Styring and Rutherford (1988) described the changes in low temperature power saturation of $\mathrm{D}^{+}$caused by the S-state transitions of the Mn cluster. They observed that $\mathrm{D}^{+}$is easier to saturate after Mn-removal by Tris washing. They proposed a cross relaxation between $\mathrm{D}^{+}$and an efficient relaxer in the presence of $\mathrm{Mn}$, which they suggested to be the $\mathrm{Mn}$ cluster. They prepared samples in various S-states by illumination with a series of flashes and measured the microwave power for half-saturation of the $\mathrm{D}^{+}$signal. This power for half-saturation varied with flash number and, from this information, they proposed possible models for the OEC Mn cluster.

Evidence of the location of YD within the reaction center was provided by Innes and Brudvig (1989). They studied the effect of adding the free-radical-relaxing agent dysprosium ion and its complexes with EDTA on the spin-lattice relaxation of PS II free radicals. They described the effects on the microwave power saturation of the EPR signal attributed to $\mathrm{D}^{+}$and used the results to determine its location within the membrane. They approximated the PS II protein surface to be planar and obtained distances from YD to the membrane surface in thylakoid, PS II membrane and 'Tris-washed PS II membrane preparations. They calculated a distance from the stromal membrane surface to $D^{+}$of $26 \AA$ 
and a distance of $27 \AA$ to the lumenal membrane surface after removal of the 17,24 and 33 $\mathrm{kDa}$ extrinsic proteins. They calculated the height of the extrinsic protein unit to be about $14 \AA$. From these results, they proposed a membrane thickness of approximately $53 \AA$ in the absence of extrinsic proteins. These results agree with distances predicted from analogy of the D1 and D2 proteins of PS II with the L and M subunits of purple bacteria described earlier. The height of the extrinsic protein unit calculated by Innes and Brudvig is comparable, but not identical, to the approximately $20 \AA$ measured by freeze-etch electron microscopy (Seibert et al., 1987).

Recent studies have focused on the relationship between the tyrosine radicals, $\mathrm{YD}^{+}$ and $\mathrm{Y}^{+}$, and the $\mathrm{Mn}$ cluster at different oxidation levels through the S-state cycle. As discussed earlier, Evelo et al. (1989) used electron spin echo spectroscopy to study the spin-lattice relaxation time of the EPR signal attributed to $\mathrm{D}^{+}$. They studied the temperature dependence and average relaxation time for PS II preparations with the intact OEC poised at various S-states by illumination with a series of flashes. In addition to the oxidation states during the S-state cycle, they calculated a distance from $D^{+}$to the OEC Mn cluster of 30-40 $\AA$ which they explained as being consistent with the results of Innes and Brudvig (1989) described above. Hoganson and Babcock (1988) measured the light-induced EPR spectrum of $\mathrm{YZ}^{+}$in intact PS II membranes using time-resolved techniques. They did their measurements at room temperature with flowing samples and exogenous electron acceptors (DCSQ or $1 \mathrm{mM}$ ferricyanide) to maintain oxygen-evolving activity. The time-resolved spectrum of $\mathrm{YZ}^{+}$recorded for these active PS II membranes was very similar to the steadystate spectrum of the stable tyrosine radical $\mathrm{YD}^{+}$and the same as the steady-state $\mathrm{YZ}^{+}$ spectrum in inhibited PS II membranes, regardless of whether Mn was still present. The similarity to the $\mathrm{YD}^{+}$signal is discussed as arising from very similar orientations of the two tyrosine radicals within the membrane bound protein complex. The similarity in line shape of the $\mathrm{YZ}^{+}$signal in different preparations implies that the interaction between $\mathrm{Mn}$ and $\mathrm{Y}_{\mathrm{Z}^{+}}$ 
is weak and does not perturb the spin distribution on this tyrosine radical. Based on these results, they conclude that the distance from $\mathrm{YZ}^{+}$to the nearest $\mathrm{Mn}$ ion must be greater than $10 \AA$ (and they may be separated by 2 or more amino acid residues). They also demonstrate that $\mathrm{YZ}_{\mathrm{Z}}$ is the intermediate electron donor between Mn and P680 for the S-state transitions $S_{1}$ to $S_{2}, S_{2}$ to $S_{3}$ and $S_{3}$ to $S_{0}$ (they claim that $S_{0}$ to $S_{1}$ occurs too quickly for them to measure, but probably goes through $\mathrm{YZ}_{\mathrm{Z}}$ also). They also describe decay kinetics of $\mathrm{YZ}^{+}$that vary with the S-state of the OEC and are indicative of the $\mathrm{Mn}$ location being close to $\mathrm{YZ}$.

Finally, several studies have addressed the effects of the Mn cluster in preventing the accessibility by exogenous reductants to the tyrosine radicals, $\mathrm{YD}^{+}$and $\mathrm{YZ}^{+}$. Sivaraja and Dismukes (1988) investigated the flash-induced reactions of $\mathrm{NH}_{2} \mathrm{OH}$ with PS II by equilibrium titrations with $\mathrm{NH}_{2} \mathrm{OH}$ and the monitoring of odd-electron species by EPR spectroscopy. They characterized and presented a plausible model for the reversible reactions of $\mathrm{NH}_{2} \mathrm{OH}$ with the $\mathrm{S}_{1}$ and $\mathrm{S}_{2}$ states of $\mathrm{PS}$ II at low $(10-100 \mu \mathrm{M}) \mathrm{NH}_{2} \mathrm{OH}$ concentrations. At slightly higher $\mathrm{NH}_{2} \mathrm{OH}$ concentrations, they proposed a structural change of the electron acceptors which blocks electron transfer from $\mathrm{Q}^{-}$to $\mathrm{Qb}$. Additionally, at high concentrations of $\mathrm{NH}_{2} \mathrm{OH}(1-2 \mathrm{mM})$ there was a parallel release of $\mathrm{Mn}$ and loss of oxygen evolution, which was best explained by cooperative loss of about $2 \mathrm{Mn}$ ions per reaction center. The stable tyrosine radical signal attributed to $\mathrm{YD}^{+}$is completely removed by $1.5 \mathrm{mM} \mathrm{NH} 2 \mathrm{OH}$, and this reduction of $\mathrm{YD}^{+}$occurs only following the release of $\mathrm{Mn}$. This suggests that bound OEC Mn ions block the access of $\mathrm{NH}_{2} \mathrm{OH}$ to YD and, presumably, also YZ. Ghanotakis et al. (1984a) had previously shown that after Mn-depletion by any of several methods, the kinetic behavior of $\mathrm{Z}^{+}$is altered, as demonstrated by a change in its EPR properties and its becoming more accessible to reduction by exogenous electron donors. The EPR signal of $\mathrm{Z}^{+}$after $\mathrm{Mn}$ removal required low microwave power in order to observe saturation, while $\mathrm{Z}^{+}$in the presence of bound 
OEC Mn saturated only at much higher microwave power. Ghanotakis et al. (1984a) discussed the increased lifetime of the $\mathrm{Z}^{+}$radical into the $100 \mathrm{~ms}$ time-range, and its decrease by the addition of reductants such as benzidine. They proposed that the OEC Mn must be located near $\mathrm{Z}$ and sterically protects $\mathrm{Z}^{+}$from reduction by exogenous reductants. Recently, Hoganson et al. (1989) reported measurements of rates of $\mathrm{YZ}^{+}$reduction by exogenous reductants such as benzidine and $\mathrm{Mn}^{2+}$. They used flash photolysis techniques to create the $\mathrm{YZ}^{+}$radical and measured its room temperature reaction kinetics with reductants by monitoring its EPR signal. They observed the same kinetics in the presence or absence of the $33 \mathrm{kDa}$ extrinsic protein for membranes depleted of $\mathrm{Mn}$. The rate of $\mathrm{YZ}^{+}$ reduction was found to be linear with benzidine concentration (indicative of second order kinetics). The rate of $\mathrm{YZ}^{+}$reduction was also linear with $\mathrm{Mn}^{2+}$ at $\mathrm{pH} 6$ and low $\mathrm{Mn}$ concentration (also second order kinetics), but reached a maximum level at concentrations five times that of the reaction center. At pH 6, The $\mathrm{Mn}^{2+}$ effect was inhibited by $\mathrm{K}^{+}$, $\mathrm{Ca}^{2+}$ and $\mathrm{Mg}^{2+}$ (indicating an electrostatic interaction). The rate was biphasic for $\mathrm{Mn}^{2+}$ at pH 7.5, for which they described two components. The fast component may represent pre-flash binding of $\mathrm{Mn}^{2+}$ at one of the native $\mathrm{Mn}$-binding sites (the first step in assembly of the Mn complex by photoactivation). The slow component may be diffusion controlled (and give the second order kinetics seen at $\mathrm{pH} 6$ ). They concluded that the intrinsic OEC $\mathrm{Mn}$ are required in order to establish the barrier which prevents reductants from reaching $\mathrm{YZ}$.

\section{Some examples of antibody effects on other enzymes}

Although several studies using antibodies to PS II protein components have been reported, none of them examined the effects of antibodies on the enzymatic activity of the oxygen-evolving complex. Other studies in much simpler systems have provided evidence 
of inhibition of enzyme activities by antibodies. Some of these activities are associated with electron transport, redox reactions or oxidase activities. A few of the more relevant examples are described here.

Nisimoto et al. (1973) raised an antiserum against NADH:hemeprotein oxidoreductase using the enzyme purified from extracts of whole cells of Rhodospirillum rubrum. Incubation of chromatophores and purified protein with this antiserum inhibited the activity of NADH-cytochrome $c 2$ reduction for both preparations. They showed that the enzyme bound in chromatophore membranes was functional in the donation of electrons from NADH to the cyclic electron transport system of the photosynthetic bacterium. Using an antibody to yeast cytochrome $b 5$, Ohba et al. (1979) also demonstrated inhibition of the $\mathrm{NADH}$-cytochrome $c$ reductase and the $\mathrm{NADH}$-dependent desaturase activities of yeast microsomes.

The purified NADPH-cytochrome $P-450$ reductase isolated from rat liver microsomes was used by Guengerich et al. (1981) to elicit polyclonal rabbit antibodies. These antibodies were shown to inhibit the enzyme's ability to reduce cytochrome $c$ and cytochrome $P-450$ to different extents, depending on the source of enzyme. Takayama, et al. (1984) raised rabbit antibody against guinea-pig liver NADPH-cytochrome $P-450$ reductase. This antibody was shown to dose-dependently inhibit the superoxide $\left(\mathrm{O}_{2}^{-}\right)$generating activity of a membrane fraction isolated from leukocytes to approximately $50 \%$ of the total activity. Fukuhara et al. (1988) studied a blood neutrophyl-derived flavin enzyme involved in $\mathrm{O}_{2}$-generating oxidase activity. They demonstrated that incubation with polyclonal antibodies raised against the isolated protein caused a maxirnum inhibition of $54 \%$ of the $\mathrm{O}_{3}^{-}$-generating activity of the membrane-solubilized oxidase. 


\section{Goals of this work}

The work described in this thesis combines several chemical, biochemical and immunological techniques into a series of experiments aimed at clarifying the structure of the oxygen-evolving complex of PS II. Specifically, the possibility of protein regions and/or amino acids serving as terminal ligands to the OEC Mn was investigated using antibodies raised to selected lumenal regions of the D1 and D2 proteins of the PS II reaction center. The selection of peptides to be used, along with the synthesis, purification and characterization of those peptides, are presented in Chapter 2. The eliciting of polyclonal antibodies to the different peptides and the characterization of the antibodies produced are presented in Chapters 3 and 4 . In Chapter 4, the binding of the antibodies to the corresponding denatured protein was demonstrated by western blots of PS II membrane preparations separated by SDS-PAGE. To confirm antibody binding to intact PS II membrane preparations and to characterize this binding with respect to extrinsic protein composition and Mn presence, a solution antibody binding assay was used (Chapter 6). The effects of antibodies on several functions of the OEC were determined and are described in Chapters 5,7 and 8. These three studies examine antibody effects on different aspects of Mn activity as the catalytic site for water oxidation. The ability of antibodies to compete with previously bound Mn was determined for PS II membrane preparations of varying extrinsic protein composition, all of which retain $\mathrm{Mn}$ before antibody addition, by measurement of the rate of oxygen evolution (Chapter 5). The ability of an antibody to block the binding and subsequent photoligation of $\mathrm{Mn}^{2+}$ is presented in Chapter 7 using a procedure to photoactivate PS II membrane preparations from which the active Mn had been removed. Finally, experiments which assayed the antibody effect on $\mathrm{Mn}^{2}+$ inhibition of diphenylcarbazide (DPC) to 2,6-dichlorophenol indophenol (DCIP) photoreduction are described in Chapter 8. These experiments address whether bound antibody can block any 
of the four components of the high-affinity Mn-binding site that become available in the presence of DPC. 


\section{WEPTIDES}

\section{Introduction}

In this chapter the peptides which correspond to lumenal regions of the D1 and D2 proteins of PS II that were chosen for synthesis, the rationale for their choice, the synthetic procedures used, the purification of the various peptides and, finally, the analysis of their composition and sequence are described. To summarize, the regions of the D1 and D2 proteins chosen as potentially Mn-binding had to fit several criteria as well as possible. First, they had to be exposed on the lumenal side of the thylakoid membrane according to the five transmembrane helix models proposed by Trebst (1986) and later confirmed by the antibody studies of Sayre et al. (1986). Secondly, the peptides had to contain as many potential Mn-binding residues as possible. And, lasty, the peptides preferred were regions of high homology among oxygenic organisms, but low homology with the anoxygenic photosynthetic bacteria as described in Chapter 1 and, in more detail, below.

Much has been published regarding the location of the OEC Mn cluster of PS II. Early evidence located the $\mathrm{Mn}$ to the interior of the thylakoid membranes within the chloroplast, meaning the lumenal side of these thylakoid membranes. Next, the OEC Mn was shown to be associated with the PS II complex. The active Mn was shown to be released by several chemical treatments which caused inhibition of oxygen evolution. Mn was also shown to be involved in the in vivo reconstitution of oxygen evolution and necessary for the photoactivation of Mn-depleted PS II preparations in vitro. All of these properties are reviewed by Brudvig et al. (1989). The spectroscopic evidence for $\mathrm{Mn}$ involvement is reviewed by Dismukes (1988), Brudvig et al. (1989) and others, and is described below with relevance to the ligand environment and in more detail in Chapter 1. 
The five transmembrane helix models for the folding patterns of the D1 and D2 proteins are the models most consistent with studies of antibody binding to proposed interhelical regions (Sayre et al., 1986). These folding patterns and the protein incorporation into the thylakoid membrane were originally predicted by hydropathic analysis of the D1 and D2 proteins (Trebst, 1986). The spinach amino acid sequence of the D1 protein (Zurawski et al., 1982) and the pea amino acid sequence of the D2 protein (Rasmussen et al., 1984) are pictured in Figure 2-1 in a folding pattern similar to that presented by Michel and Deisenhofer (1988). The processing site near the $\mathrm{C}$-terminus of the $\mathrm{D} 1$ protein as determined by Takahashi et al. (1988) is depicted as an " $\mathrm{X}$ " between alanine residues 344 and 345 . The 9 amino acid $\mathrm{C}$-terminal fragment is omitted from further diagrams, such as the one shown in Figure 2-4 which is explained below.

The sequence homologies of the $D 1$ and $D 2$ proteins with the $L$ and $M$ subunits of $R b$. capsulatus which allowed Hearst (1986) and others to suggest that the D1 and D2 proteins function as the reaction center proteins of PS II are thoroughly discussed in Chapter 1. Of more importance here, are the regions of divergence of the D1 and D2 polypeptides from the $L$ and $M$ subunits of the non-oxygen evolving organisms. These regions tend to be highly conserved amongst oxygen evolving organisms and are often sequence insertions relative to the purple bacterial sequences. In Figures 2-2 and 2-3, comparisons of the $L$ and $M$ sequences, as originally described by Hearst (1986), with the spinach sequences for the D1 and D2 proteins, are shown. The amino acid conservation between the $D 1$ and $D 2$ protein sequences of several higher plants and several cyanobacteria is described in detail by Gingrich et al. $(1988,1990)$. The regions of the five proposed transmembrane helices for the D1 and D2 proteins are marked in the figures and correspond to those described for the $\mathrm{L}$ and $\mathrm{M}$ subunits by Michel and Deisenhofer (1988) but placed on the sequence alignments proposed by Hearst (1986). The regions of interest in potential Mn ligation are both of the $\mathrm{C}$-terminal stretches and those loop regions 


\section{Figure 2-1: Folding pattern of the D1 and D2 proteins}

The five transmembrane helix models for the folding patterns of the D1 and D2 proteins are shown as predicted by Trebst (1986). The proposed protein incorporation into the thylakoid membrane is indicated with the membrane boundaries shown as horizontal dashed lines. The spinacia oleracea amino acid sequence of the D1 protein (Zurawski et al., 1982) and the pisum sativum amino acid sequence of the D2 protein (Rasmussen et al., 1984) are pictured in a folding pattern similar to that presented by Michel and Deisenhofer (1988). The " $\mathrm{X}$ " between alanine residues 344 and 345 near the $\mathrm{C}$-terminus of the D1 protein indicates the processing site as determined by Takahashi et al. (1988). 


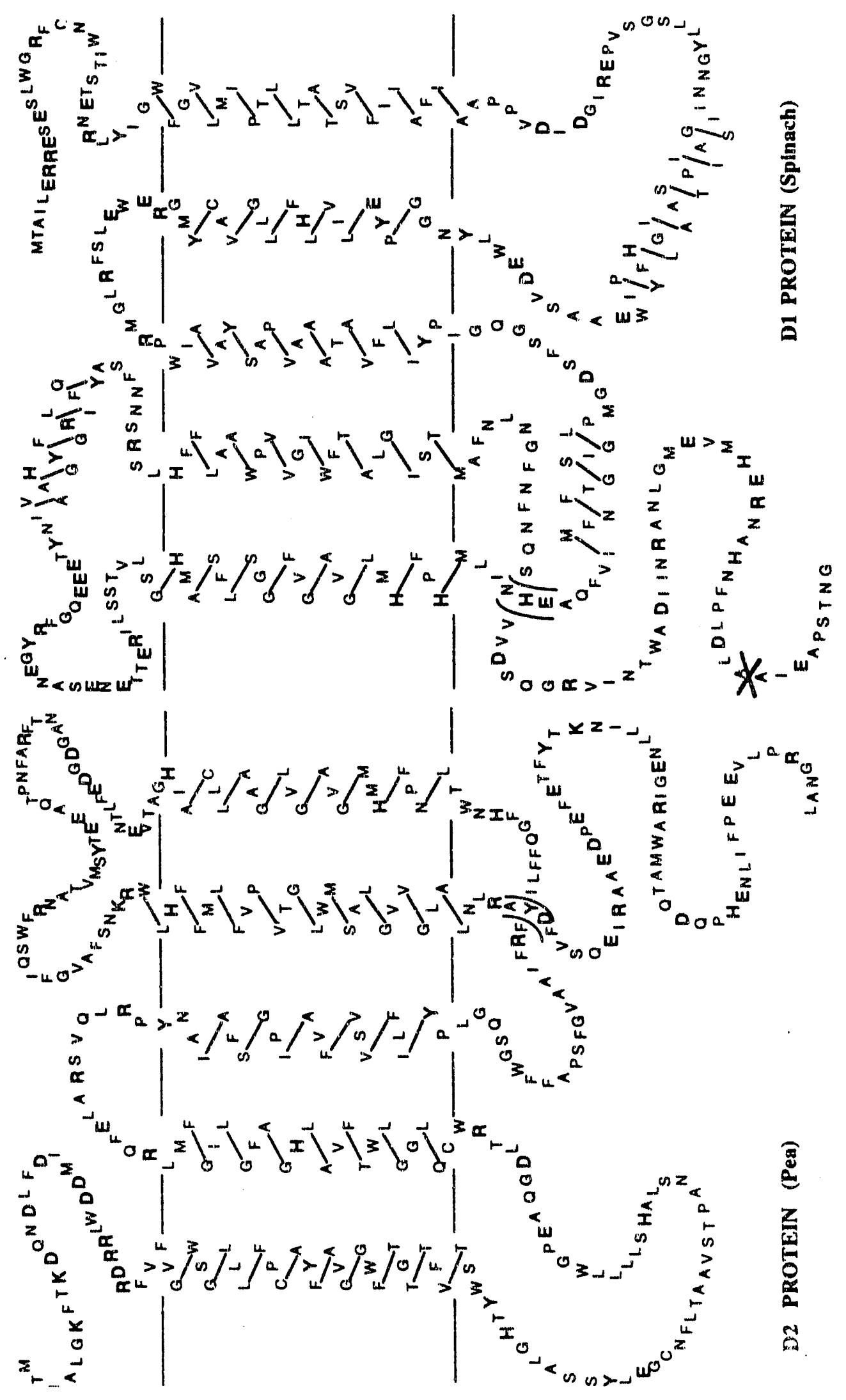




\section{Figure 2-2: Sequence comparison of D1 to $L$ subunit}

Amino acid sequence comparison of the spinach D1 protein with the purple bacterial L subunit, as originally described by Hearst (1986). The spinacia oleracea amino acid sequence is given for the Dl protein (Zurawski et al., 1982). The Rb. capsulatus amino acid sequence is given for the $\mathrm{L}$ subunit (Youvan et al., 1984). The marked and numbered regions of the five proposed transmembrane helices for the $L$ subunit correspond to those described by Michel and Deisenhofer (1988). 
Spinach D1 protein: MT.AILERRE SESLINGRFCN WITSTENRLY IGWFGVIMIP Rb. Caps. L subunit: MALLSFERKY RVPGGTLIGGSLFDFWVGPFY VGEEGVTTI,

TLLTATSVFI IAFIAAPPVD IDGIREPVSG SLLYGNIIIS GAIIPTSAAI GLHFYPIWEA EFATLGELLILWGAAMQGT WNP. ..............QL ISIFPPPVEN Helix I

ASVDEWLYNG GPYELIVLHF LLGVACYMGR EWELSFRLGM RPWIAVAYSA PVAAATAVEL GLWVAALDKG GLWOVITVCA TGAFCSWALR EVEICRKLGI GFHIPVAESM AIFAYITLVV Helix II

Helix III

IYPIGQGSFS DGMPLGISGT FNFMIIVFQAE HNILMHPFHM LGVAGVFGGS LFSAMHGSLV IRPMMMGSWG YAFPYGIWTH LDWVSNTGYTYGNFHYNPEHM IGISLEETTA WALAMHGALV Helix IV

TSSLIRETTE NESANEGYRF GQEEETYNIV AAHGYFGRII FQYASFNNSR SLHFFLAAWP

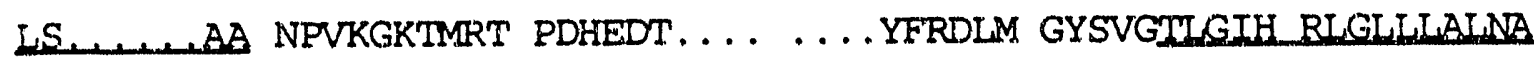
Helix $V$ VVGIWFTALG ISTMAFNLNG FNENQSVVDS QGRVINTWAD IINRANLGME VMHERNAHNF VEWSACSALV SGTIYFDLWS DWWYWWV..... NMPFWAD $\ldots \ldots \ldots \ldots \ldots$

PLDLAAIEAP STNG

......MAG GING 


\section{Figure 2-3: Sequence comparison of $D 2$ to $M$ subunit}

Amino acid sequence comparison of the spinach D2 protein with the purple bacterial $\mathrm{M}$ subunit, as originally described by Hearst (1986). The spinacia oleracea amino acid sequence is given for the D2 protein (Holschuh et al., 1984; Alt et al., 1984). The Rb. capsulatus amino acid sequence is given for the $M$ subunit (Youvan et al., 1984). The marked and numbered regions of the five proposed transmembrane helices for the $M$ subunit correspond to those described by Michel and Deisenhofer (1988). 
Spinach D2 protein: MTIAVGKFTK DEKDLFDSMD DWLRRDRFVF VGWSGLLLFP Rb. Caps. M subunit: MAEYQNEFNQ VQVAGAPEMG LKEDVDTFER TPAGMFNILG

CAYFALGGWF TG'TTFVTSWY THGLASSYLE GCNFLTAAVS TPANSLAHSL LLLWGPEAQG WMGNAQIGPI YLGIAGTVSL AEGAAWEETI GUWXYYAGFDPFIFMRDLFFFSLEPPPAEYG Helix I

DFTRWCQLGG LWAFVALHGA FALIGFMLRQ FELARSVQLR PYNAIAFSGP IAVFVSVFLI LAIAPLKQGG VWOIASLEMA ISVIAWWVRV YTRADQLGMG KHMAWAFLSA IWLWSVLGEW Helix II Helix III

YPLGQSGWFF APSFGVAAIF RFILFFQGFH NWTLNPFHMM GVAGVLGAAL LCAIHGATVE BRILMGSWSV APPYGIFSHL DWTNQFSLDHGNLFYNPEHGL SIAALYGSAL LFAMHGATIL Helix IV

NTLFEDGDGA NTFRAFNPTQ AEETYSMVTA NRFWSQIFGV AFSNKRWLHF FMLFVPVTGL AVTRFGGERE LEQIVDRGTA SERAALFWRWTMGWNATMEG. ... IHRWAIW MAVMVTLT. Helix V

WMSALGVVGL ALNLRAYDFV SQEIRAAEDP EFETFYTKNI LINEGIRAWM AAQDQPHENL .... GGIGI LLSGTVVDNW YVWAQVHGYA PVTP

IFPEEVLPRG NAL 
(between helices I and II and between helices III and IV of both proteins) which connect two transmembrane helices to each other on the lumenal side of the thylakoid membrane. Notice the particularly long sequence insertions between helices I and II of the D1 protein, and the C-terminal extensions on both the D1 and D2 proteins.

The proposals for which amino acids are capable of providing terminal ligands to the OEC Mn cluster are based on several lines of evidence, summarized here and described in more detail below. The spectroscopic evidence for the structural proposals of the Mn cluster have provided insight into possible amino acid ligands as summarized by Dismukes (1988). Early work used mainly EPR and X-ray absorption spectroscopy (EXAFS and XANES). More recently, improved sample preparations, application of the early spectroscopic methods to these samples and the introduction of pulsed EPR techniques (ESEEM and ENDOR) has provided higher resolution data which allows a more detail description of the OEC Mn complex. From the inorganic chemistry viewpoint, Pecoraro (1988) reviews the theoretically possible and chemically most probable groups that may act as ligands to $\mathrm{Mn}$ (oxyanions and imidazole groups). He also reviews the biochemical evidence, including comparison of other proteins which contain metal atom cofactors which has provided precedence for metal ion coordination within proteins, clues as to the amino acid residues preferred as ligands and likely structures of metal atom complexes within proteins.

In addition to the nitrogen groups from the peptide backbone, all of the amino acids which are theoretically possible candidates to provide ligands to $\mathrm{Mn}$ are: arginine, asparagine, aspartic acid, cysteine, glutamine, glutamic acid, histidine, lysine, methionine, serine, threonine and tyrosine. Of these, cysteine, methionine, serine and threonine can be excluded based an chemical reasoning as described by Dismukes (1988). The remaining amino acids, arginine, asparagine, aspartic acid, glutamine, glutamic acid, histidine, lysine 
and tyrosine are still possible ligand donors and are included in the diagram in Figure 2-4. This figure diagrammatically represents the five transmembrane helix models as depicted with the complete amino acid sequences in Figure 2-1. In Figure 2-4, proposed transmembrane helices are shown as numbered, darkly outlined, rectangles. Lightly outlined, unnumbered, rectangles represent other potential helical regions. Symbols represent the approximate location of the possible Mn-ligating amino acids which are predicted to be on the lumenal side of the membrane. Combining ESEEM results from DeRose et al. (1991) with EXAFS results, both discussed in Chapter 1, the most probable composition of amino acid ligands to the $\mathrm{Mn}$ cluster would be 1 or 2 histidines with the rest mainly aspartic and glutamic acids, with possibly the deamination products (aspartic and glutamic acids) of asparagine and glutamine. To simplify the diagrams, only lumenal histidine and carboxyl-containing amino acids (aspartic and glutamic acids), with the position number of histidines labeled explicitly, have been shown in further figures representing the $\mathrm{D} 1$ and $\mathrm{D} 2$ proteins in order to demonstrate relative positions. All of the possible amino acid ligands are represented schematically in Figure 2-4 and the actual sequences are shown in Figure 2-1.

Efforts were concentrated on lumenal regions of mainly the D1 protein for several reasons. First, the sequence and composition of potential Mn-binding amino acids were examined as just described. Secondly, the LF-1 mutant of Scenedesmus obliquus identified by Metz and Bishop (1980) was shown to be deficient in oxygen evolution and to lack approximately two of the four functional Mn. The LF-1 mutant was shown to have one altered protein which migrated slower on PAGE (Metz et al., 1980) which was later identified to be the D1 protein (Metz et al., 1986). Finally, the D1 protein was shown to turn over very quickly (Edelman and Reisfeld, 1978; Silverthorne and Ellis, 1980), possibly due to damage from the highly oxidizing environment surrounding the Mn cluster. This turnover was later shown to occur after an initial cleavage at the reducing side of the 
Figure 2-4: Diagram of D1 and D2 with all possible Mn ligands labeled

Diagrammatic representation of the five transmembrane helix models as depicted with the complete amino acid sequences in Figure 2-1. The approximate location of the lumenal amino acids (arginine, asparagine, aspartic acid, glutamine, glutamic acid, histidine, lysine and tyrosine) which are possible ligand donors to $\mathrm{Mn}$ are represented by the given symbols. Proposed transmembrane helices are shown as numbered, darkly outlined, rectangles. The thylakoid membrane boundaries are shown as horizontal dashed lines and the position number of histidines are labeled explicitly. 


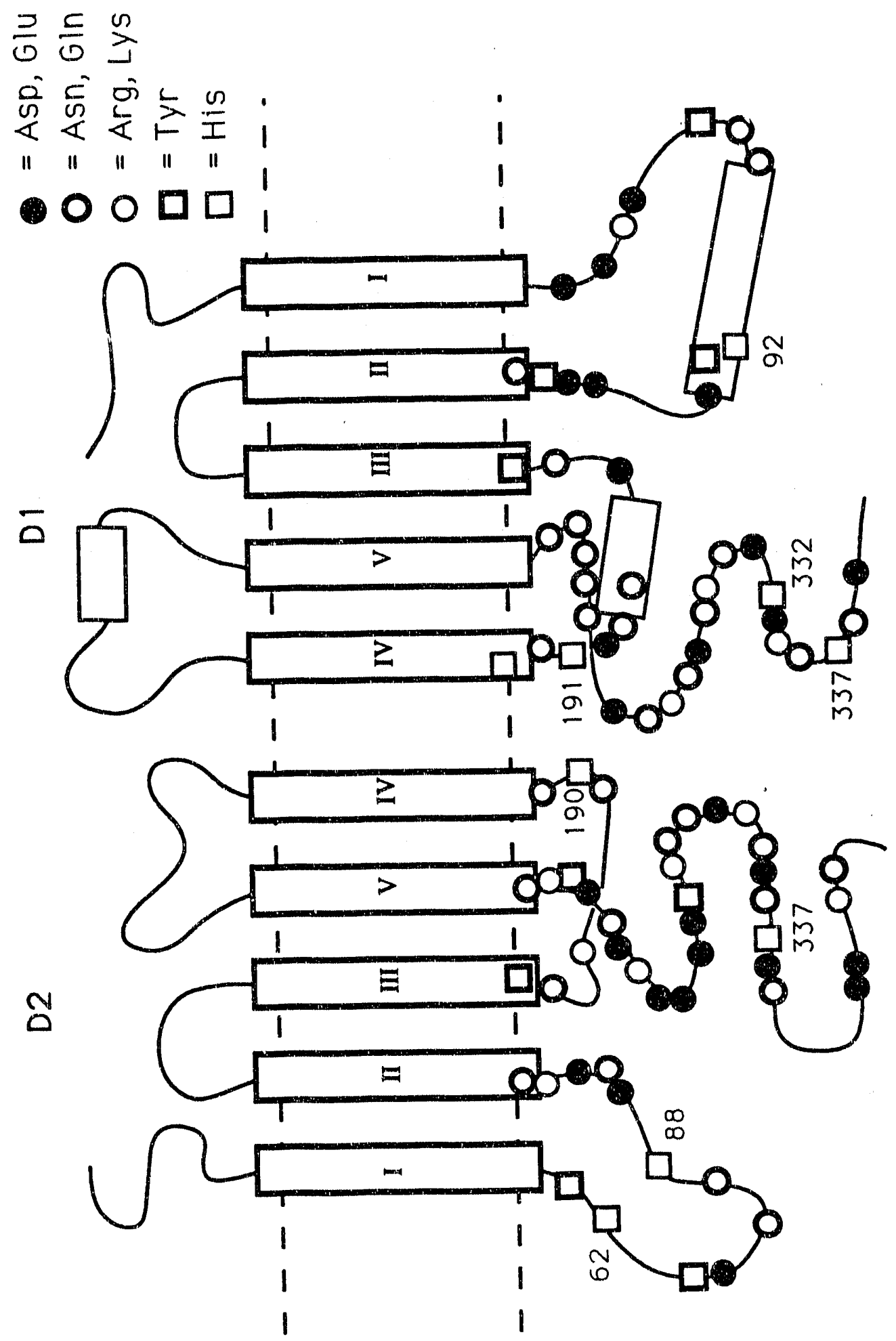


membrane near the quinone binding site (Greenberg et al., 1987). Although these authors describe the pathway for turnover of the D1 protein, the reason for the necessity of this turnover is still unclear and may be a requirement to replace D1 proteins damaged by Mn on the oxidizing side of the complex.

Several segments of the D1 and D2 proteins meeting the criteria described above were chosen for synthesis and are outlined on the schematic given in Figure 2-5. In this and following diagrams of the D1 and D2 proteins, circles or ovals surround the approximate regions of interest, which are further discussed as appropriate. The regions outlined in Figure 2-5 were chosen before the prediction of potential Mn-binding segments published by Dismukes (1988). The regions that were chosen here and those that Dismukes predicted were similar, with the C-terminal regions of D1 and D2 emphasized. But, regions closer to the C-terminus of both mature proteins and in the loop region connecting helices I and II of the D1 protein, all of which were excluded by Dismukes, were favored in this study. The $\mathrm{C}$-terminus of $\mathrm{D} 1$ above residue 338 was eliminated by Dismukes based on the cleavage of 12 to 16 residues of the protein sequence determined from the DNA sequence to form the mature functional protein as explained by Marder, et al. (1984). The actual cleavage was later shown to remove only 9 residues (Takahashi et al., 1988), leaving the C-terminus of D1 intact to residue 344 . Similarly, the $28 \mathrm{C}$-terminal residues of D2 were excluded by Dismukes based on Clamydomonas reinhardtii sequences published by Rasmussen, et al. (1984) and Rochaix, et al. (1984). These sequences appeared to show a lack of homology for oxygen-evolving organisms as analyzed by Zurawski, et al. (1982). The sequence was later corrected (Erickson, et al., 1986) and shown to be highly homologous and absent in the non-oxygen evolving photosynthetic organisms, therefore, considered here as a potential Mn-binding region. 
Figure 2-5: Diagram of D1 and D2 showing regions to be synthesized

Diagrammatic representation of the five transmembrane helix models with outlines surrounding segments of the D1 and D2 proteins which were chosen for synthesis. In this and further figures representing the D1 and D2 proteins, only lumenal histidine and carboxyl-containing amino acids (aspartic and glutamic acids) are shown, with the position number of histidines labeled explicitly. 


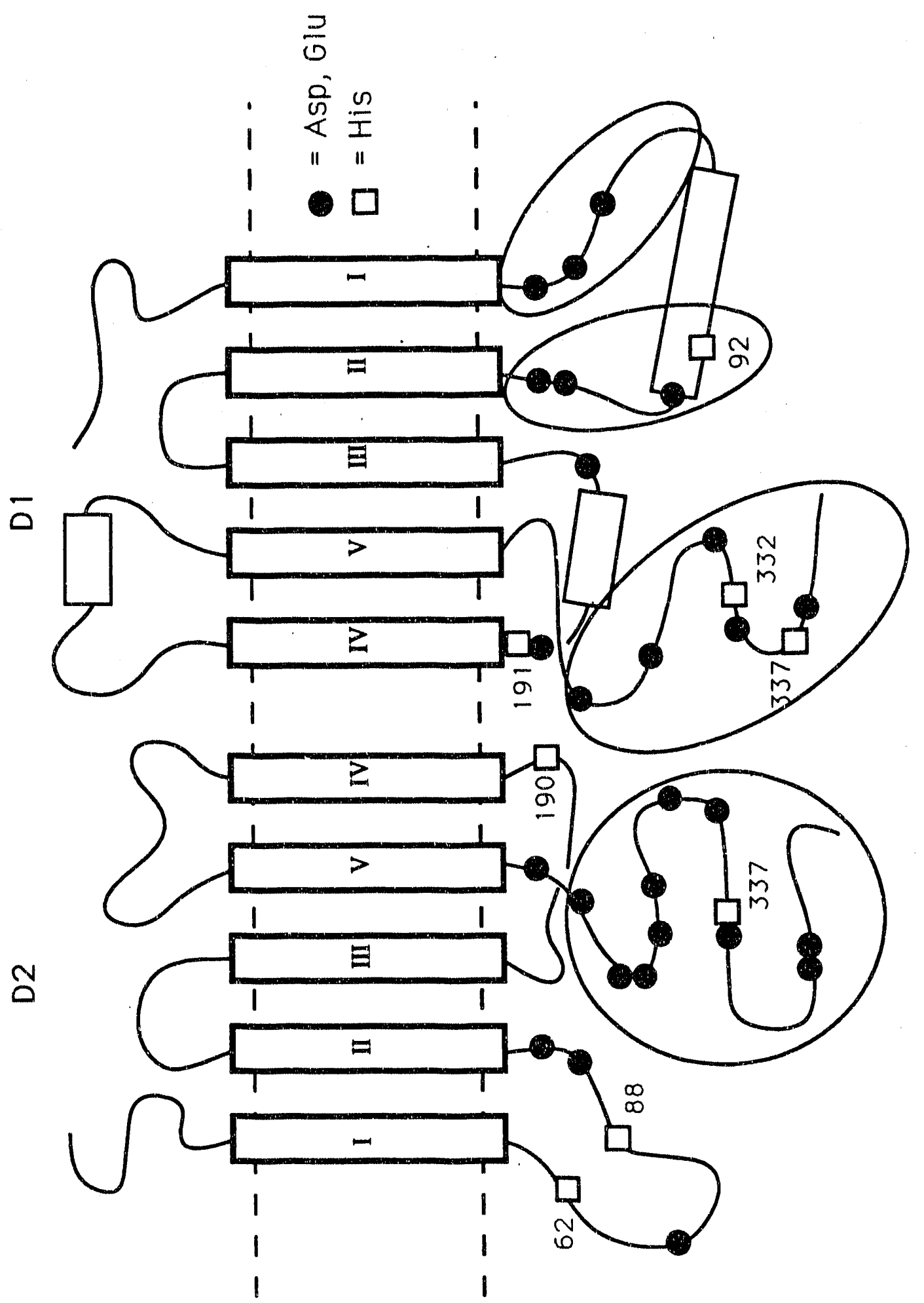




\section{Procedures}

\section{Peptide synthesis}

Peptides were synthesized at the Melvin Calvin Laboratory, with the guidance of David Koh, on an Applied Biosystems Model 430A Peptide Synthesizer using the Merrifield solid phase method and $\mathrm{t}-$ Boc chemistry as originally described by Merrifield (1963) and later reviewed by Kent and Clark-Lewis (1985). Hydrogen fluoride cleavage and deprotection was performed by the custom synthesis group led by Dr. Anita Hong at Applied Biosysterns, Foster City, California using the method of Tam, et al. (1983).

\section{Peptide purification}

Peptide purification was done by reverse phase high performance liquid chromatography (HPLC) on C18 columns using either a Waters or a Rainin HPLC system. A two solvent gradient system was used as described by Rivier et al. (1984). The solvents used were Solvent A: $0.1 \%$ trifluoroacetic acid (TFA) in 100\% water and Solvent B: $0.09 \%$ TFA in $60 \%$ acetonitrile, $40 \%$ water. Initially, a crude peptide was dissolved in a small volume (usually 5-20 ml) of Solvent $\mathrm{A}$, containing $1 \mathrm{M}$ acetic acid or 6-8 $\mathrm{M}$ urea when needed. Filtration using $2 \mathrm{ml}$ microfilters (Rainin) was always performed prior to loading samples onto HPLC columns. A small fraction $(100-300 \mu \mathrm{l})$ of this filtered solution was loaded onto an analytical $\mathrm{C} 18,300 \AA$ pore size, $1 / 4$ inch diameter column (Rainin) at a flow rate of 0.5 to $1.0 \mathrm{ml} / \mathrm{min}$. The solution was allowed to load onto the column for 20 min while flowing $100 \%$ Solvent $A$. The linear gradient used for this initial analysis started at $100 \% \mathrm{~A}$ and reached $100 \% \mathrm{~B}$ in $60 \mathrm{~min}$. After this time, the column was flushed for $20 \mathrm{~min}$ with $100 \% \mathrm{~B}$ and then changed back to $100 \% \mathrm{~A}$ over $10 \mathrm{~min}$. The effluent was monitored continuously by absorption at $220 \mathrm{~nm}$. The elution position of the major peak was used to define a shallower gradient for better separation. The shallower 
gradients incorporated this analytical elution percentage between their midpoint and two thirds point. Another analytical sample was loaded as above at $100 \% \mathrm{~A}$ for $20 \mathrm{~min}$. The amount of Solvent B was then increased in 10-20 min from 0 to $35 \%$ (a common gradient starting point, which was anywhere from 25 to $45 \%$ B depending on the peptide). The gradient proceeded from 35\% B to 65\% B (again, 65\% B was common, but the endpoints fell somewhere in the range of 40 to $80 \%$ B) in 60 or $90 \mathrm{~min}$. Finally, the solvent was changed to $100 \% \mathrm{~B}$ in 10-20 min and allowed to flow for an additional $20 \mathrm{~min}$ before returning to $100 \% \mathrm{~A}$ in $10 \mathrm{~min}$. This profile was then used for preparative runs on larger bore columns $(\mathrm{C} 18,300 \AA$ pore size, 1 inch diameter column from Rainin or Waters) using flow rates of 4 to $10 \mathrm{ml} / \mathrm{min}$. For these runs, however, the volumes of filtered peptide solution ranged from 2 to $20 \mathrm{ml}$ and were loaded as multiple injectiors or through a third solvent pump. The timing of the $20 \mathrm{~min}$ at $100 \% \mathrm{~A}$ did not begin until after completion of loading. For these larger samples, the effluent was monitored at $235 \mathrm{~nm}$ and the major peak by absorption was collected and pooled as fractions of differing purity (in the cases of several runs of the same peptide or separation into several fractions during a single run). This solution was then dried in a Speed-Vac to remove the organic solvents and acids and, if needed, lyophilized to remove any remaining water.

\section{Pepcide characterization}

Peptide composition was verified by amino acid analysis at the Melvin Calvin Laboratory, with the guidance of David Koh, using a system consisting of Applied Biosystems' Model 420A Amino Acid Derivatizer, 130A Separation System and 900A Control/Data Analysis Module. Samples containing 100-500 pmole of a particular peptide were placed in small tubes, dried by lyophilization and the tubes inserted into vials containing $6 \mathrm{M} \mathrm{HCl}$ (sequencing grade) and sealed with solid covers containing Teflon seals. These samples were acid hydmlyzed hy heating ovemight at $200^{\circ} \mathrm{C}$. After carefully removing the lid (in a hood) while still hot to avoid $\mathrm{HCl}$ condensation, the small tubes were 
removed and the hydrolysate redissolved in the volume required of distilled water to have 10-20 pmole of peptide per $20 \mu \mathrm{l}$. Nine $20 \mu \mathrm{l}$ samples were placed on thoroughly cleaned glass filter discs and run on the amino acid analyzer following three samples of amino acid standard (10 $\mu$ l of 1:100 dilution of stock from Bio Rad). The position of amino acid peaks of the standard were compared to previous standard runs for assignment to specific amino acids. The detector response to each amino acid was then calibrated to peak height or peak area by use of known standard concentrations. These calibrations were then used to assign the peaks of a hydrolyzed peptide and to calculate the amount (in pmole) of each amino acid present in that sample of peptide. These amounts were finally converted to ratios and compared to the theoretical amino acid composition of each peptide. This procedure was used to verify peptide composition, but gave no information as to peptide sequence.

Peptide sequences were confirmed by fast atom bombardment (FAB) mass spectrometry performed under the guidance of Dr. Judy Leary at the Chemistry Department, University of California at Berkeley. This method was under development at the time these sequences were analyzed. The correct sequences of synthesized peptides were easily confirmed. When fragmentation patterns of the purified peptide did not match the predicted sequence, it was not possible to assign a unique sequence. For these reasons, peptides whose sequences were not confirmed by mass spectrometry were resynthesized and repurified.

\section{Results and Discussion}

The sequences of the five peptides chosen for synthesis (along with the numbers of the starting and ending amino acids of the corresponding spinach protein) are shown in Figure 2-6. These sequences come from the spinach sequence of the DI protein (Zurawski 


\section{Figure 2-6: Sequences of peptides synthesized}

Sequences of the five peptides chosen for synthesis (along with the numbers of the starting and ending amino acids of the corresponding spinach protein). These sequences correspond to segments of the spinacia oleracea amino acid sequences of the D1 protein (Zurawski et al., 1982) and the D2 protein (Holschuh et al., 1984; Alt et al., 1984). 
et al., 1982) and the pea sequence of the D2 protein (Rasmussen et al., 1984). The peptides were successfully synthesized and deprotected as described above. Their approximate positions on the intact proteins are outlined on the schematic in Figure 2-7.

Peptide purification was done by reverse phase HPLC on C18 columns as described above. Generally, an analytical HPLC trace of a peptide showed one major, relatively sharp peak accounting for $75-95 \%$ of the total absorbance at $220 \mathrm{~nm}$ and eluted at a solvent composition in the region between $35 \% \mathrm{~B}$ and $65 \% \mathrm{~B}$ (with the remaining percentage made up with solvent A). The analytical HPLC trace of peptide Dl-a was different in that there were three broad overlapping peaks whose sum accounted for 90 $95 \%$ of the total absorbance at $220 \mathrm{~nm}$. The largest peak accounted for only $60 \%$ of the absorbance, and the next two peaks absorbed approximately equally the remaining 3035\%. Peptide D1-a proved impossible to purify, even with different column types and a variety of different solvent systems (not described here). During purification attempts, three crude peptides (D1-a, D1-c and D1-d) were used for a first attempt at antibody production using C8 HPLC beads as the carrier and adjuvant (see Chapter 3 ). When the crude products from a peptide synthesis were used as antigen, only a few sequences in addition to the desired peptide are available to elicit antibodies. These would primarily include amino acid deletions and products of early termination (peptides missing prations of the N-terninus), which would not create major complications in further assays. The region of D1 corresponding to peptide D1-a was resynthesized as a slightly shorter peptide (DI-b) which was successfully purified. Of the five peptides shown in Figure 2-6, only D1-a could not be purified. The other four peptides (D1-b, D1-c, D1-d and D2-a) all showed good analytical HPLC traces and were successfully purified as described earlier. The crude yield of peptide following deprotection was generally 1-2 mg, depending on the length and composition of the specific peptide. The final yield of peptide following preparative HPLC were more variable and ranged from 50 to $200 \mu \mathrm{g}$, this time depending 
Figure 2-7: Diagram of D1 and D2 showing synthesized peptide regions

Diagrammatic representation of the five transmembrane helix models with the approximate positions of the synthesized peptides outlined on the intact proteins. As described in Figure 2-5, only lumenal histidine and carboxyl-containing amino acids (aspartic and glutamic acids) are shown, with the position number of histidines labeled explicitly. 


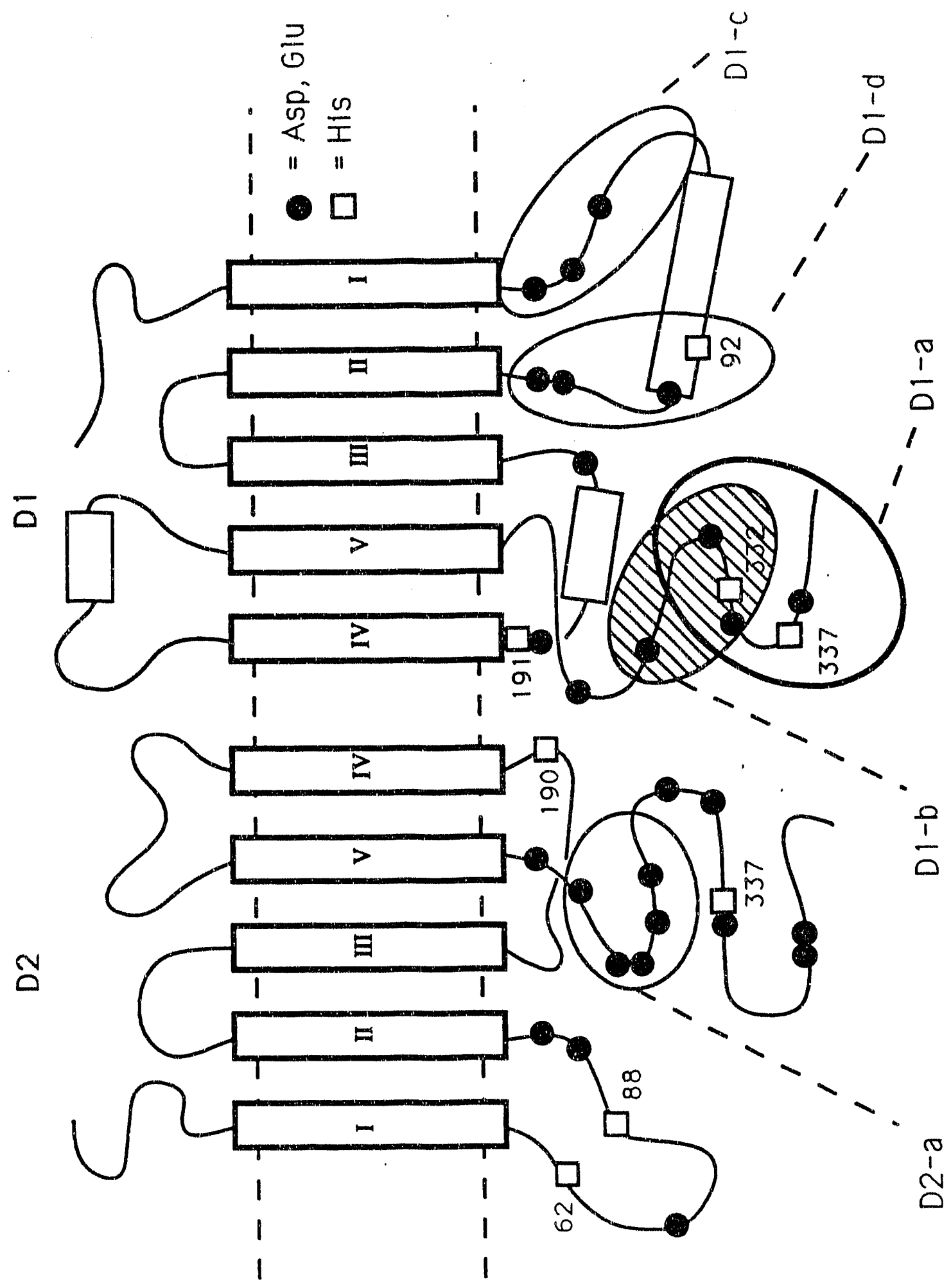


on the required purity and solubility behaviors of the individual peptide. The purity of the central fractions collected from the major peaks was very high as shown by no residual peaks on final analytical HPLC traces. These central fractions were used for subsequent antibody production, see Chapter 3 .

Peptide composition was verified by amino acid analysis using the equipment described above. Since peptide D1-a proved impossible to purify, it was not further characterized. For an example of the results of amino acid analysis, the composition of peptide D1-b is shown in Table 2-1. At this point, it should be noted that amino acid composition is always affected by the acid hydrolysis procedure used. The best procedure available at the time, which was described earlier, was chosen. The predicted effects of this hydrolysis procedure on the yield of individual residues as described by Pickering and Newton (1990) are shown in Table 2-2. To summarize, the most quantitatively reproducible residues are: Ala, Arg, Gly, His, Ile, Leu, Lys, Phe, Pro and Val. Two residues, Asn and Gln, are converted to Asp and Glu, respectively and quantitatively. Therefore, the experimental Asp value represents the sum of Asn and Asp found in the peptide, and similarly for the Glu value. The residues whose yield may vary, depending on procedural variations are Cys, Met, Trp and Tyr. Finally, the yield is predictably less than $100 \%$ for Ser and Thr (see Table 2-2). Generally, the yield of Ser is $90 \%$ and the yield of Thr is $95 \%$. Using these corrections to calculate corrected experimental amino acid compositions gave values which agree more closely with the predicted amino acid contents of known proteins. As an example, the final column of Table 2-3 shows the amino acid composition for peptide D1-b as corrected for all of these expected variations. As can be seen, the experimental sequence matches quite well with the predicted sequence when hydrolysis effects are considered. This was also the case for the other three peptides analyzed (D1-c, D1-d and D2-a) as is shown in Tables 2-4, 2-5 and 2-6. One of these peptides (D1-c), however, had shown an anomalous amino acid composition and 
Table 2-1

Amino acid composition of purified D1-b peptide, whose sequence was DII-NRA-NLGMEV-MHE-R. The given experimental amino acid ratios are not corrected for the effects of acid hydrolysis on amino acid composition.

\begin{tabular}{ccc}
\hline Amino Acid & $\begin{array}{c}\text { Predicted } \\
\text { AA Ratios }\end{array}$ & $\begin{array}{c}\text { Experimental } \\
\text { AA Ratios }\end{array}$ \\
Ala & 1 & 0.97 \\
Arg & 2 & 1.87 \\
Asn & 2 & 0 \\
Asp & 1 & 3.15 \\
Glu & 2 & 2.13 \\
Gly & 1 & 1.00 \\
His & 1 & 0.98 \\
He & 2 & 2.21 \\
Leu & 1 & 0.98 \\
Mal & 2 & 1.08 \\
\hline
\end{tabular}




\section{Table 2-2}

Effects of acid hydrolysis on amino acid composition as described by Pickering and Newton (1990). This information incorporates known effects of acid hydrolysis on individual amino acids and will be used for the calculation and explanation of corrected amino acid compositions from the experimental amino acid ratios.

\begin{tabular}{|c|c|c|}
\hline Amino Acid & $\begin{array}{c}\text { Percentage } \\
\text { Observed }\end{array}$ & $\begin{array}{l}\text { Corrections } \\
\text { and cornments }\end{array}$ \\
\hline $\mathrm{Ala}$ & $100 \%$ & \\
\hline Arg & $100 \%$ & \\
\hline Asn & $0 \%$ & becomes $100 \%$ Asp \\
\hline Asp & $100 \%+$ & $A s p+A s n$ \\
\hline Cys & $<70 \%$ & $\times 1.43$ \\
\hline Gln & $0 \%$ & becomes $100 \%$ Glu \\
\hline Glu & $100 \%+$ & Glu + Gln \\
\hline Gly & $100 \%$ & \\
\hline His & $100 \%$ & \\
\hline Ile & $100 \%$ & \\
\hline Leu & $100 \%$ & \\
\hline Lys & $100 \%$ & \\
\hline Met & $<50 \%$ & $\times 2.00$ \\
\hline Phe & $100 \%$ & \\
\hline Pro & $100 \%$ & \\
\hline Ser & $90 \%$ & x 1.11 \\
\hline Thr & $95 \%$ & $\times 1.05$ \\
\hline Trp & $<50 \%$ (we see $0 \%$ ?) & $\times 2.00$ \\
\hline Tyr & $<80 \%$ & $\times 1.25$ \\
\hline Val & $100 \%$ & \\
\hline
\end{tabular}


Table 2-3

Corrected amino acid composition of purified D1-b peptide, whose sequence was DIINRA-NLG-MEV-MHE-R. These corrected amino acid ratios incorporate the known effects of acid hydrolysis on amino acid composition as described in Table 2-2.

\begin{tabular}{cccc}
\hline Amino Acid & $\begin{array}{c}\text { Predicted } \\
\text { AA Ratios }\end{array}$ & $\begin{array}{c}\text { Experimental } \\
\text { AA Ratios }\end{array}$ & $\begin{array}{c}\text { Corrected } \\
\text { AA Ratios }\end{array}$ \\
\hline Ala & 1 & 0.97 & \\
Arg. & 2 & 1.87 & $1+2 ?$ \\
Asn & 2 & 0 & \\
Asp & 1 & 3.15 & \\
Glu & 2 & 2.13 & \\
Gly & 1 & 1.00 & \\
His & 1 & 0.98 & \\
Ile & 2 & 2.21 & \\
Leu & 1 & 1.08 & \\
Met & 2 & 0.80 & \\
Val & 1 & 0.98 & \\
\hline
\end{tabular}




\section{Table 2-4}

Corrected amino acid composition of purified D1-c peptide, whose sequence was PPVDID-GIR-EPV-SGS-LLY-GNN. These corrected amino acid ratios incorporate the known effects of acid hydrolysis on amino acid composition as described in Table 2-2.

\begin{tabular}{|c|c|c|c|}
\hline Amino Acid & $\begin{array}{l}\text { Predicted } \\
\text { AA Ratios }\end{array}$ & $\begin{array}{l}\text { Experimental } \\
\text { AA Ratios }\end{array}$ & $\begin{array}{l}\text { Corrected } \\
\text { AA Ratios }\end{array}$ \\
\hline & . & & \\
\hline Arg & 1 & 1.16 & \\
\hline Asn & 2 & 0 & \\
\hline Asp & 2 & 4.17 & $2+2 ?$ \\
\hline Glu & 1 & 0.97 & \\
\hline Gly & 3 & 2.88 & \\
\hline Ile & 2 & 2.00 & \\
\hline Leu & 2 & 2.20 & \\
\hline Pro & 3 & 3.14 & \\
\hline Ser & 2 & 1.81 & 2.01 \\
\hline Tyr & 1 & 0.81 & 1.01 \\
\hline $\mathrm{Val}$ & 2 & 2.03 & \\
\hline
\end{tabular}




\section{Table $2-5$}

Corrected amino acid composition of purified D1-d peptide, whose sequence was GLHFYP-IWE-AAS-VDE-WLY-N. These corrected amino acid ratios incorporate the known effects of acid hydrolysis on amino acid composition as described in Table 2-2.

\begin{tabular}{|c|c|c|c|}
\hline Amino Acid & $\begin{array}{l}\text { Predicted } \\
\text { AA Ratios }\end{array}$ & $\begin{array}{c}\text { Experimental } \\
\text { AA Ratios }\end{array}$ & $\begin{array}{l}\text { Corrected } \\
\text { AA Ratios }\end{array}$ \\
\hline Ala & 2 & 2.21 & \\
\hline Asn & 1 & 0 & \\
\hline Asp & 1 & 2.01 & $1+1 ?$ \\
\hline Glu & 2 & 2.05 & \\
\hline Gly & 1 & 1.00 & \\
\hline His & 1 & 0.92 & \\
\hline ne & 1 & 0.83 & \\
\hline Leu & 2 & 2.09 & \\
\hline Phe & 1 & 1.02 & \\
\hline Pro & 1 & 0.97 & \\
\hline Ser & 1 & 0.84 & 0.93 \\
\hline Trp & 2 & 0 & $?$ \\
\hline Tyr & 2 & 0.80 & 1.00 \\
\hline Val & 1 & 0.88 & \\
\hline
\end{tabular}


Table 2-6

Corrected amino acid composition of purified D2-a peptide, whose sequence was VSQEIR-AAE-DPE-FET-FYT-KN. These corrected amino acid ratios incorporate the known effects of acid hydrolysis on amino acid composition as described in Table 2-2.

\begin{tabular}{cccc}
\hline Amino Acid & $\begin{array}{c}\text { Predicted } \\
\text { AA Ratios }\end{array}$ & $\begin{array}{c}\text { Experimental } \\
\text { AA Ratios }\end{array}$ & $\begin{array}{c}\text { Corrected } \\
\text { AA Ratios }\end{array}$ \\
\hline Arg & 1 & 1.14 & \\
Asn & 1 & 0 & $1+1 ?$ \\
Asp & 1 & 2.18 & \\
Gln & 1 & 0 & $4+1 ?$ \\
Glu & 4 & 5.22 & \\
Ile & 1 & 1.00 & \\
Lys & 1 & 0.98 & 1.01 \\
Phe & 2 & 1.92 & \\
Pro & 1 & 1.07 & 0.97 \\
Ser & 1 & 0.87 & \\
Thr & 2 & 1.85 & \\
Tyr & 1 & 0.81 & \\
Val & 1 & 0.90 & \\
\hline
\end{tabular}


unexplainable mass spectrometry results after its first synthesis (data not shown), so the results of a second synthesis are those described above and in Table 2-4.

Several peptide sequences were confirmed by fast atom bombardment (FAB) mass spectrometry. This method was under development at the time these sequences were analyzed. For this reason, correct sequences were easily confirmed, but it was much more difficult to determine sequences when the experimental fragmientation pattern did not match the predicted pattern. The largest weight peak corresponded to the molecular weight of the intact, ionized peptide. Cleavage at any of the peptide backbone bonds surrounding a given amino acid yields a maximum of six different fragmentation patterns. There is one series for each of the two fragments caused by cleavage at one of the three backbone bonds per arnino acid residue (see Figure 2-8). Any combination of these fragmentation patterns can be observed, depending on the specific peptide. In addition, a high background at nearly all molecular weights is caused by fragmentation of side groups and multiple cleavages. Of the four original peptides analyzed (D1-b, D1-c, D1-d and D2-a), only D1-c gave unexplainable fragmentation patterns and a molecular weight much smaller than expected. The other three peptides and the second synthesis of peptide D1-c gave appropriate molecular weights and fragmentation patterns in agreement with those computed from the expected sequence.

In summary, the five peptides whose sequences are shown in Figure 2-6, were successfully synthesized and deprotected as described earlier. These peptides were purified by reverse phase HPLC on C18 columns. Peptide D1-a proved impossible to purify, but the other four peptides (D1-b, D1-c, D1-d and D2-a) were successfully purified. The amino acid compositions of the purified peptides were verified by amino acid analysis and confirmed by fast atom bombardment mass spectrometry. Attempts to elicit antibodies using these five peptides are described in the next chapter. 


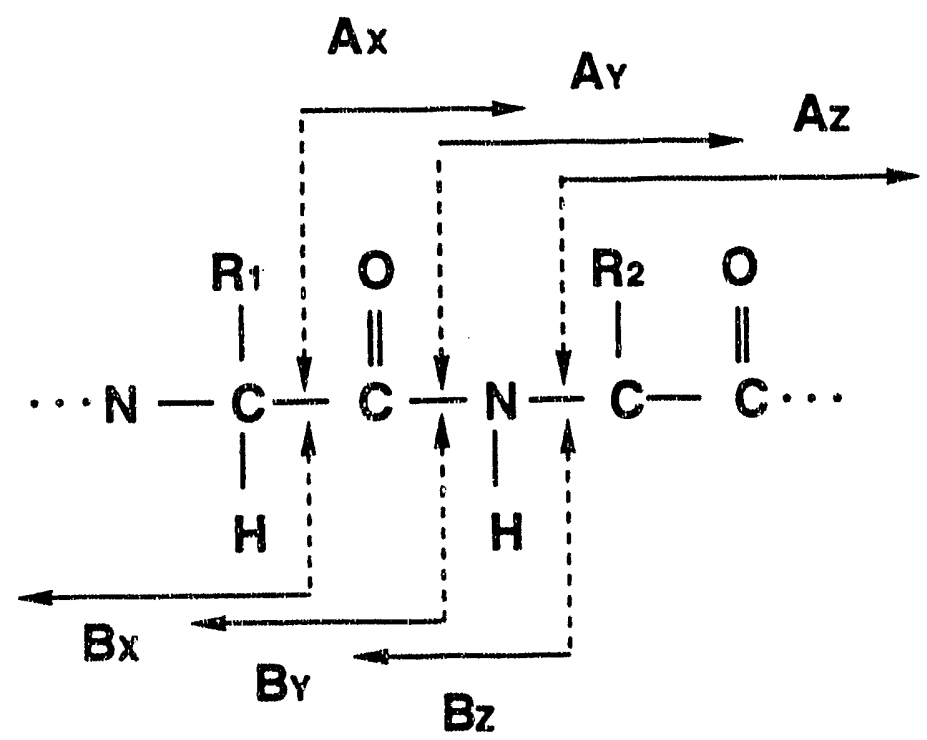

Figure 2-8: Possible peptide fragmentation patterns

Cleavage at any of the peptide backbone bonds surrounding a given amino acid yields a maximum of six different fragmentation patterns. There is one series for each of the two fragments caused by cleavage at one of the three backbone bonds per amino acid residue. The possible fragmentation patterns involving two amino acid side chains ( $R_{1}$ and $\left.R_{2}\right)$ within a protein are given and all backbone atoms are shown explicitly. 


\section{ANTIBODIES}

\section{Introduction}

The sequences of the successfully synthesized peptides discussed in the previous chapter are shown in Figure 2-6. The approximate positions of these peptides on the intact D1 and D2 proteins are outlined on the schematic in Figure 2-7. This chapter describes attempts to elicit polyclonal antibodies in New Zealand White rabbits using these five peptides as the antigens. There were several attempts to produce antibodies using the two methods described below. In each attempt, two to four different rabbits were used per peptide in order to increase the chances of antibody production.

Initially, crude peptides were noncovalently coupled to C8 HPLC beads and injected subcutaneously. The C8 HPLC beads are thought to act as carrier and adjuvant for these peptides. In a fashion similar to reverse phase HPLC, the hydrophobic regions of the peptides bind noncovalently to the $\mathrm{C} 8$ beads and are released slowly under physiological conditions. Free peptides would be destroyed quickly after injection. But, this attachment to the $\mathrm{C} 8$ beads, protects the peptides, allowing thern to be detected by the immune system and to possibly produce antibodies that recognize the peptide. This procedure was used first due to its simplicity and reported prior success rate of approximately $50 \%$ of peptides leading to polyclonal antibodies (Dr. J. Allison, Immunology DepL, UC Berkeley, CA, personal communication). This procedure successfully produced antibodies against one peptide, D1-a. The other peptides used in this procedure were D1-c and D1-d, neither of which elicited antibodies detectable by westem blotting analysis as discussed in the next chapter. 
The second procedure was much more involved, but resulted in successful antibodies against two other peptides, D1-b and D2-a, which were not elicited by the first procedure. Briefly, the second procedure involved covalent conjugation of peptides to PPD (the purified protein derivative of tuberculin bacillus), injection into the surgically exposed popliteal lymph node, and booster shots subcutaneously into the area of the same lymph node (see detailed procedure below). All of these steps, including conjugation of peptides to PPD and the use of Freund's adjuvants, were used in order to increase the antigenicity of the peptides as much as possible. PPD has been characterized as a protein which has strong activation of the immune system without many antibodies being produced against itself. Therefore, peptides conjugated to PPD should benefit from this enhanced immune response and more readily produce antibodies that will recognize it. It should be noted that even this, the procedure most likely to elicit antibodies against small peptides, produced antibodies against only 2 of the 4 peptides injected. This was consistent with the successful production of polyclonal antibodies by approximately $50 \%$ of the peptides, as expected (Dr. J. Allison, Immunology Dept., UC Berkeley, CA, personal communication).

\section{Procedures}

\section{Antibody production}

Polyclonal antibodies were raised in New Zealand White rabbits by one of two methods:

1) Crude peptides which were deprotected and cleaved from the support resin were noncovalently coupled to $\mathrm{C} 8$ beads which act as carrier and adjuvant. Approximately 0.1 $\mu \mathrm{g}$ of peptide was incubated with $100 \mu \mathrm{g}$ of $\mathrm{C} 8$ beads for 4 hours with constant gentle

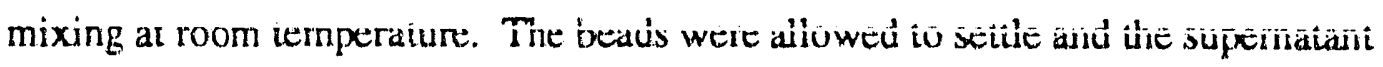


removed. The beads were then washed twice with phosphate buffered saline (PBS) and resuspended in $500 \mu \mathrm{l}$ of PBS. These suspensions were injected subcutaneously at 2 week intervals for 3 injections per rabbit following procedures provided by Dr. J. Allison (Immunology Dept., UC Berkeley, CA).

2) Approximately $5 \mathrm{Hg}$ of purified (see previous chapter) peptides were covalently coupled to $500 \mu \mathrm{g}$ of PPD (the purified protein derivative of tuberculin bacillus) by incubation with glutaraldehyde as previously described (Reichlin, 1980; Lachmann et al., 1986). Primary injections consisted of $100 \mu \mathrm{g}$ of conjugate in $200 \mu \mathrm{l}$ PBS which were emulsified with an equal volume of Complete Freund's Adjuvant. This mixture was injected into the surgically exposed popliteal lymph node (Sigel, 1983) with the assistance of the veterinary staff from the Office of Laboratory Animal Care (OLAC) at the University of California, Berkeley. Boosts 4 and 6 weeks later contained $100 \mu \mathrm{g}$ of conjugate in 200 $\mu l$ of PBS emulsified with an equal volume of Incomplete Freund's Adjuvant and were subcutaneous mainly in the region of the same lymph node. In both procedures, rabbits were bled before injections and two or more weeks after the last injection. The whole blood was allowed to clot, centrifuged at low speed and the supernatant (serum) was retained.

\section{Assay for antibody presence}

Antibodies were assayed by western blotting analysis using spinach PS II membrane preparations as the target proteins run on polyacrylamide gel electrophoresis (PAGE). The details of these procedures are described in the next chapter.

\section{Pre-immune Fab's}

Pre-immune IgG antibody binding fragments (Fab's), for use in solution binding assays, were made by procedures provided by R. Storrs (Chemistry Dept., UC Berkeley, 
CA). Rabbit pre-immune serum was diluted $1: 1$ with $0.01 \mathrm{M}$ phosphate buffered $0.15 \mathrm{M}$ saline (PBS) and centrifuged $(10,000 \times \mathrm{g}, 15 \mathrm{~min})$ to clarify. The IgG fraction was precipitated by dropwise addition of an equal volume of room temperature saturated ammonium sulfate, $\mathrm{pH} 7.4$, stirring for an additional hour and centrifugation as above. The pellet was resuspended in 1/4 of the original volume of PBS:saturated ammonium sulfate $(1: 1, v / v)$ to wash, centrifuged as above and repeated. At $0-4^{\circ} \mathrm{C}$, the pellet was dissolved in $2 / 3$ of the original serum volume of PBS and dialyzed against 20 volumes of Fab Buffer (0.1 M phosphate buffer, pH 7.2, $4 \mathrm{mM}$ EDTA) overnight at $4^{\circ} \mathrm{C}$ without stirring and then for $4 \mathrm{~h}$ with stirring after a change of buffer. After dialysis, the retentate was centrifuged as above to remove insoluble protein. The weight of IgG was estimated by UV absorption at $280 \mathrm{~nm}(1.37 \mathrm{OD} / \mathrm{mg}$ per $\mathrm{ml})$. Dithiothreitol (DTT) was added to 1 mM final concentration. Digestion with papain (1\% by weight) was performed for 2 to $4 \mathrm{~h}$ with gentle agitation at $37^{\circ} \mathrm{C}$. Finally, chromatography through Sephadex G-50 fine (equilibrated with Fab Buffer), with monitoring at $280 \mathrm{~nm}$, quenched the digestion and separated antibody fragments from papain. Fab's and Fc's elute in the void volume, while papain comes out later.

\section{Results and Discussion}

The rnethod utilizing crude peptide mixtures non-covalently coupled to C8 HPLC beads was used twice. The first series used only one peptide, D1-a, injected into 2 rabbits. Both rabbits successfully produced antibodies (anti-D1-a) which recognized the D1 protein on western blots of spinach PS II membrane preparations. The binding of this particular antibody was first demonstrated using ELISA techniques with the immunizing peptide as the substrate target (data not shown). Although this assay gave positive results, recognition of the $D 1$ protein was required and, therefore, western blotting techniques 
became the primary assay for antibody presence. Discussion of this assay and the specific results are deferred to the next chapter, and the results described there will be used as conclusions of the presence or lack of antibody here without further elaboration. The second series using the C8 HPLC beads used 2 crude peptides (D1-c and D1-d) injected into 4 rabbits each. All of these rabbits failed to produce antibodies as assayed by western blotting.

The second method, involving coupling of peptides 10 PPD and injection into the popliteal lymph node, was used once with 4 peptides (D1-b, D1-c, D1-d and D2-a) injected into 3 rabbits each. Two of these peptides, D1-b and D2-a, successfully elicited antibodies (anti-D1-b and anti-D2-a) that recognized the D1 and D2 proteins, respectively, on western blots of spinach PS II membrane preparations. Both of these antibodies gave positive results on western blots at greater dilutions than did anti-D1-a, indicating that they are either stronger binding antibodies or that their serum concentration is greater.

Pre-immune IgG antibody binding fragments (Fab's) were successfully prepared using the procedure described above. The antibody fragment peak was collected as several fractions. The OD at $280 \mathrm{~nm}$ was measured and the fraction with highest protein concentration was used for the solution binding experiments described in Chapter 6. 


\section{WESTERN BLOTTING ASSAYS}

\section{Introduction}

Western blotting was used for several purposes. It was first used to analyze the serum taken from individual rabbits for the presence of antibody. ELISA techniques using the immunizing peptide as antigen had given reasonable positive results for anti-D1-a, but did not address whether the antibodies recognized the intact D1 protein. Mainly for this reason, western blotting analysis was used as the primary screening method for the remainder of antibody analyses. The procedure used for these analyses involved comparison of pre-immune serum binding versus "immune" serum binding at several different dilutions in order to control for nonspecific binding of the primary and secondary antibodies and developing time with the final substrate. These blots were performed on membrane strips zut from a blot of a polyacrylamide gel electrophoresis (PAGE) of PS II membranes. The strips were processed in separate compartments of a Bio-Rad 25-well western blotting tray in order to minimize cross contamination. Alkaline phosphataselabeled secondary antibodies were used to detect primary antibody presence.

The second procedure which was used appeared to be more sensitive and provided greater discrimination with lower background binding. It was not used for the primary screening due mainly to the requirement for $\left[{ }^{125}\right.$ I] containment which would have been difficult using the Bio-Rad blotting tray. This assay was therefore used as final confirmation of antibody specificity as well as to deternine binding to different types of preparations (see below). The main difference in this procedure involved the binding of [125I]-labeled secondary antibody and its detection by autoradiography. 


\section{Procedures}

\section{PS II membrane preparation}

PS II membrane fragments were prepared from spinach leaves essentially as described by Berthold, et al. (1981), but including modifications from Ford and Evans (1983), Rutherford et al. (1984) and Dr. J.-L. Zimmermann (Service Biophysique, CENSaclay, France). Spinach leaves (4-6 bunches) obtained from local markets were washed using de-ionized water and then deveined. They were then placed in a Waring blender with $200 \mathrm{ml}$ of cold Grinding Medium (50 mM Hepes pH 7.5, $1 \mathrm{mM}$ EDTA, $0.4 \mathrm{M} \mathrm{NaCl}, 4$ $\mathrm{mM} \mathrm{MgCl} 2,5 \mathrm{mM}$ sodium ascorbate, $0.2 \% \mathrm{BSA}$, the last 2 added shortly before grinding) per bunch of spinach. They were ground with a short pulse and then $10 \mathrm{~s}$ on

medium speed. The mixture was filtered through 2 layers of cheesecloth and then 16 of layers cheesecloth and immediately centrifuged $\left(10 \mathrm{~min}, 6000 \times \mathrm{g}, 4^{\circ} \mathrm{C}\right.$, Sorvall GS3 or GSA rotor). The grinding and filtering steps were performed in a cold room $\left(4^{\circ} \mathrm{C}\right)$ as quickly as possible to keep protease damage to a minimum. Further steps were performed on ice under dim light and all buffers were ice cold. The pelleted chloroplasts were resuspended using a small paint brush into $40 \mathrm{ml}$ (per bunch) of Washing Medium (150 $\mathrm{mM} \mathrm{NaCl}, 8 \mathrm{mM} \mathrm{MgCl} 2,50 \mathrm{mM}$ Hepes $\mathrm{pH} 7.5)$ and centrifuged as above. The pellet containing broken chloroplasts was resuspended into a small volume of Resuspension Medium (50 mM MES-NaOH pH 6.0, $15 \mathrm{mM} \mathrm{NaCl}, 10 \mathrm{mM} \mathrm{MgCl}$ ). The Chl concentration was measured using acetone extracts and following the method described by Arnon (1949). Generally, a yield of 100-150 mg Chl for 4-6 bunches of spinach was found at this point in the procedure. Triton X-100 detergent was dissolved in Resuspension Medium and added to make the final mixture $25 \mathrm{mg}$ Triton/mg Chl and $2 \mathrm{mg}$ $\mathrm{Chl} / \mathrm{ml}$ solution. The mixture was incubated at $4^{\circ} \mathrm{C}$ with gentle stirring for $20 \mathrm{~min}$ in complete darkness. The PS II-enriched membrane fragments were pelleted by 
centrifigation ( $30 \mathrm{~min}, 35000 \times \mathrm{g}, 4^{\circ} \mathrm{C}$, Sorvall SS34 rotor). They were resuspended in Resuspension Medium and centrifuged ( $1 \mathrm{~min}, 2000 \times \mathrm{g}, 4^{\circ} \mathrm{C}$, Sorvall SS34 rotor) to remove excess starch. This pellet was discarded and the supernatant was centrifuged again ( $30 \mathrm{~min}, 35000 \times \mathrm{g}, 4^{\circ} \mathrm{C}$, Sorvall SS34 rotor). The final pellet contains oxygen-evolving PS II membranes and was generally resuspended at $>2 \mathrm{mg} \mathrm{Chl/ml} \mathrm{in} \mathrm{SMN} \mathrm{Buffer}(0.4 \mathrm{M}$ sucrose, $20 \mathrm{mM}$ MES- $\mathrm{NaOH}$ pH 6.5, $15 \mathrm{mM} \mathrm{NaCl}, 10 \mathrm{mM} \mathrm{MgCl}$ ). An average final yield was 60-100 mg Chl from 4-6 bunches of spinach. These PS II membrane preparations had oxygen evolution rates of $450-550 \mu \mathrm{mol} \mathrm{O} 2 / \mathrm{mg} \mathrm{Chl} \mathrm{per} \mathrm{h}$ and were stored in aliquots at $-80^{\circ} \mathrm{C}$ until used.

\section{Tris treatment of PS II membranes}

As described by Preston and Seibert (1991a), spinach PS II membranes were Mndepleted (Tris-treated) by centrifugation $(30,000 \times \mathrm{g}, 10 \mathrm{~min})$ and resuspending at $500 \mu \mathrm{g}$ $\mathrm{Ch} / \mathrm{ml}$ in $1.0 \mathrm{M}$ Tris- $\mathrm{HCl} \mathrm{pH} 9.4,0.4 \mathrm{M}$ sucrose. The mixture was incubated for $30 \mathrm{~min}$ under room lights at $4^{\circ} \mathrm{C}$ with occasional mixing. The membranes were collected by centrifugation $(30,000 \times \mathrm{g}, 10 \mathrm{~min})$, washed once in SMN Buffer and resuspended in the same buffer.

\section{Carboxypeptidase A treatment of PS II membranes}

Carboxypeptidase A-treated PS II membranes were prepared as described in Preston and Seibert (1991b). Carboxypeptidase A type II from bovine pancreas (E.C. 3.4.17.1) was purchased from Sigma (St. Louis, MO) and used as provided. After thawing, Tris-treated PS II membranes at $200 \mu \mathrm{g} \mathrm{Chl} / \mathrm{ml}$ were incubated for $1 \mathrm{~h}$ with the protease at $20^{\circ} \mathrm{C}$ in the dark in Digestion Buffer $(0.4 \mathrm{M}$ sucrose, $20 \mathrm{mM} \mathrm{MES}-\mathrm{NaOH}$ pH $6.5,20 \mathrm{mM} \mathrm{NaCl}$ ). Carboxypeptidase $A$ was used at a concentration of $2: 1 \mathrm{w} / \mathrm{w}$ enzyme:Chl with the addition of $1 \mathrm{mM}$ phenylmethylsulfonyl fluoride to inhibit endopeptidase activity. The conditions for this protease treatment were selected to ensure 
that the reaction proceeded to completion. At the end of the treatment, the protease was inhibited by the addition of 20 volumes of ice cold Digestion Buffer containing $1 \mathrm{mM} 1,10$ phenanthroline. The membranes were collected by centrifugation $\left(10 \mathrm{~min}, 35000 \mathrm{xg}, 4^{\circ} \mathrm{C}\right.$, Sorvall SS34 rotor), washed once in Digestion Buffer and resuspended in SMN Buffer.

\section{Polyacrylamide Gel Electrophoresis}

Polyacrylamide gel electrophoresis of the desired preparations, usually spinach PS II membranes, were run using [ $14 \mathrm{C}]$-methylated protein standards (Amersham CFA.626) or unlabeled low molecular weight protein standards (Bio-Rad) for calibration of molecular weights. The gels used contained $0.1 \%$ sodium dodecyl sulfate (SDS) and $6 \mathrm{M}$ urea and were run following the "discontinuous buffer" procedures described by Laemmli (1970) as modified for PS II proteins (Ljungberg et al., 1986) and incorporating suggestions made by N. Bowlby (Dept. of Cell. and Molec. Biol., Univ. of Michigan, Ann Arbor). The gels were either $15 \%$ acrylamide or $10-20 \%$ acrylamide gradient separating gels, both with $6 \%$ acrylamide stacking gels. The $4 x$ Stacking Gel Buffer (0.5 M Tris pH 6.8, 6.5 M urea) differed from the $4 \mathrm{x}$ Separating Gel Buffer (1.5 M Tris $\mathrm{pH} 8.8,6.5 \mathrm{M}$ urea) as required for this system. Samples were diluted $1: 1(v / v)$ with $2 x$ loading buffer (urea, SDS, glycerol, DTT and bromphenol blue in Stacking Gel Buffer) and incubated for $1-24 \mathrm{~h}$ at $4^{\circ} \mathrm{C}$ before loading. The $20 \times 20 \mathrm{~cm}$ gels were run for 40-50 hours at 50-60 V (constant voltage, room temp.). Often, gels were stained for $4 \mathrm{~h}(0.2 \% \mathrm{w} / \mathrm{v}$ coomassie brilliant blue R-250 in $45 \%$ $\mathrm{v} / \mathrm{v}$ methanol and $10 \% \mathrm{v} / \mathrm{v}$ acetic acid) followed by rapid destaining for $1-2 \mathrm{~h}(45 \% \mathrm{v} / \mathrm{v}$ methanol and $7 \% \mathrm{v} / \mathrm{v}$ acetic acid) and slow destaining overnight (10\% v/v methanol and $7 \%$ $\mathrm{v} / \mathrm{v}$ acetic acid).

\section{Electroblotting}

Electroblotting onto Immobilon-P Transfer Membranes (Millipore) was performed in a Bio-Rad trans-blot cell. Before blotting, the membranes were briefly immersed in 
$100 \%$ methanol, placed in distilled water for $5 \mathrm{~min}$, and soaked for 15-20 min in Transfer Buffer (25 mM Tris base, $192 \mathrm{mM}$ glycine, 15\% v/v methanol, $\mathrm{pH}$ 8.2-8.3). All filters and the gels themselves were also soaked in Transfer Buffer for 15-20 min prior to placement in the electroblotting apparatus. The blotting cassette was assembled and placed in the apparatus (with the membrane side of the assembly facing the anode electrode). The apparatus was filled with Transfer Buffer and then run at $14 \mathrm{~V}$ overnight in the cold room $\left(4^{\circ} \mathrm{C}\right)$.

\section{Western Blotting}

The procedures described by Towbin et al. (1979) were used, with some modifications, for western blotting. The blot was removed from the electroblotting apparatus and rinsed once with distilled water. A portion of the blot was cut and stained for $10 \mathrm{~min}(0.2 \% \mathrm{w} / \mathrm{v}$ coomassie brilliant blue R-250 in $45 \% \mathrm{v} / \mathrm{v}$ methanol and $10 \% \mathrm{v} / \mathrm{v}$ acetic acid) followed by rapid destaining for $5-10 \mathrm{~min}(45 \% \mathrm{v} / \mathrm{v}$ methanol and $7 \% \mathrm{v} / \mathrm{v}$ acetic acid). The remainder of the membrane was rinsed once with PBS (0.01 M phosphate buffer, $0.15 \mathrm{M} \mathrm{NaCl}$ ) and placed in heat-sealable bags which were cut open and resealed between each wash or incubation. It was then blocked for $2 \mathrm{~h}$ (5\% BSA, PBS). After washing once for $5 \mathrm{~min}(0.1 \% \mathrm{BSA}, 0.05 \%$ Tween-20, PBS), it was incubated for 2 to 4 $h$ with antiserum at 1:100 to 1:1000 dilution (in 1\% BSA, 0.05\% Tween-20, PBS). Following 3 washes as above, it was incubated with [125I]-labeled secondary antibody (goat-anti-rabbit IgG, Amersham IM.134) at 1:1000 dilution in 1\% BSA, 0.05\% Tween20, PBS. Finally, it was washed 3 times as before, rinsed with distilled water, dried, and autoradiographed using Kodak film and 1 or 2 intensifying screens at $-70^{\circ} \mathrm{C}$.

For enzymatic detection, the procedure was similar to that described above. After rinsing, strips of the Immobilon-P blot were cut to fit into a Bio-Rad 25-well western blotting tray, in which all incubations were performed with $4-5 \mathrm{ml}$ of solucion per well on a 
shaker platform at room temperature. If the membrane ever dried out, it was re-wet in methanol for $5 \mathrm{~s}$ or $5 \%$ Tween-20 for $15-20 \mathrm{~min}$ and then rinsed briefly with distilled water. The strips of membrane were rinsed once with TBS $(20 \mathrm{mM}$ Tris- $\mathrm{HCl} \mathrm{pH} \mathrm{7.4,}$ $0.9 \% \mathrm{NaCl})$. They were then blocked for $2 \mathrm{~h}(5 \% \mathrm{BSA}, \mathrm{TBS})$. After washing once for 5 $\min (0.1 \% \mathrm{BSA}, 0.05 \%$ Tween-20,TBS), they were incubated for 2 to $4 \mathrm{~h}$ with antiserum at 1:100 to 1:1000 dilution (in 1\% BSA, 0.05\% Tween-20, TBS). Following 3 washes as above, they were incubated with alkaline phosphatase-labeled secondary antibody (BioRad) at 1:3000 dilution in 1\% BSA, $0.05 \%$ Tween-20, TBS. After washing 3 times as above, a final wash was performed with TBS. The freshly prepared substrate $(0.56 \mathrm{mM}$ BCIP, $0.48 \mathrm{mM} \mathrm{NBT}, 10 \mathrm{mM}$ Tris- $\mathrm{HCl} \mathrm{pH}$ 9.5) was then added. The blots were watched for color development (5-20 $\mathrm{min}$ ) before quenching with two $5 \mathrm{~min}$ washes with distilled water. These blots were then photographed and/or stored in darkness to avoid fading.

\section{Results and Discussion}

Polyacrylamide gel electrophoresis was run as described above with several different sources of protein samples in order to perform a western blot to characterize the antibody raised against the D1-a peptide (anti-D1-a). The binding of this particular antibody had previously been demonstrated using ELISA techniques with the immunizing peptide as the substrate target (see Chapter 2), but specific recognition of the D1 protein was required. The gel was run in duplicate, one was stained with coomassie brilliant blue (Figure 4-1) and the other was used for western blotting (Figures 4-2 and 4-3). Each sample was run in duplicate to load different amounts of protein with the exception of the three DEPC-modified preparations, which contained the same amounts of protein treated with differing amounts of DEPC. In Figure 4-1, the samples expected to contain the D1 protein are: PS II membrane preparation from spinach (lane 2), oxygen-evolving spinach 


\section{Figure 4-1: PAGE of various PS II preparations}

Polyacrylamide gel electrophoresis after staining with coomassie brilliant blue. The samples were: PS II membrane preparation from spinach (lane 2), oxygen-evolving spinach core preparations (lanes 3 and 4), spinach reaction center complex preparations (lanes 5 and 6), DEPC-modified spinach core preparations (lanes 8, 9 and 10), PS II membrane preparations from Synechococcus sp. (lanes 11 and 12) and partially purified reaction centers from $R b$. capsulatus (lanes 13 and 14). Pre-stained protein standards of $17,27,39,50,75$ and $130 \mathrm{kDa}$ were run in lanes 1 and 15. Protein standards of 14.4 , $21.5,31,45,66.2$ and $92.5 \mathrm{kDa}$ were run in lane 7 and their approximate positions are marked on the right side of the figure. The positions of the D1 and D2 proteins are also marked. The stacking gel was $6 \%$ acrylamide and the separating gel was a 10 to $20 \%$ acrylamide gradient gel. The entire gel contained $6 \mathrm{M}$ urea and $0.1 \%$ SDS and was run for $40 \mathrm{~h}$ at $4^{\circ} \mathrm{C}$ at a constant voltage of $50 \mathrm{~V}$. 

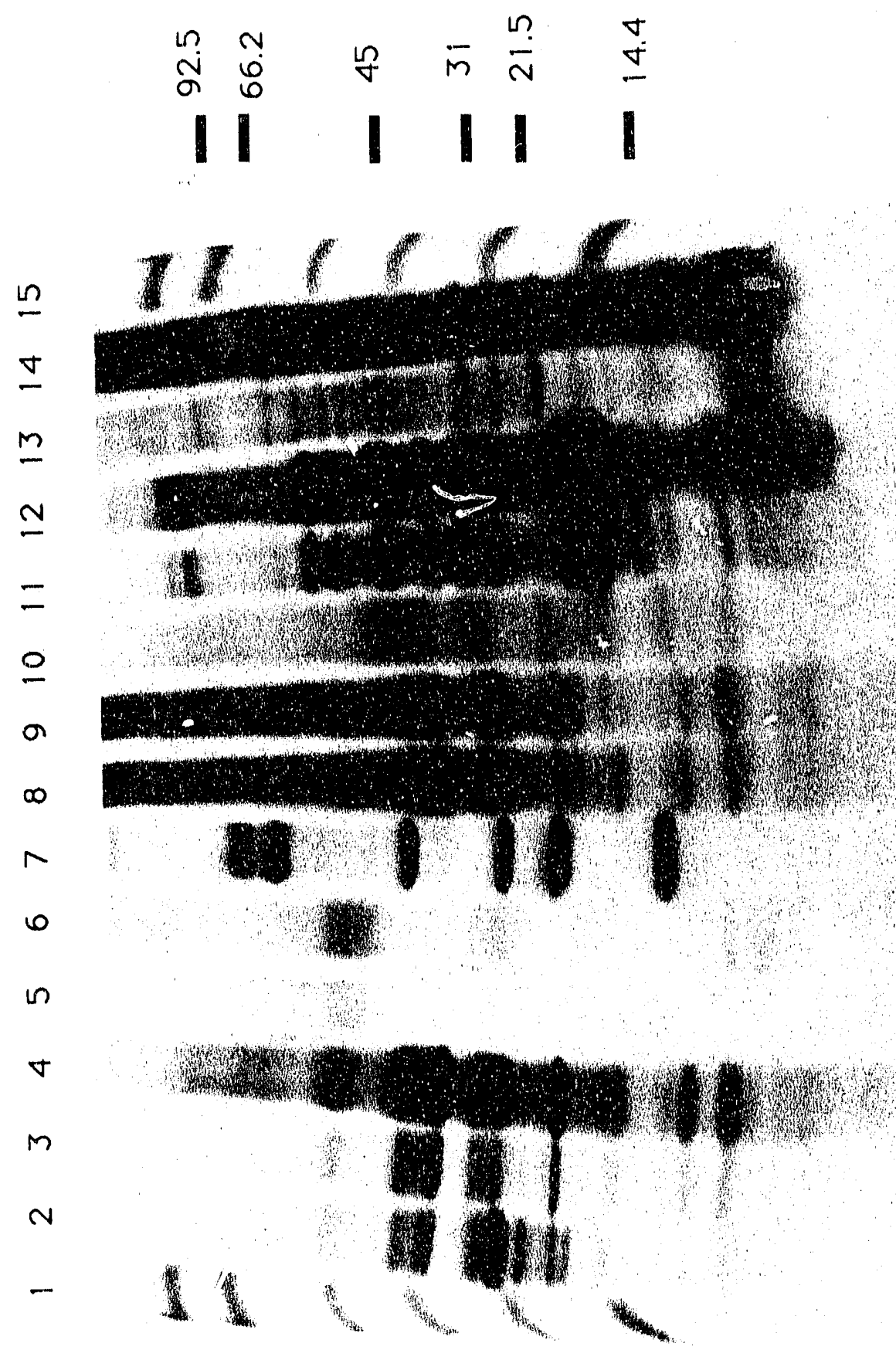

岂

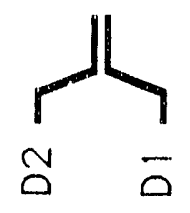


core preparations (lanes 3 and 4), spinach reaction center complex preparations (lanes 5 and 6), DEPC-modified spinach core preparations (lanes 8,9 and 10) anú PS II membrane preparations from the thermophilic cyanobacterium Synechococcus sp. (lanes 11 and 12). Partially purified reaction centers from Rhodobacter capsulatus were used to examine potential cross-reactivity with the $\mathrm{L}, \mathrm{M}$ and $\mathrm{H}$ subunits of the purple bacterial reaction center (lanes 13 and 14). Pre-stained protein standards of 17, 27, 39, 50, 75 and $130 \mathrm{kDa}$ were run in lanes 1 and 15 as approximate molecular weight markers and to monitor progress during the electrophoretic process. As better molecular weight markers, protein standards of $14.4,21.5,31,45,66.2$ and $92.5 \mathrm{kDa}$ were run in lane 7 . This lane also contained a small amount, not obvious by coomassie staining, of [ $\left.{ }^{14} \mathrm{C}\right]$-labeled protein standards of 14.3, 30, 46 (and/or 50), 69, 92.5 (and/or 100) and $200 \mathrm{kDa}$ to be used as references in western blotting. These particular gels were run under conditions chosen to minimize the broadening of the bands corresponding to the D1 and D2 proteins. It was necessary to produce bands as sharp as possible in order for western blotting to distinguish between these two generally diffuse and closely spaced PAGE bands. The gels contained 6 $\mathrm{M}$ urea and $0.1 \%$ SDS to maximize denaturation. The stacking gels were $6 \%$ acrylamide and the separating gels were 10 to $20 \%$ acrylamide gradient gels. These gels were run for $40 \mathrm{~h}$ at $4^{\circ} \mathrm{C}$ (in a cold room) at a constani voltage of $50 \mathrm{~V}$. It should be noted that the bands corresponding to the D1 and D2 proteins (best seen in lane 3) are indeed very sharp, but their separation is fairly small, even after a $40 \mathrm{~h}$ electr: phoresis, which is considered quite long for this type of PAGE. Also, the reaction center complex preparations (lanes 5 and 6 ) seem to show only slight staining at the positions expected for the D1 and D2 proteins, but show a darker, diffuse, region at approximately $50 \mathrm{kDa}$ which corresponds to aggregation of the D1 and D2 proteins as described by Nanba and Satoh (1987) for this type of preparation. 
Some discussion as to the choice of samples used and their protein compositions would be useful at this point. The spinach reaction center complex preparation was a gift from A. Williamson (Sauer research group, Chemistry Dept., UC Berkeley, CA). This reaction center complex preparation (Figure 4-1, lanes 5 and 6) corresponds to the preparation of simplest protein composition currently available, would be used for a few of the further studies, but does not evolve oxygen. As explained in Chapter 1, this preparation has the ability to perform charge separation as described by Chapman et al. (1988). As demonstrated by Seibert et al. (1989), this preparation contains the four components of the high-affinity Mn-binding site as measured by the assay for $\mathrm{Mn}^{2+}$ inhibition of DPC-stimulated DCIP photoreduction described by Hsu et al. (1987). This preparation contains the D1 and D2 reaction center proteins, the large and small protein subunits of Cyt $b-559$ and the $4.2 \mathrm{kDa}$ polypeptide.

The spinach core preparation (Figure 4-1, lanes 3 and 4) is the smallest characterized oxygen-evolving preparation, would also be used for some of the experiments listed below, and provides the most predictatiy interpretable protein content and, hence, pattern after coomassie staining of the gel. This sample was provided by $M$. Latimer (Sauer research group, Chemistry Dept., UC Berkeley, CA). In addition to the DI protein, the D2 protein, the large and small protein subunits of Cyt $b-j 59$ and the $4.2 \mathrm{kDa}$ polypeptide, this preparation contains several other proteins which are apparently required for the expressior of oxygen evolution. These proteins are CP43, CP47, the $33 \mathrm{kDa}$ extrinsic polypeptide, a $20 \mathrm{kDa}$ polypeptide and several small polypeptides of $<5 \mathrm{kDa}$ with unknown functions.

The PS II membrane preparation from spinach (Figure 4-1, lane 2) was the sample containing the most spinach PS II proteins. In addition to the proteins present in the oxygen-evolving spinach core preparation described above, this preparation contains two other extrinsic polypeptides of 17 and $24 \mathrm{kDa}$ and a significant quantity of loosely 
associated light-harvesting proteins (multiple overlapping bands in the $30 \mathrm{kDa}$ region). This preparation was representative of the largest complex to be used in further experiments (oxygen evolution assays, Chapter 5; solution binding assays, Chapter 6; photoactivation assays, Chapter 7; and assay of high-affinity Mn-binding sites, Chapter 8).

The DEPC-modified spinach core preparations (Figure 4-1, lanes 8,9 and 10) were from a collaboration with M. Latimer (Sauer research group, Chemistry Dept., UC Berkeley, CA). He was mainly interested in chemically labeling the PS II histidines with DEPC and identifying the sites of protein labeling in the presence and absence of the active Mn. Here the protein banding for different levels of chemical modification and the detectability of the D1 prowin by western blotting was being examined. This work was not. continued, but results of similar experiments were later published by Tamura et al. (1989a) and are described in Chapters 7 and 8.

The PS II membrane preparation from the thermophilic cyanobacterium Synechococcus sp. (Figure 4-1, lanes 11 and 12) was a kind gift from V. DeRose (also of the Sauer research group, Chemistry Dept., UC Berkeley, CA). She has done EPR and Xray spectroscopies using this preparation and compared the results to those from spinach preparations (DeRose, 1990). This preparation was used here to test for cross-reactivity with the expectedly homologous PS II reaction center proteins of a cyanobacterium and to western blot a sample which contains more protein components than the spinach PS II membrane preparation (see Figure 4-1), including higher PS I contamination.

The partially purified reaction centers from $R b$. capsulatus (Figure 4-1, Lanes 13 and 14) were a gift from G. Armstrong (Hearst research group, Chemistry Dept., UC Berkeley, CA) from preparations by S. Worland (Sauer and Hearst research groups, Chemistry Dept., UC Berkeley, CA). These samples were used to examine potential cross-reactivity, especially with the $L$ and $M$ subunits of the purple bacterial reaction center 
which have been shown to exhibit homology to the D1 and D2 proteins of PS II (Hearst, 1986). The lumenal region of the D1 protein selected for the peptide which elicited this antibody was chosen to minimize use of regions homologous to the L subunit (see Chapter 2), so cross-reactivity was experted to be minimal.

Autoradiograms of a western blot using the antibody raised against the D1-a peptide (anti-D1-a) at 1:100 dilution with [125 $]$-labeled secondary antibody for detection are shown in Figures 4-2 and 4-3. This western blot used the second gel of the pair described above, whose coomassie-stained partner is shown in Figure 4-1. These figures correspond to two exposures of the same westem blot to emphasize different aspects of the results. Figure 4-2 is a $4 \mathrm{~h}$ exposure which demonstrates that there is one major band at approximately $30 \mathrm{kDa}$ (identified to be the $\mathrm{D} 1$ protein, as described below) detected in 4 of the 5 samples expected to contain the D1 protein. The spinach samples are: PS II membrane preparation (lane 2), oxygen-evolving core preparation (lanes 3 and 4), and DEPC-modified oxygen-evolving core preparation (lanes 8 and 9 , but not 10 where the majority of the protein was retained in the well). For the PS II membrane preparation from Synechococcus sp. (lanes 11 and 12), the most intensely labeled band is at approximately $28 \mathrm{kDa}$. The reaction center complex preparation (lanes 5 and 6) did not show labeling in this region at this exposure, probably due to its low initial concentration and the aggregation described earlier. The aggregate does show slight labeling in lane 6. The reaction center preparation from Rhodobacter capsulatus (lanes 13 and 14) also does not show cross-reactivity with the L, M and $\mathrm{H}$ subunits at this level of exposure, as expected.

A $14 \mathrm{~h}$ exposure of the same western blot described above is shown in Figure 4-3. The antibody raised against the D1-a peptide (anti-D1-a) binds strongest to a single band at the appropriate location for the D1 protein. This can be seen best by comparing the proteins in lane 3 (Figure 4-1) with the $31 \mathrm{kDa}$ standard in lane 7 to determine the position of the D1 and D2 proteins. A description of the banding pattern of lanes 3 and 4 (Figure 4 


\section{Figure 4-2: Western blot of gel in Fig. 4-1 using anti-D1-a}

Autoradiogram of a western blot using the antibody raised against the D1-a peptide (antiD1-a) at 1:100 dilution with [125 $]$-labeled secondary antibody used for detection. This autoradiogram was a $4 \mathrm{~h}$ exposure of a westem blot which used the second gel of the pair whose coomassie-stained partner is shown in Figure 4-1. Samples and gel conditions were identical to those given for Figure 4-1. Lane 7 also contained a small amount, not obvious by coomassie staining, of [ $\left.{ }^{14} \mathrm{C}\right]$-labeled protein standards of $14.3,30,50$ and $64 \mathrm{kDa}$ and their approximate positions are marked on the right side of this figure. 

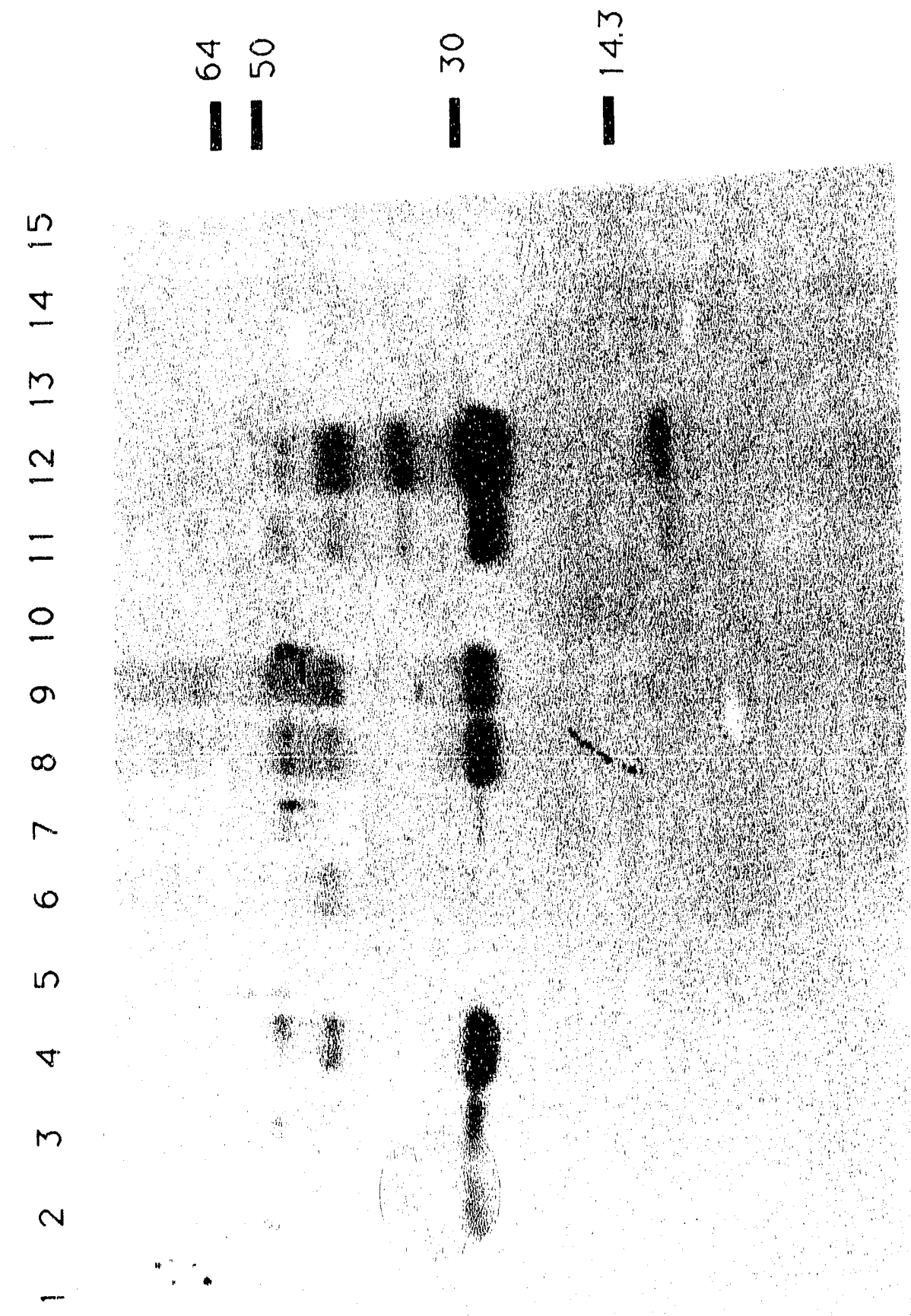

$\frac{1}{10}$

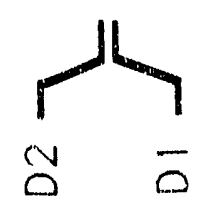


Figure 4-3: Darker exposure of western blot of gel in Fig. 4-1 using antiD1-a

Autoradiogram of a darker exposure of the western blot using anti-D1-a at 1:100 dilution with [ $\left.{ }^{125}\right]$-labeled secondary antibody used for detection. This autoradiogram was a $14 \mathrm{~h}$ exposure of the same western blot shown in Figure 4-2. Samples and gel conditions were identical to those given for Figure 4-1. Lane 7 also contained a small amount, not obvious by coomassie staining, of $\left[{ }^{14} \mathrm{C}\right]$-labeled protein standards of $14.3,30,50$ and $64 \mathrm{kDa}$ and their approximate positions are marked on the right side of this figure. 

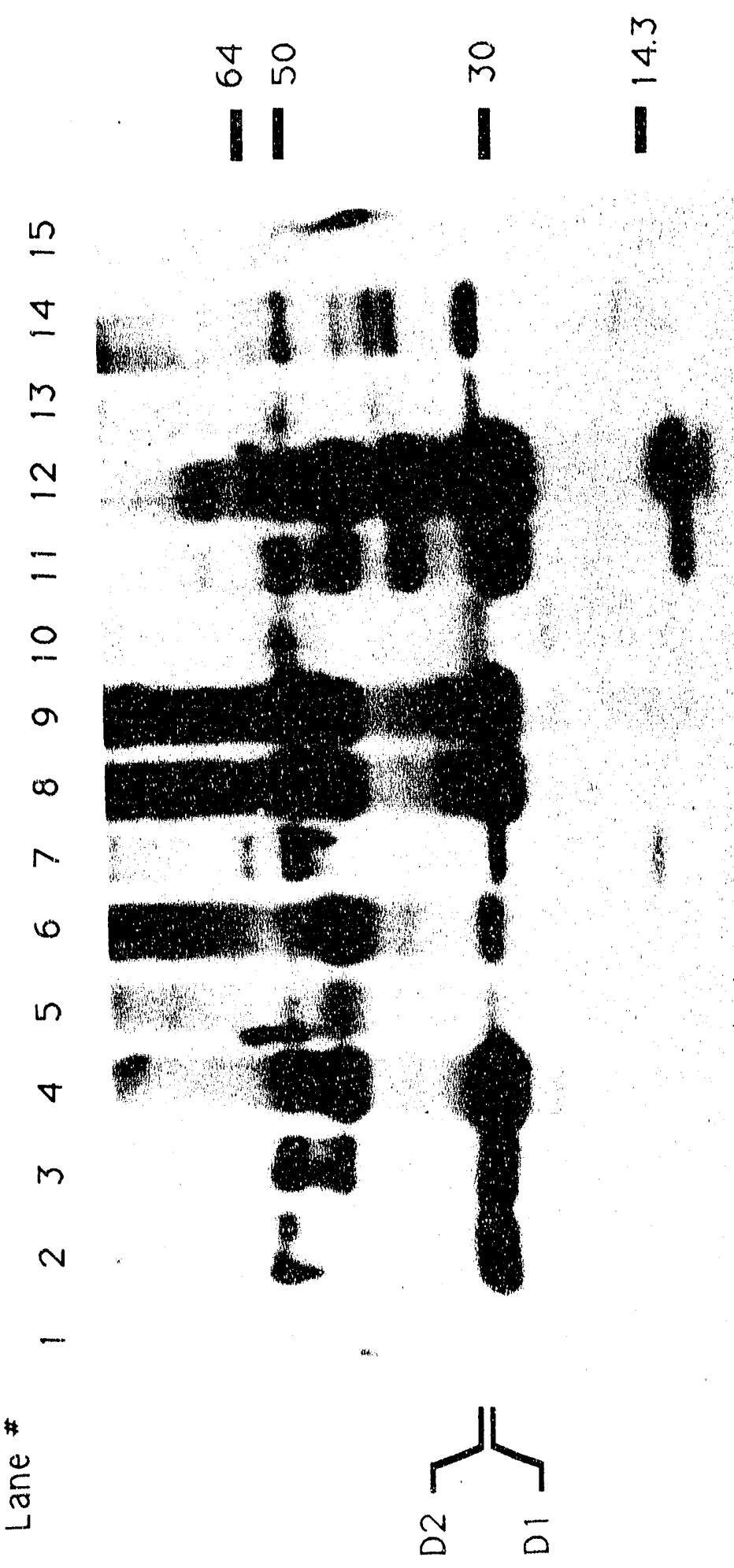

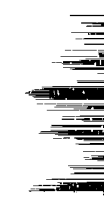


1) will aid in this assignment. From the bottom, the first 2 clear bands below $14.4 \mathrm{kDa}$ correspond to the small and large polypeptide subunits of Cyt $b-559$. Note that since this a gradient gel, the low molecular weight region is compressed relative to the migrations observed on linear gels. The next, faint, band is probably some remaining $17 \mathrm{kDa}$ extrinsic protein. At approximately $20 \mathrm{kDa}$, a dark band corresponding to the $20 \mathrm{kDa}$ protein which may serve a role analogous to the purple bacterial reaction center $\mathrm{H}$ subunit. Above this, a faint band is seen which is probably some remaining $24 \mathrm{kDa}$ extrinsic protein. The next wide band is actually 3 or 4 bands on close inspection and correspond to remaining light harvesting proteins, the D1 protein, the $\mathrm{D} 2$ protein and the $33 \mathrm{kDa}$ extrinsic protein (going up). The next group of bands, around the $45 \mathrm{kDa}$ region, corresponds to CP43 and CP47 (the approximately 45 and $51 \mathrm{kDa}$ proteins, respectively). Finally, the smears at $50 \mathrm{kDa}$ and above represent aggregation products which contain the D1 and D2 proteins. Next, comparing this relationship to the position of the main labeled band in any lane (Figures 4-2 and 4-3) relative to the $30 \mathrm{kDa}$ [ $14 \mathrm{C}$ ]-labeled standard in lane 7 . A particularly good comparison is seen between lane 6 (Figure 4-3), containing the reaction center complex preparation, and the $30 \mathrm{kDa}$ standard in lane 7. Note that this band is detected here in lane 6 even though it was not apparent after coomassie staining (Figure 4-1). The $30 \mathrm{kDa}$ $[14 \mathrm{C}]$-labeled standard appears as a faint coomassie band below the $31 \mathrm{kDa}$ protein standard (see Figure 4-1).

The difference in overall background between the two exposures of the western blot (Figures 4-2 and 4-3) is the reverse of what one would expect and is courtesy of the photographic reproduction of the autoradiograms. Figure 4-3 also demonstrates background binding to bands in addition to the main D1 protein band, specifically to two bands in the $50 \mathrm{kDa}$ region assigned to aggregation of the D1 and D2 proteins as described by Nanba and Satoh (1987). There is also binding to other bands, in particular, relatively strong binding to higher bands for Synechococcus sp. (possibly aggregation products) and 
weak binding to several bands in $R b$. capsulatus. This is consistent with results from several other groups which demonstrate somewhat specific background binding of rabbit antibodies to several bands in photosynthetic preparations from various organisms (L. McIntosh, MSU-DOE Plant Research Lab. and Biochemistry Dept., Michigan State Univ., East Lansing, MI, personal communication). This binding can be eliminated by increasing the stringency of the western protocol, as described below. Nevertheless, by far the major band detected is still the one corresponding to the D1 reaction center protein of PS II.

An analysis $c$ the coomassie stained gel (Figure 4-1) and the autoradiograms of the corresponding western blot (Figures 4-2 and 4-3), makes it apparent that in addition to the sharpening of the bands corresponding to the D1 and D2 proteins, a greater separation between them would make analysis more straightforward. In order to maximize this separation between the D1 and D2 proteins and retain some sharpness in their bands, suggestions made by N. Bowlby (Dept. of Cell. and Molec. Biol., Univ. of Michigan, Ann Arbor), mainly pertaining to sample preparation and temperature control, were incorporated into the final PAGE protocol which is described above (see Procedures section). Heating was avoided and the gels maintained at approximately constant room temperature by circulating $20^{\circ} \mathrm{C}$ water through the apparatus's cooling unit. Before loading, samples were incubated overnight at $4^{\circ} \mathrm{C}$ after addition of an equal volume of " $2 \mathrm{x}$ loading huffer" containing SDS, urea and glycerol. The commonly used short incubation with heating to $37^{\circ} \mathrm{C}$ caused increased aggregation and anomalous banding patterns and was replaced by this procedure.

Figure 4-4 shows coomassie stained gels which were products of the two best. procedures developed. These are each half of two polyacrylamide gels run as explained above. The two gels differ in the acrylamide percentages, the left side of Figure 4-4 shows a $15 \%$ acrylamide gel while the right side of Figure 4-4 shows a 10-20\% acrylamide gradient gel. All gels contained $6 \mathrm{M}$ urea and $0.1 \%$ SDS as before, the stacking gels were 


\section{Figure 4-4: PAGE examples of the best resolution for the D1 and D2 proteins}

Polyacrylamide gel electrophoresis after staining with coomassie brilliant blue. The two gels differ in the acrylamide percentages, the left side shows a $15 \%$ acrylamide gel while the right side shows a 10-20\% acrylamide gradient gel. All gels contained $6 \mathrm{M}$ urea and $0.1 \%$ SDS, the stacking gels were $6 \%$ acrylamide and the gels were run for $40 \mathrm{~h}$ at a constant voltage of $50 \mathrm{~V}$ at controlled room temperature. Both gels have the same samples in corresponding lanes. The samples were: purified $33 \mathrm{kDa}$ extrinsic protein (2nd lanes), oxygen-evolving spinach core preparation ( $3^{\text {rd }}$ lanes), spinach reaction center complex preparation (4th lanes), PS II membrane preparation from Synechococcus $\mathrm{sp}$. (6 $6^{\text {th }}$ lanes) and partially purified reaction centers from $R b$. capsulatus ( $7^{\text {th }}$ lanes). Pre-stained protein standards of $17,27,39,50,75$ and $130 \mathrm{kDa}$ were run in the and $8^{\text {th }}$ lanes. Protein standards of $14.4,21.5,31,45,66.2$ and $92.5 \mathrm{kDa}$ were run in the $5^{\text {th }}$ lanes and their approximate positions are marked between the two gels. The positions of the D1 and D2 proteins are also marked. 

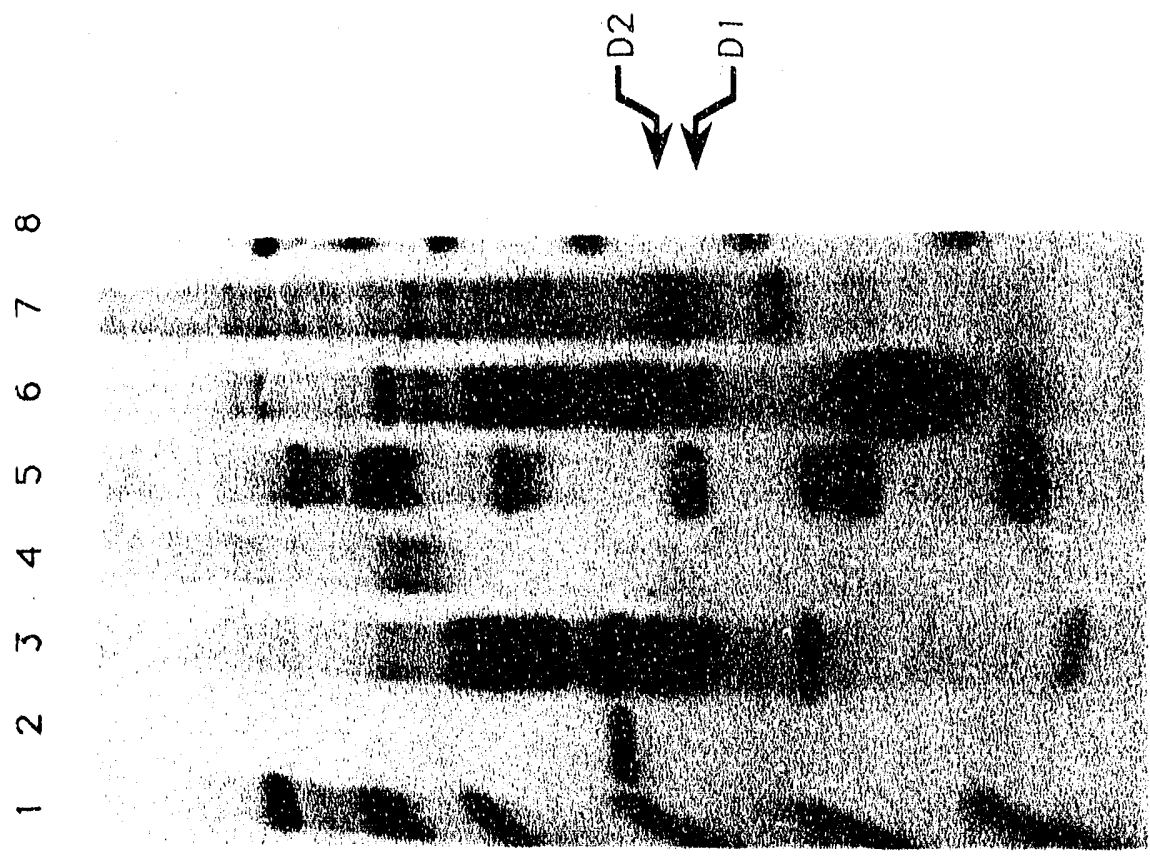

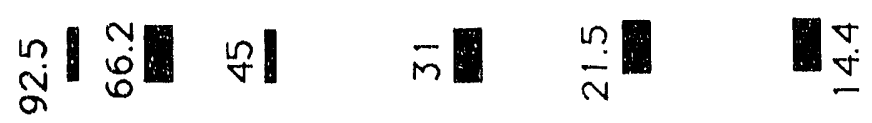

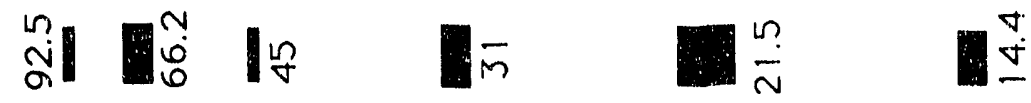

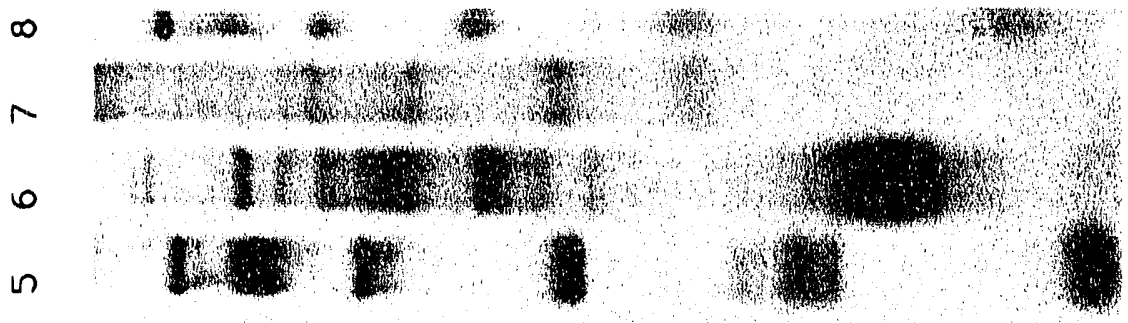

$\checkmark$ th

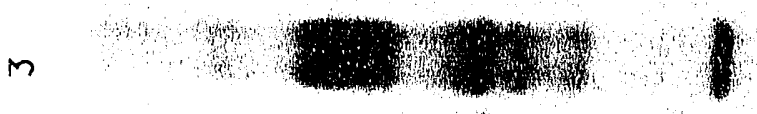

จ 1

- rav 10

: 
$6 \%$ acrylamide and the gels were run for $40 \mathrm{~h}$ at a constant voltage of $50 \mathrm{~V}$, but this time at controlled room temperature. The samples run on the two gels shown in Figure 4-4 were some of those run on the gel shown in Figure 4-1, but only one sample of appropriate protein content was used. Both gels have the same samples in corresponding lanes. The samples in the $2^{\text {nd }}$ lanes (Figure 4-4) were purified $33 \mathrm{kDa}$ extrinsic protein for use in other experiments (see Chapters 5,6 and 7). No other bands or background streaking were apparent, indicating a greater than $95 \%$ purity. The other samples were: oxygenevolving spinach core preparation ( $3^{\text {rd }}$ lanes), spinach reaction center complex preparation (4th lanes), PS II membrane preparation from the thermophilic cyanobacterium Synechococcus sp. (6 $6^{\text {th }}$ lanes) and partially purified reaction center preparation from $R b$. capsulatus ( $7^{\text {th }}$ lanes). Pre-stained protein standards of $17,27,39,50,75$ and $130 \mathrm{kDa}$ were again run in the $1^{\text {st }}$ and $8^{\text {th }}$ lanes as approximate molecular weight markers and to monitor progress during the electrophoretic process. And, as better molecular weight markers, protein standards of $14.4,21.5,31,45,66.2$ and $92.5 \mathrm{kDa}$ were run in the $5^{\text {th }}$ lanes. These lanes also contained a small amount, not obvious by coomassie staining, of [ ${ }^{14} \mathrm{C}$-labeled protein standards of $14.3,30,46$ (and/or 50), 69, 92.5 (and/or 100) and 200 $\mathrm{kDa}$ to be used as references in western blotting.

A new oxygen-evolving spinach core preparation was used for the gels in Figure 44 , and the simpler banding pattern shows greater purity. From the bottom, the first dark band corresponds to the $20 \mathrm{kDa}$ protein which may serve a role analogous to the purple bacterial reaction center $\mathrm{H}$ subunit. The small and large polypeptide subunits of Cyt $b-559$ have run off the bottom of the gel in the left side of Figure 4-4, while only the large subunit is seen below $14.4 \mathrm{kDa}$ in the right side of Figure 4-4. The next set of bands correspond to the $\mathrm{D} 1$ protein, the $\mathrm{D} 2$ protein and the $33 \mathrm{kDa}$ extrinsic protein (going up). As can be seen in both gels of Figure 4-4, the bands corresponding to the D1 and D2 proteins are very well resolved in these gels, although at some sacrifice in their sharpness. The next group of 
bands, around the $45 \mathrm{kDa}$ region, corresponds to CP43 and CP47 (the approximately 45 and $51 \mathrm{kDa}$ proteins, respectively). The smears at $50 \mathrm{kDa}$ and around $64 \mathrm{kDa}$ again represent aggregation products which contain the D1 and D2 proteins. Noticeably, the purity of this preparation is quite high, as demonstrated by the lack of bands corresponding to light harvesting proteins and the 17 and $24 \mathrm{kDa}$ extrinsic proteins. All further PAGE gels run for western blotting purposes followed these procedures, but usually used spinach PS II membrane preparations as the samples. Gels of $15 \%$ acrylamide were preferentially used due to the better separation of the D1 and D2 proteins, even though more small polypeptides were sacrificed.

Thus far, the goal was to develop a western blotting procedure that could be used to screen sera for antibodies raised against additional peptides and, concurrently, characterize the binding properties of anti-D1-a with respect to several sources of photosynthetic reaction centers. The characterization of anti-D1-a is described in the previous paragraphs and the corresponding figures. The gel procedures described earlier, examples of which are shown in Figure 4.4, were then used to run gels without lane divisions (one wide lane) loaded only with PS II membrane preparations. The 15\% acrylamide gels, with SDS and urea as above, were run for $40-45 \mathrm{~h}$ at a constant voltage of $50 \mathrm{~V}$ at controlled room temperature. Approximate gel migration was obtained by coomassie staining of one inch cut from an end of the original gel before blotting (Figure 4-5, lane 1). The rest was electroblotted onto an Immobilon-P membrane overnight as previously described. The membrane was removed, rinsed in distilled water and allowed to dry. It was cut into 1/4 inch strips parallel to the running direction, labeled, placed in wells of a Bio-Rad blotting tray, re-wet with methanol (5-10 s) or 5\% Tween-20 (15-20 min) and rinsed with distilled water. Blotting continued as described earlier for detection with alkaline phosphataselabeled secondary antibody. Generally, three wells corresponding to one rabbit's serum contained immune serum at 1:100 dilution, immune serum at 1:1000 dilution and pre- 


\section{Figure 4-5: Western blots using enzymatic detection}

Qualitative results of screening of sera from four rabbits. The strips are westem blots using antibodies raised against several peptides. Alkaline phosphatase-labeled secondary antibody was used for the detection. The 15\% acrylamide gels, with SDS and urea as in Figure 4-4, were loaded only with PS II membrane preparation and were run for $40.45 \mathrm{~h}$ at a constant voltage of $50 \mathrm{~V}$ at controlled room temperature. One inch cut from an end of the original gel before blotting was coomassie stained (lane 1). Lanes 2-5 correspond to sera from two rabbits immunized with the D1-b peptide. Lanes 6-9 comespond to sera from two rabbits immunized with the D2-a peptide. Lane 2 is a 1:100 dilution and lane 3 is a 1:1000 dilution of serum from the same rabbit. Similarly for the pairs of lanes 4 and 5, 6 and 7 as well as 8 and 9. The position of the D1 protein was obtained from blotting with anti-D1-a (not shown) and the expected position of the D2 protein was estimated from the coomassic stained gel portion. 

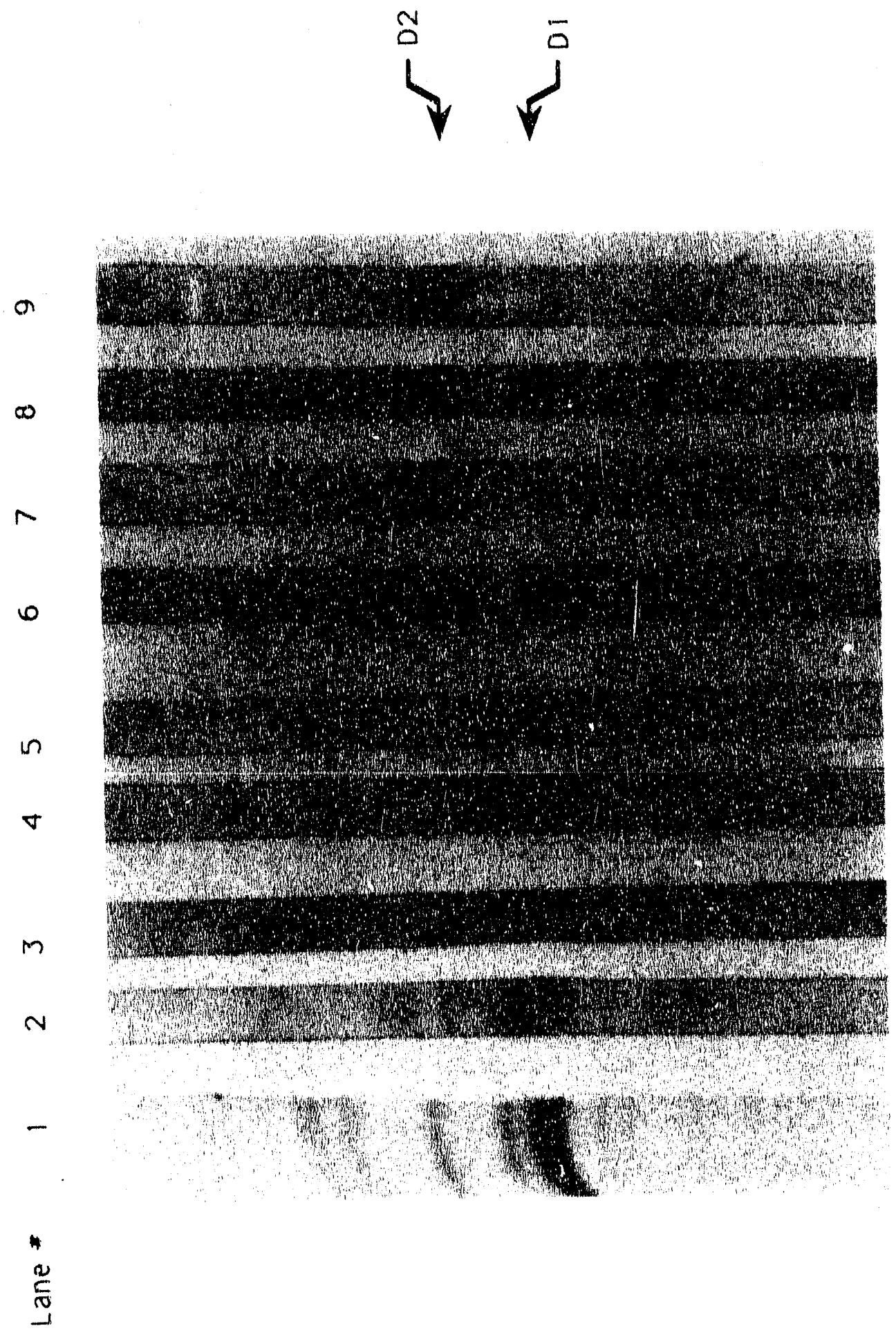
immune serum at 1:100 dilution. An example of the results for four rabbits is shown in Figure 4-5. The pre-immune lanes were left off this figure due to no detection of crossreaction after longer incubations with the substrate (which increases the background) for any of the four sets. Lanes $2-5$ correspond to sera from two rabbits immunized with the D1-b peptide. Lanes 6-9 correspond to sera from two rabbits immunized with the D2-a peptide. Lane 2 is a 1:100 dilution and lane 3 is a 1:1000 dilution of serum from the same rabbit. Similarly for the pairs of lanes 4 and 5,6 and 7 as well as 8 and 9. The position of the DI protein was obtained from blotting with anti-D1-a (not shown) and the expected position of the D2 protein was estimated from the coomassie stained gel portion. As can be seen, lanes 2 and 3 show weak binding to the D1 protein. Lanes 4 and 5 shows stronger binding to the D1 protein (this serum was used as anti-D1-b). Lanes 6,7,8 and 9 all show strong binding to the D2 protein (the serum used in lanes 8 and 9 was used as anti-D2-a). This procedure gives qualitative results because of variability between different wells, mainly due to the length of time allowed for color development. Nevertheless, it made possible the assay of many samples of rabbit serum in order to find ones that indeed recognized the desired proteins and which could be further characterized using the [125 ]labeled secondary antibody procedure, an example of which is described below.

The two peptides successfully used to generate antibodies against the Di protein contain one segment in common (from lle 321 to Arg 334) and differ mainly in that peptide D1-a contains an extra 10 amino acids on the carboxyl end. Carboxypeptidase A presumably removes the C-terminus of the D1 protein, stopping at Arg 334. Therefore, the binding sites for the three antibodies (anti-D1-a, anti-D1-b and anti-D2-a) were better characterized by comparison of binding to carboxypeptidase A-treated PS II membranes relative to untreated PS II membranes in western blots. Autoradiograms of thret western blots using the three antibodies are shown in Fig 4-6. Samples were PS II (lanes 2, 5 and 8) and carboxypeptidase A-treated PS II (lanes 3.6 and 9) membrane preparations. Lanes 


\title{
Figure 4-6: Western blots of PS II and carboxypeptidase A-treated PS II preparations
}

\begin{abstract}
Autoradiograms of three western blots of PS II membrane preparations (lanes 2, 5 and 8) and carboxypeptidase A-treated PS II membrane preparations (lanes 3,6 and 9). Antibodies raised against the carboxyl ends of the D1 and D2 proteins were used. Blotting was with anti-D1-a (lanes 1-3), anti-D1-b (lanes 4-6) and anti-D2-a (lanes 7-9). Secondary antibody labeled with [ $125 \eta$ was used for detection. Lanes 1,4 and 7 contained [ ${ }^{14} \mathrm{C}$ ]labeled protein standards of $14.3,30$ and $46 \mathrm{kDa}$. The positions of these standards, which are marked to the left of each blot, were determined from a set of autoradiograms exposed for a longer period of time than the ones shown.
\end{abstract}



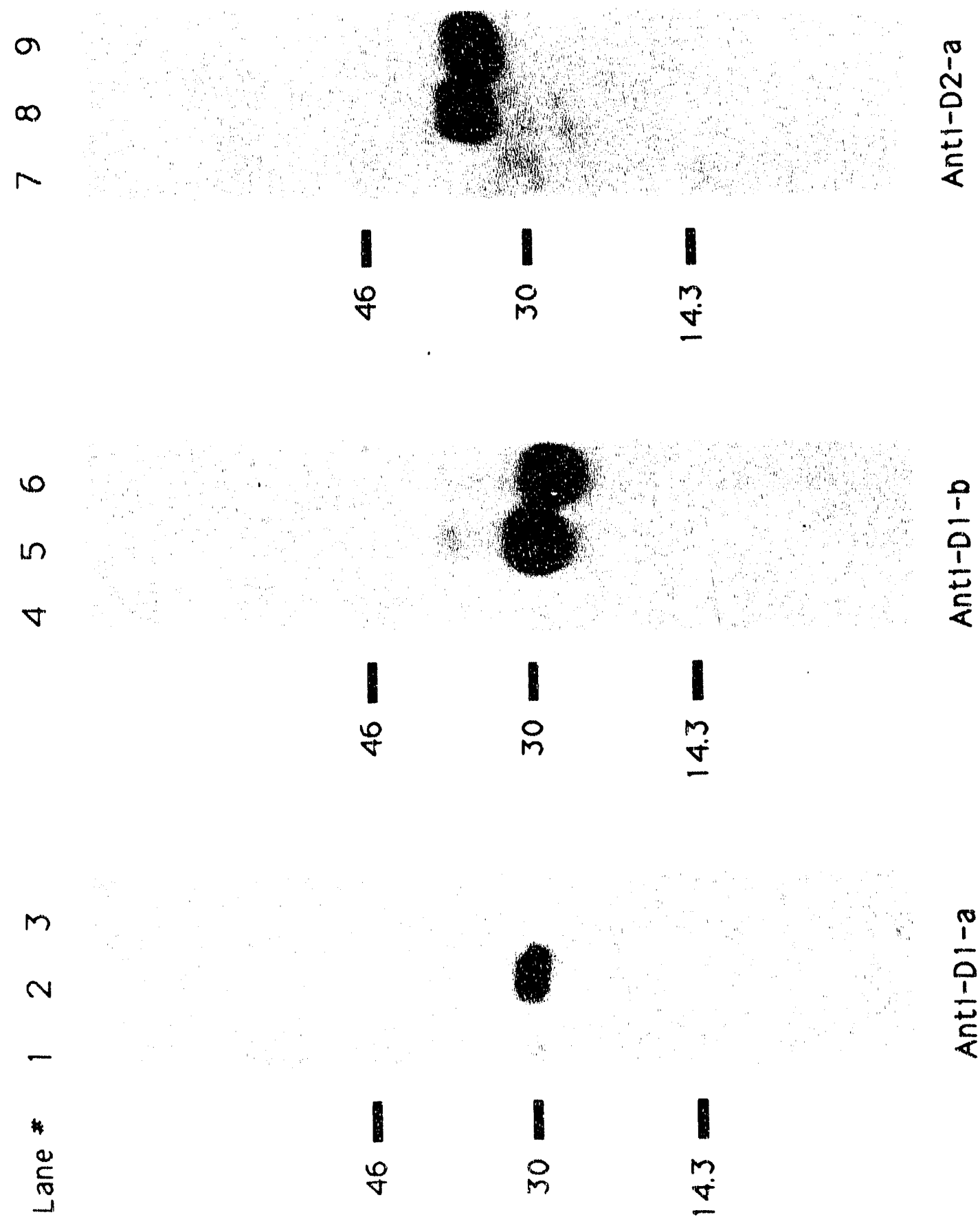

$\frac{\frac{0}{1}}{\frac{1}{6}}$

$\stackrel{0}{\frac{0}{c}}$
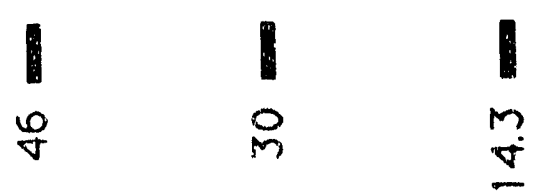
1,4 and 7 contained $\left[{ }^{14} \mathrm{C}\right]$-labeled protein standards which are seen faintly here, but whose positions were determined from autoradiograms exposed for a longer period of time than the ones shown. Blotting was with anti-D1-a (lanes 1-3), anti-D1-b (lanes 4-6) and anti-D2-a (lanes 7-9). Western blotting indicates that all three of these antibodies bound to their corresponding denatured protein (D1 or D2) as expected (Figure 4-6). Anti-D1-b and anti-D2-a showed reactivity at greater dilution than anti-D1-a (not shown). The antibody to the D1-a peptide (anti-D1-a) did not, however, bind to denatured PS II membranes in which a small fragment of the D1 protein had been removed by treatment with carboxypeptidase A. The other two antibodies, anti-D1-b and anti-D2-a still bound. For these samples, the D2 protein shows slightly increased electrophoretic mobility relative to that in untreated PS II membranes. The D1 protein shows a greater increase in mobility after carboxypeptidase A treatment, consistent with the digestion of more residues from the $C$-terminus of the $\mathrm{D} 1$ protein than from the $\mathrm{C}$-terminus of the $\mathrm{D} 2$ protein. The lack of binding of anti-D1-a to the carboxypeptidase A-treated PS II membranes can be interpreted to mean that the binding site detected by this western blotting procedure is to the carboxyl side of Arg 334. The binding sites of anti-D1-b and anti-D2-a cannot be further characterized using these results. 


\section{OXYGEN EVOLUTION ASSAYS}

\section{Introduction}

The first set of experiments performed in order to see if antibodies had any effect on the functioning of the oxygen-evolving complex (OEC) of PS II was the measurement of oxygen evolution rates of PS II membrane preparations after a preincubation with antibody. Since all preparations which were used contained the intact OEC Mn, the mechanism of action upon antibody addition would presumably have been the displacement of $\mathrm{Mn}$ or alteration of the structure in such a manner as to change oxygen evolution rates.

As can be seen in the results section, many different PS II membrane preparations were used, mostly testing one of the antibodies (anti-D1-a). The reason for sequentially using the different preparations was to initially maximize oxygen evolution rates which would increase the accuracy of observed antibody effects. The oxygen evolution rates are highest for preparations whose lumenal side is the most intact. As one removes extrinsic polypeptides, the OEC becomes increasingly labile and exhibits generally decreasing rates of oxygen evolution. To maximize oxygen evolution, these preparations have increasing requirements for addition of cofactors such as $\mathrm{Cl}^{-}$and $\mathrm{Ca}^{2+}$. The lumenal side of these preparations becomes increasingly accessible upon removal of the extrinsic proteins, facilitating antibody binding and potentially making the OEC more easily affected by the binding of antibodies.

The spinach PS II membrane preparations used here have the following extrinsic polypeptide composition: PS II membranes contain all three $(17,24$ and $33 \mathrm{kDa})$ proteins still bound. $\mathrm{NaCl}$-treated PS II membranes lack the 17 and $24 \mathrm{kDa}$ proteins, but retain the $33 \mathrm{kDa}$ protein. $\mathrm{CaCl}_{2}$-treated PS II membranes lack all three extrinsic proteins, but have 
been shown (Ono and Inoue, 1983b) to retain all of the Mn necessary for oxygen evolution when assayed with added $\mathrm{Cl}^{-}$and $\mathrm{Ca}^{2+}$. Urea-treated PS II membranes also lack the three extrinsic proteins and have been shown (Miyao and Murata, 1985) to retain the Mn necessary for oxygen evolution when assayed with added $\mathrm{Cl}^{-}$and $\mathrm{Ca}^{2+}$. The urea treatment must be done in the presence of high concentrations of $\mathrm{NaCl}$ (200 $\mathrm{mM}$ or greater) in order to retain the OEC Mn.

PS II membranes require nearly no added $\mathrm{Cl}^{-}$or $\mathrm{Ca}^{2+}$ for $100 \%$ oxygen evolution activity. For NaCl-treated PS II membranes, the requirement is raised to $30 \mathrm{mM} \mathrm{Cl}^{-}$and 5 $\mathrm{mM} \mathrm{Ca} 2+$ for $100 \%$ activity (Miyao and Murata, 1984). $\mathrm{CaCl}_{2}$-treated PS II membranes and urea-treated PS II membranes show a maximum of $20 \%$ activity with $200 \mathrm{mM} \mathrm{Cl}^{-}$and $10 \mathrm{mM} \mathrm{Ca}^{2+}$ (Miyao, et al., 1987). This activity can be raised to almost $100 \%$ upon the addition of a two times or greater molar excess of purified $33 \mathrm{kDa}$ protein prior to the measurement of oxygen evolution (Miyao and Murata, 1985).

In this chapter, results of assays for oxygen evolution using various PS II membrane preparations which had been preincubated with immune serum (anti-D1-a) are presented. Pre-immune serum was used as a control for nonspecific effects. The preparations used included PS II membranes, $\mathrm{NaCl}$-treated PS II membranes, $\mathrm{CaCl}_{2}$ treated PS II membranes and urea-treated PS II membranes. For preparations lacking the $33 \mathrm{kDa}$ protein, assays were performed with and without the addition of purified $33 \mathrm{kDa}$ protein. The results indicate that the antibodies have no deleterious effects on the $\mathrm{Mn}$ of the OEC. During prolonged incubations, it appears that anti-D1-a stabilizes the OEC Mn against release, allowing reconstitution of oxygen evolution upon addition of the $33 \mathrm{kDa}$ protein. 


\section{Procedures}

\section{BS II membrane preparation}

PS II membrane fragments were prepared from spinach leaves essentially as described by Berthold, et al. (1981), but including modifications from Ford and Evans (1983), Rutherford et al. (1984) and Dr. J.-L. Zimmermann (Service Biophysique, CENSaclay, France). The details of this preparation are presented in the previous chapter.

\section{$\mathrm{NaCl}$ treatment of PS II membranes}

$2 \mathrm{M} \mathrm{NaCl}$-extracted PS II membranes (NaCl-treated PS II membranes) lack 17 and $24 \mathrm{kDa}$ extrinsic proteins and were prepared as described by Åkerlund, et al. (1982). After thawing, spinach PS II membranes were centrifuged $(30,000 \times \mathrm{g}, 10 \mathrm{~min})$. The membranes were resuspended at $500 \mu \mathrm{g} \mathrm{Ch} / \mathrm{ml}$ in $2 \mathrm{M} \mathrm{NaCl}, 50 \mathrm{mM}$ MES-NaOH pH 6.5, $0.4 \mathrm{M}$ sucrose. The incubation was carried out for $30 \mathrm{~min}$ in darkness at $4^{\circ} \mathrm{C}$ with occasional mixing. The membranes were then collected by centrifugation $(30,000 \mathrm{x} \mathrm{g}, 10$ $\mathrm{min})$. The treatment was repeated once, after which the membranes were washed twice in SMN Buffer and then resuspended in the same buffer to approximately 2-3 $\mathrm{mg}$ of $\mathrm{Chl}$ per $\mathrm{ml}$.

\section{$\mathrm{CaCl} 2$ treatment of $\mathrm{PS} I 1$ membranes}

$1 \mathrm{M} \mathrm{CaCl}$ 2-extracted PS II membranes ( $\mathrm{CaCl}_{2}$-treated PS II membranes) were compositionally the same as $2.6 \mathrm{M}$ urea, $200 \mathrm{mM} \mathrm{NaCl}$-extracted PS II membranes (ureatreated PS II membranes, Miyao and Murata, 1985) and lack 17, 24 and $33 \mathrm{kDa}$ extrinsic proteins. $\mathrm{CaCl}_{2}$-treated PS II membranes and urea-treated PS II membranes can be prepared from intact PS II membranes or NaCl-treated PS II membranes. All of these samples were handled under dim green light in the cold room. After thawing, spinach PS 
II rnembranes were centrifuged $(30,000 \times \mathrm{g}, 10 \mathrm{~min})$. The membranes were resuspended at $500 \mu \mathrm{g} \mathrm{Chl} / \mathrm{ml}$ in $1 \mathrm{M} \mathrm{CaCl}_{2}, 50 \mathrm{mM} \mathrm{MES}-\mathrm{NaOH} \mathrm{pH} 6.5,0.4 \mathrm{M}$ sucrose. The inclubation was carried out for $30 \mathrm{~min}$ in darkness at $4^{\circ} \mathrm{C}$ with gentle mixing. The membranes were then collected by centrifugation $(30,000 \times \mathrm{g}, 10 \mathrm{~min})$. The treatment was repeated once, after which the membranes were washed twice in SMN Buffer and then resuspended in the same buffer to approximately $2-3 \mathrm{mg}$ of $\mathrm{Chl}$ per $\mathrm{ml}$.

\section{Urea treatment of PS II membranes}

Urea-treated PS II membranes were PS II membrane preparations (or $\mathrm{NaCl}$-treated PS II membranes) extracted with $2.6 \mathrm{M}$ urea, $200 \mathrm{mM} \mathrm{NaCl}$ to remove the remaining extrinsic polypeptides. Into SM24 centrifuge tubes, SMNC50 Buffer $(0.4 \mathrm{M}$ sucrose, 50 mM MES-NaOH pH $6.5,100 \mathrm{mM} \mathrm{NaCl}, 50 \mathrm{mM} \mathrm{CaCl} 2$ ) was added to $0.5 \mathrm{ml}$ of PS II membranes to bring the total volume to $8-10 \mathrm{ml}$ and centrifuged $(18,000 \mathrm{rpm}=30,000 \mathrm{xg}$, $15 \mathrm{~min}, \mathrm{SS} 34$ rotor with adaptor). The pellet was resuspended in $10 \mathrm{ml}$ ( $2.6 \mathrm{M}$ urea, 200 $\mathrm{mM} \mathrm{NaCl}, 50 \mathrm{mM}$ MES-NaOH $\mathrm{pH} 6.5$ ) and incubated on a rocker for $30-40 \mathrm{~min}$ in the dark at $4^{\circ} \mathrm{C}$. Then, this mixture was centrifuged, resuspended, incubated and centrifuged all as above. The pellet was resuspended into $8 \mathrm{ml}$ of SMNC50 Buffer, centrifuged as above, resuspended in $1 \mathrm{ml}$ final volume of SMNC50 Buffer and stored at $-80^{\circ} \mathrm{C}$ in $0.5 \mathrm{ml}$ aliquots.

\section{Isolation of 17 and $24 \mathrm{kDa}$ proteins}

The 17 and $24 \mathrm{kDa}$ proteins were isolated as a mixture from the $\mathrm{NaCl}$-treated $\mathrm{PS} \mathrm{II}$ supernatants of 2 washes of PS II membranes. These mixtures were centrifuged $(30,000 \mathrm{x}$ $\mathrm{g}, 10 \mathrm{~min}$ ) and the supernatants were pooled together and concentrated by Amicon filtration using a YM-10 membrane. The $\mathrm{NaCl}$ was then removed by dialysis against $20 \mathrm{mM} \mathrm{MES}-$ $\mathrm{NaOH}$ pH 6.5. The absorption at $280 \mathrm{~nm}$ was taken to get the total protein concentration, which was then diluted to $0.5-1 \mu \mathrm{g}$ of protein per $\mathrm{ml}$ with $20 \mathrm{mM}$ MES-NaOH pH 6.5. 
This preparation was then combined with an equivalent volume of $2 \times$ Buffer A ( $40 \mathrm{mM}$ MES-NaOH pH 6.5, 0.8 $\mathrm{M}$ sucrose, $30 \mathrm{mM} \mathrm{NaCl}, 10 \mathrm{mM} \mathrm{MgCl} 2$ ) and frozen in aliquots at $-20^{\circ} \mathrm{C}$ until use.

\section{Isolation of $33 \mathrm{kDa}$ protein}

The $33 \mathrm{kDa}$ protein was isolated from the supernatants of $1 \mathrm{M} \mathrm{CaCl} 2$ treatment of PS II membranes previously treated with $\mathrm{NaCl}$. PS II membranes were treated twice as above with $\mathrm{NaCl}$ to remove the 17 and $24 \mathrm{kDa}$ proteins. Following two washes with Buffer $\mathrm{A}$, two $30 \mathrm{~min}$ incubations with $1 \mathrm{M} \mathrm{CaCl}$ ? were done to remove the $33 \mathrm{kDa}$ protein from the membranes. These mixtures were centrifuged $(30,000 \times \mathrm{g}, 10 \mathrm{~min})$ and the supernatants were pooled together and concentrated by Amicon filtration using a YM-30 membrane. The $\mathrm{CaCl}_{2}$ was then removed by dialysis against $20 \mathrm{mM} \mathrm{MES-NaOH}$ pH 6.5. The absorption at $276 \mathrm{~nm}$ (20 per mM per cm, Miyao and Murata, 1984) was taken to get the total protein concentration, which was then diluted to $0.5-1 \mu \mathrm{g}$ of protein per $\mathrm{ml}$ with $20 \mathrm{mM}$ MES-NaOH pH 6.5. This preparation was then combined with an equivalent volume of $2 \times$ Buffer A (40 mM MES-NaOH pH 6.5, $0.8 \mathrm{M}$ sucrose, $30 \mathrm{mM} \mathrm{NaCl}, 10$ $\mathrm{mM} \mathrm{MgCl} 2$ ) and frozen in aliquots at $-20^{\circ} \mathrm{C}$ until use.

\section{Exygen evolution assays}

Each assay consisted of $30 \mu \mathrm{g}$ chlorophyll (PS II, $\mathrm{NaCl}$-treated PS II, $\mathrm{CaCl}$ treated PS II, or urea-treated PS II) incubated with antisera or pre-immune serum for 1 to 4 $h$ at $0-4^{\circ} \mathrm{C}$ in the dark. Incubation with pre-immune serum was used as a control for a measure of the possible nonspecific effects of serum addition on the assay. Experiments using reaction center cores or urea-treated cores were done as above with $6 \mu \mathrm{g}$ chlorophyll (roughly the same number of reaction centers as for PS II experiments). Urea- or $\mathrm{CaCl}_{2}$ treated samples were assayed with or without an additional incubation with $35 \mu \mathrm{g}$ of 33 $\mathrm{kDa}$ protein for $30 \mathrm{~min}$ to $1 \mathrm{~h}$ before the assay. This amount of $33 \mathrm{kDa}$ protein was 
equivalent to a purified $33 \mathrm{kDa}$ protein to $\mathrm{Chl} \mathrm{w} / \mathrm{w}$ ratio of 0.3 for PS II membranes and 2.0 for PS II core preparations (Murata, et al., 1984). These ratios correspond to absolute stoichiometries of purified $33 \mathrm{kDa}$ protein to reaction center of approximately $2: 1$ for both preparations.

The incubated samples were then assayed with a Clark-type oxygen electrode (Yellow Springs Instr., Ohio). DCBQ (10 $\mu$ l of $0.1 \mathrm{~g} / \mathrm{ml}$ stock in DMSO) as acceptor was added in a final volume of $1.6 \mathrm{ml}$ SMNC Buffer $(0.4 \mathrm{M}$ sucrose, $50 \mathrm{mM} \mathrm{MES}-\mathrm{NaOH} \mathrm{pH}$ $6.5,50 \mathrm{mM} \mathrm{NaCl}, 50 \mathrm{mM} \mathrm{CaCl} 2$ ). The cuvette was maintained at a constant temperature of $24^{\circ} \mathrm{C}$ and its contents magnetically stirred. Illumination from a slide projector was passed through a $360 \mathrm{~nm}$ cutoff filter and a spherical flask filled with water (focused the light and acted as a heat filter). The rate of oxygen evolution was calculated from the initial slope after applying continuous light, at or slightly above saturation levels.

\section{Results and Discussion}

This chapter describes a set of experiments aimed at characterizing possible direct antibody effects on the OEC of PS II reaction centers by studying the oxygen evolution of PS II-enriched membrane preparations of differing extrinsic polypeptide composition. Preincubations with anti-D1-a were compared to parallel preincubations with pre-immune serum in order to account for non-specific effects of the serum. In all tables, each rate of oxygen evolution represents the average of 3-5 measurements and has an accuracy of approximately $\pm 10 \mu \mathrm{mol} \mathrm{O} 2 / \mathrm{mg} \mathrm{Chl} \mathrm{per} \mathrm{h}$. In Table 5-1, data from an experiment using various PS II membrane preparations treated by preincubation with anti-D1-a or preimmune serum for 1-2 $\mathrm{h}$ is presented. Thereafter, in Tables 5-2 through 5-4, results from experiments using PS II membrane preparations depleted of the extrinsic proteins are presented. Treatment of PS II membranes with $2.6 \mathrm{M}$ urea $(+200 \mathrm{mM} \mathrm{NaCl})$ or $1 \mathrm{M}$ 
$\mathrm{CaCl}_{2}$ removes the three extrinsic polypeptides while leaving the OEC Mn cluster intact. These preparations svolve sxygen to only a small extent, but can be reconstituted to near $100 \%$ activity after incubation with purified $33 \mathrm{kDa}$ protein. The effects of anti-D1-a on these preparations were inivestigated by varying the length of preincubation as well as the order of addition of sera and $33 \mathrm{kDa}$ protein.

Table 5-1, shows the results from an experiment using PS II membrane preparations of varying extrinsic polypeptide composition. PS II membranes contain all three $(17,24$ and $33 \mathrm{kDa})$ proteins still bound. PS II membranes incubated with anti-D1-a or pre-immune serurn for 1-2 h showed no difference in oxygen evolution, both evolving near control PS II levels ( $476 \mu \mathrm{mol} \mathrm{O} / \mathrm{mg} \mathrm{Chl}$ per hr) when assayed in SMN Buffer containing low $\mathrm{Cl}^{-}$and $\mathrm{Ca}^{2+}$ concentrations. $\mathrm{NaCl}$-treated PS II membranes lack the 17 and $24 \mathrm{kDa}$ extrinsic proteins. After incubation with anti-D1-a or pre-immune serum for 1$2 \mathrm{~h}, \mathrm{NaCl}$-treated PS II membranes showed no difference in oxygen evolution. Both treatments resulted in oxygen evolution of slightly more than $90 \%$ of the control PS II levels. This preparation was assayed for oxygen erolution in SMN Buffer containing at least $30 \mathrm{mM} \mathrm{Cl}^{-}$and $5 \mathrm{mM} \mathrm{Ca} 2+$. Finally, CaCl2-treated PS II membranes were also incubated with aniw-DI-a or pre-inmune serum for $1-2 \mathrm{~h}$. These $\mathrm{CaCl}_{2}$-treated PS II membranes lack all three extrinsic proteins and also showed no difference in oxyger: evolution for the two preincubations, both evolving at near 20\% of control PS II levels when assayed in SMN Buffer containing $200 \mathrm{mM} \mathrm{Cl}^{-}$and $10 \mathrm{mM} \mathrm{Ca}^{2+}$.

The next experiment was performed in order to determine the required amourt of purified $33 \mathrm{kDa}$ protein necessary 10 reconstitute a substantial fraction of the oxygen evolution for PS II preparations lacking the $33 \mathrm{kDa}$ protein. This was necessary so that these preparations could be assayed more reliably by addition of the $33 \mathrm{kDa}$ protein after preincubation with antibody. The results in Table 5-2 are for oxygen evolution rates of camples containing $30 \mu \mathrm{g}$ of chlorophyll assayed in $S M N$ Buffer with $200 \mathrm{mM} \mathrm{Cl}^{-}$and 10 


\section{Table 5-1}

Oxygen evolution of various PS II membrane preparations following preincubations with anti-Dl-a or pre-imm ne serum for 1-2 h. Prior to incubation with the antibod ss, PS II membranes were treated with $2 \mathrm{M} \mathrm{NaCl}$ to remove the 17 and $24 \mathrm{kDa}$ extrinsic polypeptides or treated with $1 \mathrm{M} \mathrm{CaCl}_{2}$ to remove the 17,24 and $33 \mathrm{kDa}$ extrinsic polypeptides.

Oxygen evolution ( $\mu \mathrm{mol} \mathrm{O}_{2} / \mathrm{mg} \mathrm{Chl} \mathrm{per} \mathrm{h)}$

$\begin{array}{lccc} & \text { No } & \text { Ant- } & \text { Non- } \\ \text { Sample Type } & \text { Preincubation } & \text { D1-a } & \text { Immune }\end{array}$

PS II membranes

$476(100 \%) \quad 468(98 \%) \quad 460(97 \%)$

$\mathrm{NaCl}$-ireated PS II membr.

$438(92 \%) \quad 445(93 \%) \quad 430(90 \%)$

$\mathrm{CaCl}_{2}$-treated PS II membr.

$104(22 \%) \quad 114(24 \%)$

$95(20 \%)$ 


\section{Table 5.2}

Oxygen evolution of two PS II membrane preparations lacking all three extrinsic polypeptides. PS II mernbranes were treated with $1 \mathrm{M} \mathrm{CaCl}_{2}$ or with $2 . \mathrm{M}$ urea, $200 \mathrm{mM}$ $\mathrm{NaCl}$ to remove the 17,24 and $33 \mathrm{kDa}$ extrinsic polypeptides. Oxygen evolution was rieasured after incubations with increasing amounts of $33 \mathrm{kD}$ a protein, but no antibody.

Oxygen evolution ( $\mu \mathrm{mol} \mathrm{O}_{2} / \mathrm{mg} \mathrm{Chl}$ per $\mathrm{h}$ )

\begin{tabular}{ccc}
\cline { 2 - 3 } Amount $33 \mathrm{kDa}$ Added & $\begin{array}{c}\mathrm{CaCl} 2- \\
\text { PS II }\end{array}$ & $\begin{array}{c}\text { Urea-NaCl- } \\
\text { PS II }\end{array}$ \\
\hline $0 \mu \mathrm{g}$ & $83(18 \%)$ & $105(23 \%)$ \\
$7 \mu \mathrm{g}$ & $166(36 \%)$ & $158(34 \%)$ \\
$17 \mu \mathrm{g}$ & $241(52 \%)$ & $299(64 \%)$ \\
$35 \mu \mathrm{g}$ & $249(54 \%)$ & $399(86 \%)$ \\
$50 \mu \mathrm{g}$ & $249(54 \%)$ & $415(89 \%)$ \\
$67 \mu \mathrm{g}$ & $257(55 \%)$ & $432(93 \%)$
\end{tabular}

${ }^{*}$ Control untreated PS II membranes gave rate of 465 (100\%) 
$\mathrm{mM} \mathrm{Ca}{ }^{2}+$ following 1-2 $\mathrm{h}$ incubations with different amounts of purified $33 \mathrm{kDa}$ protein. The oxygen evolution of $\mathrm{CaCl}_{2}$-treated PS II membranes incubated with increasing amounts of $33 \mathrm{kDa}$ protein ranged from $20 \%$ of control PS II evolution to about $55 \%$ with $35 \mathrm{\mu g}$ or more $33 \mathrm{kDa}$ added. For urea-treated PS II membranes, the rate of oxygen evolution relative to control PS II membranes ranged from $20 \%$ with $0 \mu \mathrm{g} 33 \mathrm{kDa}$ protein added to around $90 \%$ with $35 \mu \mathrm{g}$ or more added. These results indicate that the $\mathrm{CaCl}_{2}$ treatment damaged a large fraction of the reaction centers, rendering them unable to reconstitute oxygen evolution upon addition of $33 \mathrm{kDa}$ protein. The urea treated sarnples gave results more consistent with those described by Miyao and Murata (1985). Therefore, urea-treated samples were used for the remainder of PS II experiments described in this chapter. The amount of purified $33 \mathrm{kDa}$ protein added for these experiments and those described in Chapter 7 was equivalent to $35 \mu \mathrm{g}$ of $33 \mathrm{kDa}$ protein per $30 \mu \mathrm{g}$ of chlorophyll.

Table 5-3 presents results of an experiment that examined several variables in the assay of oxygen evolution following preincubations with anti-D1-a or pre-immune serum. SMNC10 Buffer and SMNC50 Buffer refer to the assay buffers used, which were SMN Buffer with $10 \mathrm{mM}$ or $50 \mathrm{mM} \mathrm{CaCl}_{2}$, respectively. The lack of $33 \mathrm{kDa}$ protein, or its addition following antibody incubation, are indicated by "NO $33^{\text {" }}$ and "With 33," respectively. Two amounts of sera were added to different sets of samples, $1 x$ and $4 x$ indicates this variable. Each pair of urea-treated PS II membranes incubated with anti-D1-a or pre-immune serum for 1-2 h showed no difference in oxygen evolution, both samples of a pair evolving at about $30 \%$ of control PS II levels. This result is consistent for the two assay buffers as well as for the two amounts of added sera. Each pair of urea-treated PS II membranes incubated with anti-D1-a or pre-immune serum for $1-2 \mathrm{~h}$ and then $35 \mu \mathrm{g}$ of purified $33 \mathrm{kDa}$ protein added $1 \mathrm{~h}$ before assay showed similar rates of oxygen evolution. Within a pair, the two samples varied by approximately $5 \%$ of the control PS II rate, indicating that anti-D1-a does not inhibit the rebinding of the $33 \mathrm{kDa}$ protein. Anti-D1-a 


\section{Table 5.3}

Oxygen evolution of PS II membrane preparations lacking all three extrinsic polypeptides following preincubations with varying amounts of anti-D1-a or pre-irnmune serum for 1-2 h. Prior to incubation with the antibodies, PS II membranes were treated with $2.6 \mathrm{M}$ urea, $200 \mathrm{mM} \mathrm{NaCl}$ to remove the 17,24 and $33 \mathrm{kDa}$ extrinsic polypeptides. Oxygen evolution was measured in several buffers after an incubation with or without purified $33 \mathrm{kDa}$ extrinsic protein.

Oxygen evolution ( $\mu \mathrm{mol} \mathrm{O} / \mathrm{mg} \mathrm{Chl} \mathrm{per} \mathrm{h)}$

\begin{tabular}{lcccc}
\cline { 2 - 4 } & $\begin{array}{c}\text { SMNC10 } \\
\text { SO 33 }\end{array}$ & $\begin{array}{c}\text { SMNC10 } \\
\text { With 33 }\end{array}$ & $\begin{array}{c}\text { SMNC50 } \\
\text { NO 33 }\end{array}$ & $\begin{array}{c}\text { SMNC50 } \\
\text { With 33 }\end{array}$ \\
\hline No preinc. & $125(27 \%)$ & $344(75 \%)$ & $137(30 \%)$ & $344(75 \%)$ \\
Anti-D1-a & $144(32 \%)$ & $394(86 \%)$ & $125(27 \%)$ & $344(75 \%)$ \\
Pre-immune & $150(33 \%)$ & $375(82 \%)$ & $125(27 \%)$ & $337(74 \%)$ \\
\hline $4 x$ Anti-D1-a & $144(32 \%)$ & $419(92 \%)$ & $137(30 \%)$ & $319(70 \%)$ \\
\hline $4 x$ Pre-immune & $119(26 \%)$ & $387(85 \%)$ & $119(26 \%)$ & $306(67 \%)$ \\
\hline
\end{tabular}

* Control untreated PS II membranes gave rate of $456(100 \%)$ 
also does not appear to have any deleterious effects on the Mn cluster of the OEC. It is interesting to note that for all pairs of samples to which the $33 \mathrm{kDa}$ protein was added there is a slightly greater rate of oxygen evolution for the anti-D1-a sample relative to the corresponding pre-immune serum sample. The samples assayed in SMNC10 Buffer gave generally higher rates, so this buffer was used for assays described in the next experiment.

The data in Table 5-4 is from an experiment which tested the antibody effects on the stability of the OEC Mn during prolonged incubations. This was examined because, for a given pair of samples during previous experiments, the one incubated with andi-D1-a consistently gave slightly higher rates of oxygen evolution than the sample incubated with pre-immune serum. Also, the removal of the 2 more loosely bound of the 4 OEC Mn by aging $\mathrm{CaCl}_{2}$-treated membranes in low $\mathrm{NaCl}$ buffer had been described (Ono and Inoue, 1985; Cole et al., 1987). Urea-treated PS II membranes were incubated in SMN Buffer with anti-D1-a or pre-immune serum for 2-4 days. Then, $35 \mu \mathrm{g}$ of purified $33 \mathrm{kDa}$ protein was added $1 \mathrm{~h}$ before assay. For a pair of samples, higher oxygen evolution rates for the anti-D 1-a sample was measured relative to the pre-immune serum sample (Table 5-4). This difference became more pronounced as the length of incubation increased and is much more apparent for the samples incubated with the $4 x$ serum concentration. Also note that the difference is enhanced when the assay for oxygen evolution is performed after incubation with added $33 \mathrm{kDa}$ protein. For this experiment, it appears that anti-D1-a is stabilizing the OEC Mn during the prolonged incubations, allowing reconstitution of oxygen evolution upon addition of the $33 \mathrm{kDa}$ protein.

In summary, this chapter has shown that preincubation with anti-D1-a does not seem to markedly change the rate of oxygen evolution for any of the PS II membrane preparations examined. In PS II membrane preparations from which the $33 \mathrm{kDa}$ protein was removed, preincubation with anti-D1-a has little effect on the rate of oxygen evolution. 
Table 5-4, Days 1 and 2

Oxygen evolution of PS II membrane preparations lacking all three extrinsic polypeptides following preincubations with varying amounts of anti-D1-a or pre-immune serum for 0-4 days. Prior to incubation with the antibodies, PS II membranes were treated with $2.6 \mathrm{M}$ urea, $200 \mathrm{mM} \mathrm{NaCl}$ to remove the 17,24 and $33 \mathrm{kDa}$ extrinsic polypeptides. Oxygen evolution was measured after an incubation with or without purified $33 \mathrm{kDa}$ extrinsic protein. Note: This table is continued on the next page.

\section{Oxygen evolution ( $\mu \mathrm{mol} \mathrm{O} / \mathrm{mg} \mathrm{Chl} \mathrm{per} \mathrm{h)}$}

$\begin{array}{lcccc} & \text { Day 1: } & \text { Day 1: } & \text { Day 2: } & \text { Day 2: } \\ \text { Sample Type } & \text { NO 33 } & \text { With 33 } & \text { NO 33 } & \text { With 33 }\end{array}$

No preinc.

Anti-D1-a

Pre-immune

4x Anti-D 1-a

4x Pre-immune

$$
125(27 \%)
$$

$344(75 \%)$

$106(23 \%)$

$319(70 \%)$

$144(32 \%)$

$394(86 \%)$

$106(23 \%)$

$375(82 \%)$

$150(33 \%)$

$375(82 \%)$

$106(23 \%)$

$262(58 \%)$

$144(32 \%)$

$419(92 \%)$

$106(23 \%)$

$312(68 \%)$

$119(26 \%)$

$387(85 \%)$

$190(42 \%)$

*Control untreated PS II membranes gave rate of 456 (100\%) 


\section{Table 5-4, Days 3 and 4}

Oxygen evolution of PS II membrane preparations lacking all three extrinsic polypeptides following preincubations with varying amounts of anti-D1-a or pre-immune serum for 0-4 days. Prior to incubation with the antibodies, PS II membranes were treated with $2.6 \mathrm{M}$ urea, $200 \mathrm{mM} \mathrm{NaCl}$ to remove the 17,24 and $33 \mathrm{kDa}$ extrinsic polypeptides. Oxygen evolution was measured after an incubation with or without purified $33 \mathrm{kDa}$ extrinsic protein. Note: This table continues from the previous page.

\section{Oxygen evolution ( $\mu \mathrm{mol} \mathrm{O}_{2} / \mathrm{mg} \mathrm{Chl} \mathrm{per} \mathrm{h}$ )}

\begin{tabular}{lcccc} 
& $\begin{array}{c}\text { Day 3: } \\
\text { No 33 }\end{array}$ & $\begin{array}{c}\text { Day 3: } \\
\text { With 33 }\end{array}$ & $\begin{array}{c}\text { Day 4: } \\
\text { NO 33 }\end{array}$ & $\begin{array}{c}\text { Day 4: } \\
\text { With 33 }\end{array}$ \\
\hline No preinc. & $75(16 \%)$ & $219(48 \%)$ & $-0(-0 \%)$ & $167(37 \%)$ \\
Anti-D1-a & $75(16 \%)$ & $219(48 \%)$ & $28(6 \%)$ & $167(37 \%)$ \\
Pre-immune & $72(16 \%)$ & $187(41 \%)$ & $-0(\sim 0 \%)$ & $103(23 \%)$ \\
$4 x$ Anti-D1-a & $99(15 \%)$ & $175(38 \%)$ & $9(2 \%)$ & $122(27 \%)$ \\
$4 \times$ Pre-immune & $47(10 \%)$ & $125(27 \%)$ & $\sim 0(-0 \%)$ & $19(4 \%)$ \\
\hline
\end{tabular}

*Control untreated PS II membranes gave rate of $456(100 \%)$ 
The same result is obtained whether purified $33 \mathrm{kDa}$ protein is added before or after the antibody incubation. The addition of purified $33 \mathrm{kDa}$ protein is required to reach the maximal rate of oxygen evolution for these preparations. Finally, it appears that anti-D1-a stabilizes the OEC Mn during prolonged incubations, and allows reconstitution of oxygen evolution upon addition of the $33 \mathrm{kDa}$ protein. 


\section{SOLUTION BINDING ASSAYS}

\section{Introduction}

Solution binding assays were used in order to determine which antibodies actually bound to native PS II membranes in solution. Although the antibodies were sho'wn to bind to the appropriate one of the D1 or D2 proteins on western blots, whether they bind in: solution was examined because of the negative results in other solution stucies such as oxygen evolution (Chapter 5) and initial studies of Mn photoactivation (Chapter 7).

This assay was adapted from the procedures of Sayre et al. (1986) who used it to study the orientation of the D1 and D2 proteins in the thylakoid menibrane. More precisely, they elicited antibodies to peptides corresponding to regions of the D1 and D2 proteins which are not found in transmembrane helical regions as proposed by the 5 transmembrane helix model described by Trebst (1986) or the 7 transmembrane helix model detailed by Rao et al. (1983). Their peptides were chosen such that binding to closed thylakoid membranes vs inside-out thylakoid membranes would distinguish between the two proposed models. The model of Trebst (1986), containing 5 transmembrane helices was shown to be correct by this antibody analysis.

This procedure was modified by using isolated PS II membrane fragments instead of intact thylakoids. This allowed for the study of binding of antibodies to the preparations used for other experiments and to manipulate the extrinsic polypeptide composition, the cofactors added, and the digestion and processing of the C-termini of the D1 and D2 proteins. 


\section{Procedures}

\section{PS IImembrane preparation}

PS II membrane fragments were prepared from spinach leaves essentially as described by Berthold, et al. (1981), but including modifications from Ford and Evans (1983), Rutherford et al. (1984) and Dr. J.-L. Zimmermann (Service Biophysique, CENSaclay, France). The details of this preparation are presented in Chapter 4.

\section{Qther PS II oreparations}

Several other PS II membrane preparations were used here. All of them were prepared starting with the PS II membrane iragments described above. The details of the preparation of $\mathrm{NaCl}$-treated PS II membranes and $\mathrm{CaCl}_{2}$-treated PS II membranes are presented in Chapter 5. The details of the preparation of Tris-treated PS II membranes and carboxypeptidase A-treated PS II membranes are presented in Chapter 4.

\section{$\mathrm{NH}_{2} \mathrm{OH}$ treatment of PS II preparations}

Immediately before starting the binding assay, samples of each membrane preparation were treated at $500 \mu \mathrm{g} \mathrm{Chl} / \mathrm{ml}$ for $1 \mathrm{~h}$ with $2 \mathrm{mM}$ hydroxylamine in SMN Buffer at $4^{\circ} \mathrm{C}$ in the dark with occasional mixing (to remove $\mathrm{Mn}$ without altering the extrinsic protein composition) as described by Tamura and Cheniae (1985). The membranes were then collected by centrifugation $(30,000 \times \mathrm{g}, 10 \mathrm{~min})$ and washed twice in SMNC Buffer before resuspension in the same buffer.

\section{Solution assay for antibody binding}

The procedure used in this study is a modified version from that of Sayre et al. (1986). Approximately $20 \mu \mathrm{g} \mathrm{Chl}$ of PS II membrane preparations (untreated, $\mathrm{NaCl}$ treated, $\mathrm{CaCl}_{2}$-treated, urea-treated, $\mathrm{NH}_{2} \mathrm{OH}$-treated, or carbox ypeptidase A-treated) were 
pre-incubated at $0.4 \mathrm{mg} \mathrm{Chl} / \mathrm{ml}$ in SMN Buffer containing $80 \mathrm{mM} \mathrm{NaCl}, 2 \% \mathrm{BSA}, 0.04 \%$ Tween-20, and 10-40\% pre-immune Fab (prepared as described in Chapter 3) for $2 \mathrm{~h}$. Twenty $\mu$ of antiserum (or pre-immune serum) was simultaneously pre-incubated in SMN Buffer containing $120 \mathrm{mM} \mathrm{NaCl}, 3 \%$ galactose, $3 \% \mathrm{BSA}$, and $0.06 \%$ Tween-20. This combination of incubations was needed to reduce nonspecific binding of pre-immune serum. Equal volumes of PS II membranes and antiserum were then mixed and incubated on ice for 2 to $4 \mathrm{~h}$ with periodic mixing. Each sample was then washed 3 times by centrifugation for $5 \mathrm{~min}$ in a microfuge at $4^{\circ} \mathrm{C}$ and then resuspended in SMN Buffer containing $200 \mathrm{mM} \mathrm{NaCl}, 2 \% \mathrm{BSA}, 0.04 \%$ Tween-20. The secondary antibody, [125I]labeled donkey anti-rabbit Ig (Amersham IM.134), was added at 1:200 final dilution. After incubation for 2 to $4 \mathrm{~h}$ with periodic mixing, the samples were washed 3 times as above. Each membrane pellet was resuspended in SMN Buffer and equal fractions of approximately $5 \mu \mathrm{g}$ Chl each were used for chlorophyll determination and gamma counting. Chlorophyll determination was done in $80 \%$ acetone (by adding 4 volumes of $100 \%$ acetone per volume of PS II) as described by Amon (1949). Counts per minute (CPM) values for each sample were first normalized to $5 \mu \mathrm{g} \mathrm{Chl} \mathrm{and} \mathrm{then} \mathrm{corrected} \mathrm{for}$ non-specific [ ${ }^{125}$ ] binding. This was done by subtracting values for pre-immune samples from their respective immune samples.

\section{Results and Discussion}

Several attempts were required in order to optimize the assay and get reproducible results with low background binding. The most important were: pre-incubation of the PS II preparation with pre-immune Fab, pre-incubation of the immune or pre-immune serum with galactose, the inclusion of Tween-20 and BSA in the incubation buffers and the addition of $200 \mathrm{mM} \mathrm{NaCl}$ to all wash buffers. After the assay, chlorophyll determination 
of ail samples was used to normalize CPM. All of these procedural changes are included in the final procedure described above.

The results from one of the first successful assays are given in Table 6-1. This experiment addressed the question of whether anti-D1-a bound differentially to PS II membranes with different extrinsic polypeptide compositions. Additionally, this experiment examined whether anti-D1-a bound differentially to the same PS II membrane preparations after incubation with the $33 \mathrm{kDa}$ extrinsic protein. The $33 \mathrm{kDa}$ extrinsic protein was added by incubation with purified $33 \mathrm{kDa}$ protein as described in Chapter 5 . Differing from the final procedure, this assay started with $10 \mu \mathrm{g} \mathrm{Chl} \mathrm{per} \mathrm{sample} \mathrm{and} \mathrm{ended}$ with analysis of final samples of approximately $2 \mu \mathrm{g}$ Chl for counting of radioactivity and an equivalent amount for determination of Chl content. The difference in CPM between the immune and pre-immune samples were calculated after correction for the actual amount of sample by $\mathrm{Chl}$ determination. As can be seen from these differences, the sample lacking the 17 and $24 \mathrm{kDa}$ proteins ( $\mathrm{NaCl}$-treated PS II membranes) binds 50\% more [ ${ }^{125} \mathrm{I}$, and therefore more antibody, than the sample of intact PS II membranes. Likewise, the sample lacking the 17, 24 and $33 \mathrm{kDa}$ proteins (urea-treated PS II membranes) binds $200 \%$ more [125] than the sample of $\mathrm{NaCl}$-treated PS II membranes. From these results, it appears that anti-D1-a binding is increased by the removal of the extrinsic proteins from PS II. For the samples pre-incubated with the $33 \mathrm{kDa}$ extrinsic protein, generally little change or a decrease in binding (for urea-treated PS II membranes) is apparent. For intact PS II membranes, the change caused by $33 \mathrm{kDa}$ protein pre-incubation is a slight increase of $13 \%$ of the original binding. For NaCl-treated PS II membranes, the binding to the $33 \mathrm{kDa}$ protein pre-incubated sample is $14 \%$ lower than without treatment. The magnitude of these changes is on the order of the error inherent in these measurements. Finally, urea-treated PS II membranes pre-incubated with the $33 \mathrm{kDa}$ protein show a decrease of $49 \%$ from the original sample. From these results, two types of binding sites (epitopes) for anti-D1-a on 
Table 6-1

Binding in solution of anti-D1-a to PS II membrane fragments of varying extrinsic polypeptide composition. Prior to incubation with the antibodies, PS II membranes were treated with $2 \mathrm{M} \mathrm{NaCl}$ to remove the 17 and $24 \mathrm{kDa}$ extrinsic polypeptides or treated with $2.6 \mathrm{M}$ urea, $200 \mathrm{mM} \mathrm{NaCl}$ to remove the 17,24 and $33 \mathrm{kDa}$ extrinsic polypeptides. Subsequently, samples from each treatment were incubated with purified $33 \mathrm{kDa}$ extrinsic protein. Finally, the membranes were incubated for $4 \mathrm{~h}$ with antibody and then with [125]-labeled secondary antibody as described in the Procedures section. The values given are CPM remaining associated with $2 \mu \mathrm{g}$ Chl of PS II membranes.

\begin{tabular}{ccc}
\hline Preparation & Difference & $\begin{array}{r}+33 \mathrm{kDa} \\
\text { Difference }\end{array}$ \\
PS II & 2,960 & 3,340 \\
NaCl-PS II & 4,430 & 3,790 \\
Urea-PS II & 13,300 & 6,740 \\
\hline
\end{tabular}


the $\mathrm{DI}$ protein as determined by these solution binding assays can be proposed. One of the epitupes is more exposed ano seems to be available even in the presence of all three extrinsic polypeptides. The second epitope becomes available only upon removal of the 33 $\mathrm{kDa}$ protein and is obstructed by pre-incubation with the $33 \mathrm{kDa}$ protein for preparations previously lacking it.

The results shown in Table 6-2 address the question of whether anti-D1-a binds differentially to PS II membranes with different extrinsic polypeptide compositions in the presence or absence of the Mn cluster. The Mn cluster was removed by treatment with 2. $\mathrm{mM}$ hydroxylamine which, as opposed to the common treatment with $5 \mathrm{mM}$ hydroxylamine, was shown to remove most of the OEC Mn while retaining the major portion of the three extrinsic proteins (Tamura and Cheniae, 1985). This assay started with $25 \mu \mathrm{g} \mathrm{Chl} \mathrm{per} \mathrm{sample} \mathrm{and} \mathrm{ended} \mathrm{with} \mathrm{analysis} \mathrm{of} \mathrm{final} \mathrm{samples} \mathrm{of} \mathrm{approximately} 5 \mu \mathrm{g}$ Chl for counting of radioactivity and an equivalent amount for determination of Chl content. The difference in CPM between the imn: ane and pre-immune samples was again calculated after correction for the actual amount of sample by $\mathrm{Chl}$ determination. As can be seen from these differences, the percentage change between the samples of different extrinsic protein composition is small, and far from results in Table 6-1. This may be best explained by the lass of $\mathrm{Mn}$ from the urea-treated PS II membranes of the experiment of Table 6-1. If this was the case, the results of Table 6-1 would be consistent with the results explained here and shown in Table 6-2. For' the samples treated with hydroxylamine, a definite inc.ease in binding is apparent. For intact PS II membranes, the increase caused by hydroxylamine treatrnent is $86 \%$ of the original binding. For $\mathrm{NaCl}$-treated PS II membranes, the binding to the hydroxylamine treated sample is $114 \%$ higher than without treatment. Finally, ureatreated PS II membranes subsequently treated with hydroxylamine show an increase of $22.0 \%$ over the original sample. From these results, two types of binding sites (epitopes) for anti-DI-a on the DI protein as deternined by these solution binding assays can be 


\section{Table 6-2}

Binding in solution of anti-Dl-a to PS II membrane fragments of varying extrinsic polypeptide composition and varying Mn content. Prior to incubation with the antibodies, PS II membranes were treated with $2 \mathrm{M} \mathrm{NaCl}$ to remove the 17 and $24 \mathrm{kDa}$ extrinsic polypeptides or treated with $2.6 \mathrm{M}$ urea, $200 \mathrm{mM} \mathrm{NaCl}$ to remove the 17,24 and $33 \mathrm{kDa}$ extrinsic polypeptides. Subsequently, the Mn cluster was removed from samples of each extrinsic polypeptide composition by treatment with $2 \mathrm{mM}$ hydroxylamine. Finally, the membranes were incubated for $4 \mathrm{~h}$ with antibody and then with [125I]-labeled secondary antibody as described in the Procedures section. The values given are CPM remaining associated with $5 \mu \mathrm{g}$ Chl of PS II membranes.

\section{$\mathrm{NH}_{2} \mathrm{OH}$}

Preparation Difference Difference

$\begin{array}{ccc}\text { PS II } & 4,130 & 7,680 \\ \text { NaCl-PS II } & 4,830 & 10,350 \\ \text { Urea-PS II } & 4,970 & 15,920\end{array}$


proposed. One of these epitopes is more exposed and seems to be available even in the presence of all three extrinsic polypeptides. The other, possibly more interesting, epitope becomes available only upon removal of the Mn cluster by treatment with hydroxylamine. The difference between the three PS II preparations after hydroxylamine treatment is consistent with the protection of this second epitope by the extrinsic proteins, particularly by the $33 \mathrm{kDa}$ protein, as discussed earlier.

The results of solution antibody binding assays using Tris-treared, but not otherwise denatured, PS II membranes are shown in Table 6-3. The numbers given represent CPM for $5 \mu \mathrm{g}$ of $\mathrm{Chl}$ after normalization for the actual amount of $\mathrm{Chl}$ in each gamma-counted sample and subtraction of the normalized background (as measured by the binding of pre-immune serum). The results of this assay show that all three antibodies were able to bind to Tris-treated PS II membranes in solution. However, anti-D1-a binding to PS II membranes treated with carboxypeptidase A was much reduced, as expected from the western blots in Figure 4-6. Treatment with carboxypeptidase $A$ did not affect the binding of anti-D2-a to any great extent. On the other hand, the binding of anti-D1-b was slightly increased ( $20 \%)$, indicating that the epitopes for boch antibodies were still present and that the epitope for anti-D1-b was more exposed in this material. The solution binding assay shows that anti-D1-a binding to carboxypeptidase A-treated PS II membranes was reduced by about $50 \%$. The difference in apparent binding of anti-D1-a to carboxypeptidase A-treated PS II membranes in the solution assay compared to the western blot (Figure 4-6) may be a result of several factors. Most importantly, the difference in stringency of the two procedures may allow detection in solution of weakly binding antibodies, which may not have been observed on the western blot. These experiments provide evidence that the strongest binding portion of the anti-D1-a serum binds to the carboxyl-terminal end (about 10 residues before the processing point) of the DI protein. This portion of the anti-D1-a serum does not appear to share binding sites with anti-D1-b. 


\section{Table 6-3}

Binding of anti-D1-a, anti-D1-b and anti-D2-a to PS II membrane fragments and carboxypeptidase A-treated PS II membrane fragments in solution. PS II membranes were Tris-treated to remove $\mathrm{Mn}$ and the three extrinsic polypeptides prior to carboxypeptidase $\mathrm{A}$ treatment and incubation with the antibodies. Subsequently, the membranes were incubated for $4 \mathrm{~h}$ with antibody and then with [ $125 \mathrm{n}$-labeled secondary antibody as described in the Procedures section. The values given are CPM remaining associated with $5 \mu \mathrm{g}$ Chl of PS II membranes.

\begin{tabular}{ccc}
\hline $\begin{array}{c}\text { Antibody } \\
\text { Incubation }\end{array}$ & PS II & $\begin{array}{c}\text { Carboxypeptidase A- } \\
\text { treated PS II }\end{array}$ \\
\hline anti-D1-a & 7,430 & 3,810 \\
anti-D1-b & 8,530 & 10,880 \\
anti-D2-a & 8,770 & 7,130 \\
\hline
\end{tabular}


The peptides against which the antibodies were raised share a common sequence (lle 321 to Arg 334) and one of the binding sites for the anti-D1-a serum could be in this region, of low affinity and detected here by the solution binding assay while not apparent by western blotting (Chapter 4$)$.

To summarize, it appears that anti-D1-a binding, as measured by the solution binding assay, is slightly increased by the removal of the extrinsic proteins from PS II. Two types of binding sites (epitopes) for anti-D1-a on the Dl protein as determined by the solution binding assays can be proposed. One of the epitopes is more exposed and seems to be available even in the presence of all three extrinsic polypeptides. The second epitope becomes available only upon removal of the $33 \mathrm{kDa}$ protein and is obstructed by preincubation with the $33 \mathrm{kDa}$ protein for preparations previously lacking it. Another separation into two types of binding sites (epitopes) for anti-D1-a on the D1 protein can be postulated relating to the presence of the Mn cluster. One of these epitopes is more exposed and seems to be available even in the presence of all three extrinsic polypeptides. The other, possibly more interesting, epitope becomes available only upon removal of the Mn cluster by treatment with hydroxylamine, and is probably the epitope detected by the assay of high-affinity Mn-binding sites (Chapter 8). Finally, PS II membranes treated with carboxypeptidase $\mathrm{A}$ were used in the solution binding assay to further characterize the three antibodies. The sites to which these three antibodies appear to bind are discussed above. 


\section{PHOTOACTIVATION ASSAYS}

\section{Introduction}

The measurement of oxygen evolution rates from a variety of PS II preparations demonstrated that antibody binding had no adverse effects on the functioning of the intrinsic OEC Mn of PS II membranes (see Chapter 5). The only effect observed was the stabilization of the Mn complex by anti-D1-a during prolonged incubations of PS II membranes depleted of the 17,24 and $33 \mathrm{kDa}$ extrinsic polypeptides by $\mathrm{CaCl}_{2}$ treatment. If a decrease in oxygen evolution rates had been seen, the antibody's mechanism of action on that particular PS II membrane preparation with the intact OEC Mn complex would have been displacement of $\mathrm{Mn}$ or alteration of the structure in such a manner as to change oxygen evolution activity. Since the antibodies produced no decrease in oxygen evolution, and the antibodies were shown to bind to PS II membranes in solution with the degree of binding increasing upon $\mathrm{Mn}$ removal (see previous chapter), the reverse experiment was tested. This was to first bind the antibodies to PS II membranes depleted of $\mathrm{Mn}$ and some or all of the three extrinsic proteins and then assay for the effect of the antibodies on the rebinding of $\mathrm{Mn}$ by measuring the extent of photoactivation of oxygen-evolving activity.

The photoactivation process in which the oxygen-evolving ability is restored to thylakoids that were prepared or treated in a fashion to remove the active $\mathrm{Mn}$ from its native location in the OEC of PS II has been known for quite some time. As explained by Blankenship et al. (1975), the procedure of Yamashita et al. (1971) can be used to reactivate Tris-washed chloroplasts, which do not initially evolve oxygen, to a final yield of $100 \%$ of the control rate of oxygen evolution. Tamura and Cheniae (1986) summarized the wide variety of preparation procedures and the various, often conflicting, results that were 
available before they applied the photoactivation procedure to PS II-enriched membrane preparations. The early studies had used cultured algae, intact chloroplasts from leaves greened by widely spaced flashes, Tris-extracted chloroplasts or leaves in which the OEC $\mathrm{Mn}$ had been inactivated by $\mathrm{NH}_{2} \mathrm{OH}$ treatment. These systems gave results which indicated a requirement for light in order to ligate $\mathrm{Mn}^{2+}$ and observe oxygen evolution. The requirements for protein synthesis, state of protein phosphorylation, involvement of PS I, presence of $\mathrm{Ca}^{2+}$ and/or stromal factors were not clearly delineated. Actually, the requirement of illumination, although apparent, had no well defined function. Among the possible explanations was that of Blankenship et al. (1975) indicating a light-driven transport of $\mathrm{Mn}^{2+}$ across the thylakoid membrane. The most convincing model from studies using intact thylakoid was presented by Ono and Inoue (1983a). They proposed a scheme involving 2 binding sices, one for $\mathrm{Mn}^{2+}$ and another for $\mathrm{Ca}^{2+}$. They claimed that $\mathrm{Mn}^{2+}$ and $\mathrm{Ca}^{2+}$ could both inhibit each other's binding to the appropriate site and that photoactivation proceeded only when $\mathrm{Mn}^{2+}$ and $\mathrm{Ca}^{2+}$ were both in the correct binding site.

Tamura and Cheniae (1986), in the first report using PS II-enriched membrane preparations, began to better define the requirements for photoactivation of oxygen evolution ability by re-ligation of $\mathrm{Mn}^{2+}$. They washed PS II membranes with $\mathrm{CaCl}_{2}$ and then treated them with redox reagents in order to solubilize the 17,24 and $33 \mathrm{kDa}$ extrinsic polypeptides and the majority of OEC Mn. They showed that photoligation of $\mathrm{Mn}^{2+}$ required both light and approximately $50 \mathrm{mM} \mathrm{Ca}^{2+}$. They observed an apparent competition between $\mathrm{Mn}^{2+}$ and $\mathrm{Ca}^{2+}$ for both the $\mathrm{Mn}$ - and $\mathrm{Ca}$-binding sites. Both of these results agree with the data of Ono and Inoue (1983a) discussed above. The $\mathrm{Mn}^{2+}$ photoligation, as shown by Mn quantitation, was said to occur without the extrinsic proteins, but addition of the $33 \mathrm{k.Da}$ protein was required for expression of oxygen evolution. They claimed that their results excluded light-driven $\mathrm{Mn}^{2+}$ transport across 
thylakoid membranes as the requirement for illumination in this system, indicating that light was required in the actual ligation of Mn to its site in the OEC of PS II. The following interesting data which they did not emphasize was also presented in this publication. They claimed maximum photoactivation of $50 \%$ (at $4^{\circ} \mathrm{C}$ ) and $75 \%$ (at $23^{\circ} \mathrm{C}$ ). They explained that this $<100 \%$ yield was not a consequence of photoinhibition of the PS II donor side, but did not show data to support this (see below for a discussion of the involvement of photoinhibition). Using the data they did present, one can calculate a maximum oxygen evolution rate of $192 \mu \mathrm{mol} \mathrm{O} 2 / \mathrm{mg} \mathrm{Chl} \mathrm{per} \mathrm{h}$ for their PS II preparation before $\mathrm{Mn}$ and extrinsic protein removal. Using their values of 25 and $92 \mu \mathrm{mol}$ of $\mathrm{O}_{2} / \mathrm{mg} \mathrm{Chl}$ per $\mathrm{h}$ for $\mathrm{Mn}$ depleted and photoactivated samples, respectively, a maximum of $35 \%$ photoactivation can be calculated. This value, however, is probably an overestimate considering that similar starting preparations are now known to evolve oxygen at $400-500 \mu \mathrm{mol} \mathrm{O} 2 / \mathrm{mg} \mathrm{Chl}$ per $\mathrm{h}$ under appropriate conditions. They may, in fact, have also photoactivated PS II centers which were inactive in their original preparation. They also gave results indicating a pH maximum for photoactivation between $\mathrm{pH} 6.2$ and 6.5 with a significant decrease for $\mathrm{pH}$ greater than 7.0, all similar to the $\mathrm{pH}$ profile shown for the stability of intact OEC Mn (Critchley et al., 1982; Homann, 1985). Finally, they mention, but do not pursue, the observation that addition of $\mathrm{CaCl}_{2}$ to the oxygen evolution assay medium gave an increase in rate of as much as $50 \%$ when $\mathrm{CaCl}_{2}$ was not present during the photoactivation step (see below for clarification of the role of $\mathrm{Ca}^{2+}$ ).

The first detailed model of the photoactivation process was proposed by Tamura and Cheniae (1987). They studied the photoligation of $\mathrm{Mn}^{2+}$ and photoactivation of oxygen evolution using $\mathrm{NH}_{2} \mathrm{OH}$ - and Tris-treated PS II membranes. They concluded that at the optimal $\mathrm{pH}$ of 6.5 , only light and $\mathrm{Mn}^{2+}$ were essential for photoactivation, but addition of $\mathrm{Ca}^{2+}$ was required for maximum oxygen evolving activity. They performed a kinetic analysis from which they deduced a rate constraint ( $\mathrm{t} 1 / 2 \sim 125 \mathrm{~ms})$ and the 
involvement of an unstable intermediate (half-life of approximately $1 \mathrm{~s}$ ). In this study, they showed evidence for photoinhibition by weak light aging of PS II membranes without $\mathrm{Mn}^{2+}$ prior to photoactivation (contradicting their previous observations, see above). The effect of weak light aging is to inhibit photoactivation and the photoreduction of DCIP by $\mathrm{Mn}^{2+}$ (but not by DPC or TPB) and is not observed if the incubation includes $\mathrm{Mn}^{2+}$. These results indicated photodamage to the $\mathrm{Mn}^{2}+$ binding site without loss of primary electron transport through the PS II reaction center. Finally, they proposed the following biochemical features to describe the photoactivation process: 1) Sequential weak binding and photooxidation of $2 \mathrm{Mn}^{2+}$ ions before their ligation to PS II with high affinity is required. 2) Ligation of the first $\mathrm{Mn}$ inn promotes the weak binding of the second $\mathrm{Mn}^{2+}$, which occurs via the slow rate-limitting step. 3) Photooxidation of this second $\mathrm{Mn}^{2+}$ leads to the ligation of 2 more $\mathrm{Mn}^{2+}$ ions during a light-independent reaction. And 4) $\mathrm{Mn}^{2+}$ and $\mathrm{Ca}^{2+}$ can both interact at the binding sites for either cation in PS II.

The function of $\mathrm{Ca}^{2+}$ was studied further and reported by Tamura et al. (1989b). They showed that PS II membranes devoid of Mn required only light and the addition of $\mathrm{Mn}^{2+}$ in order to photoligate $\mathrm{Mn}$, but this was not sufficient to reconstitute oxygen evolution. Incubation of these inactive, but Mn-containing, PS II membranes with $\mathrm{Ca}^{2+}$ in the dark led to recovery of oxygen evolution (and the release of approximately $1 \mathrm{Mn} / \mathrm{PS} \mathrm{II}$, which was presumed to be bound at the Ca-binding site). The ability of divalent cations to reconstitute oxygen evolution after dark incubation with the Mn-religated PS II membranes was as follows: $\mathrm{Ca}^{2+}>\mathrm{Sr}^{2+} \gg \mathrm{Ba}^{2+}, \mathrm{Mg}^{2+}$. This ordering of cations is similar to the requirement for regaining oxygen evolution in PS II membranes lacking $\mathrm{Ca}^{2+}$ and the 17 and $24 \mathrm{kDa}$ extrinsic proteins (Ghanotakis et al., 1984b). They also indicated a maximurn yield of photoactivation in the range of $40-50 \%$, a measurement of $1.2-1.6 \mathrm{Ca} / 200 \mathrm{Chl}$ and a block in the $S_{2}$ to $\mathrm{S}_{3}$ transition for $\mathrm{Ca}^{2+}$-deficient preparations (shown by them using thermoluminescence measurements). Finally, they conclude that: 1) photoligation of $\mathrm{Mn}^{2+}$ 
does not require $\left.\mathrm{Ca}^{2+}, 2\right)$ this $\mathrm{Mn}$-complex formed during photoligation of $\mathrm{Mn}^{2+}$ is inactive in oxygen evolution, and 3) the inactive $\mathrm{Mn}$-complex can be changed to an active complex by incubation in the dark with $\mathrm{Ca}^{2+}$.

In the most comprehensive publication on the mechanism of photoactivation, Miller and Brudvig (1989) described the kinetics and the cofactor requirements in much greater detail than previously available. They studied the reconstitution by "light-dependent photoactivation" of the Mn complex and oxygen evolution in PS II membrane preparations depleted of $\mathrm{Mn}$. They measured the $\mathrm{Mn}^{2+}$ and $\mathrm{Ca}^{2}+$ dependences of the effective rate constant and yield of photoactivation. They discussed the molecular details of the elementary steps in photoactivation and proposed a revised mechanism for photoactivation, including dissociation constants and binding stoichiometries for $\mathrm{Mn}^{2+}$ and $\mathrm{Ca}^{2+}$. Experimentally, they treated PS II membranes with $\mathrm{NH}_{2} \mathrm{OH}$ to deplete them of $\mathrm{Mn}$ and then photoactivated using the procedures of Tamura and Cheniae (1987). They used various $\mathrm{Mn}^{2+}$ and $\mathrm{Ca}^{2+}$ concentrations and took samples at different points during the incubation in order to study the cation dependences and kinetics of the process. They reported a strong correlation between rate of oxygen evolution, EPR multiline signal amplitude and Mn content of the membranes. In these data, they presented values of photoactivation yields between 30 and $40 \%$ (of the typical control rate of $450 \mu \mathrm{mol} \mathrm{O} 2 / \mathrm{mg}$ Chl per h). In agreement with Ono and Inoue (1983a) and Tamura and Cheniae (1987), they observed a competition between $\mathrm{Mn}^{2+}$ and $\mathrm{Ca}^{2+}$ for the $\mathrm{Ca}^{2+}$ binding site. But, they also noted a slight competition of $\mathrm{Ca}^{2+}$ with $\mathrm{Mn}^{2+}$ for the $\mathrm{Mn}$-binding site. They compared their results with the two models available in the literature: 1) The "1 stage model" of Ono and Inoue (1983a), which requires that both $\mathrm{Mn}^{2+}$ and $\mathrm{Ca}^{2+}$ must be bound in their appropriate sites to allow assembly and photoactivation. And 2) The "2 stage model" of Tamura and Cheniae (1987), which states that PS II can photoligate $4 \mathrm{Mn}$ ions in the absence of $\mathrm{Ca}^{2+}$ without reconstituting oxygen evolution and then bind $\mathrm{Ca}^{2+}$ in 
the dark to regain the ability to evolve oxygen. Results and simulations by Miller and Brudvig (1989) are most consistent with the "2 stage model" of Tamura and Cheniae (1987), where $\mathrm{Mn}^{2+}$ is involved in the rate-determining step, but $\mathrm{Ca}^{2+}$ stimulates the yield of photoactivation and is not involved in the rate-determining step. Since they observed optimal yields of $40 \%$ of control oxygen evolution activity, they proposed that photoactivation must occur in parallel with inactivating photochemical processes (commonly lumped together and called photoinhibition). The authors divided these effects into three possible types of damage to PS II which may limit the yield of photoactivation: 1) damage during isolation and/or $\mathrm{NH}_{2} \mathrm{OH}$-treatment, 2) Photoinhibition, which they defined as light-induced loss of primary electron transport through PS II and 3) Photoinactivation, which they explained as light-induced loss of photoactivation capability without the loss of primary electron transport. They measured or calculated the contribution due to each of these 3 types of damage under conditions that would yield $40 \%$ photoactivation of oxygen evolution. Of the total yield possible, they assigned $25 \%$ to photoinhibition (as measured by decrease in DPC-stimulated DCIP photoreduction). Using their mathematical model of photoactivation, they calculated that at least $90 \%$ of the total PS II centers were competent for photoactivation at the start of the process, and explained that damage during isolation and $\mathrm{NH}_{2} \mathrm{OH}$-treatment must account for maximaily $10 \%$ of the total. This leaves $25 \%$, which they attributed to the photoinactivation process (see above for data from Tamura and Cheniae, 1987, where weak light aging of PS II membranes without $\mathrm{Mn}^{2+}$ prior to photoactivation indicated this type of damage). From their model, they also calculated dissociation constants and binding stoichiometries for the binding of $\mathrm{Mn}^{2+}$ and $\mathrm{Ca}^{2+}$ to both the $\mathrm{Mn}$ - and Ca-binding sites. To the $\mathrm{Mn}$-binding site, one $\mathrm{Mn}^{2}+$ binds with $\mathrm{K}_{\mathrm{d}}=51$ $\mu \mathrm{M}$ or one $\mathrm{Ca}^{2}+$ binds with $\mathrm{K}_{\mathrm{d}}=70 \mathrm{mM}$. To the $\mathrm{Ca}$-binding site, one $\mathrm{Ca}^{2}+$ binds with $\mathrm{K}_{\mathrm{d}}=0.3 \mathrm{mM}$ or one $\mathrm{Mn}^{2+}$ binds with $\mathrm{K}_{\mathrm{d}}=90 \mu \mathrm{M}$. Note that both the binding stoichiometries and dissociation constants differ from the values determined from the components of the high-affinity Mn-binding site as measured by the Mn $2+/ D P C$ non- 
competitive assay for DCIP photoreduction (see Chapter 8). These differences can be explained by the different experimental conditions used in the two cases. The chemical model which Miller and Brudvig presented can be schematically represented as follows:
1) $1^{\mathrm{st}} \mathrm{Mn}^{2+}$ binds $-\ldots--\mathrm{hv}--\cdot->\mathrm{Mn}^{3+}$,
2) $2^{\text {nd }} \mathrm{Mn}^{2+}$ binds $----\mathrm{hv}-\cdots-->\left(\mathrm{Mn}^{3+}\right) 2$,
3) $3^{\text {rd }} \& 4^{\text {th }} \mathrm{Mn}^{2+}$ bind $---n(h v)-->(M n) 4$, ligated but inactive,
4) $\mathrm{Ca}^{2+}$ binds -..----> (Mn)4 active in $\mathrm{O}_{2}$ evolution.

This is a simplification, showing only the steps leading to active OEC formation, of the more correct scheme which would express the binding of every cation as a different equilibrium. In this model, the "2 stages" are 1) photoligation of $\mathrm{Mn}^{2+}$ requiring light and $\mathrm{Mn}^{2+}$ (steps 1-3), and 2) binding of $\mathrm{Ca}^{2+}$ which is required for expression of oxygen evolution (step 4). Considering the evidence for an unstable intermediate (Tamura and Cheniae, 1987), Miller and Brudvig concluded that one $\mathrm{Mn}^{2}+$ ion is bound and photooxidized in the rate-determining step of photoactivation and that it corresponds to the second $\mathrm{Mn}^{2+}$ bound (step 2 above).

This chapter describes experiments based on modifications of the Mn photoactivation protocol first applied to PS II-enriched membrane preparations by Tamura and Cheniae (1986), as discussed above. The procedure involves incubation of Mndepleted (Tris- or hydroxylamine-treated) PS II membranes under low light (approximately $1 \mathrm{~W} / \mathrm{m}^{2}$ at the sample) in the presence of $\mathrm{MnCl}_{2}$ and $\mathrm{CaCl}_{2}$ with DCIP as the electron acceptor at room temperature for 30-45 min. In the report of Tamura and Cheniae (1986), with $33 \mathrm{kDa}$ protein added for the oxygen evolution assay, this treatment yielded an increase of oxygen evolution rates of $25 \%$ for Tris-treated PS II membranes, $35 \%$ for Tristreated PS II membranes photoactivated in the presence of $33 \mathrm{kDa}$ protein and apparently 
50-60\% for $\mathrm{NH}_{2} \mathrm{OH}$-treated PS II membranes (Tamura and Cheniae, 1987). Other groups have reported photoactivation yields of $10-25 \%$ oxygen evolution activity starting with $\mathrm{NH}_{2} \mathrm{OH}$-treated PS II membranes. After optimizing the photoactivation procedure, Miller and Brudvig (1989) reported $40 \%$ as being consistently their maximum yield of oxygen evolution.

As done in the experimental series to examine antibody effects on oxygen evolution (Chapter 5), a variety of PS II membrane preparations have again been used. Preparations that lack all of the extrinsic polypeptides, thereby increasing the chances of antibody effects while simultaneously accepting a decrease in yield of photoactivation, were examined first. Then, the yield of photoactivation was maximized by removing less of the extrinsic proteins. The first preparation used, Tris-treated PS II membranes, lack all three extrinsic proteins $(17,24$ and $33 \mathrm{kDa}$ ) and have lost all of the OEC Mn. The other preparation used, $\mathrm{NH}_{2} \mathrm{OH}$-treated PS II membranes, lack two extrinsic proteins (17 and $24 \mathrm{kDa}$ ) and the OEC Mn, but retain the majority of the $33 \mathrm{kDa}$ extrinsic protein. For both preparations, the maximum reconstitution of oxygen evolution occurred with $1 \mathrm{mM} \mathrm{MnCl}, 50 \mathrm{mM} \mathrm{CaCl} 2$ and the presence of $33 \mathrm{kDa}$ protein. This required addition of purified $33 \mathrm{kDa}$ protein in the case of Tris-treated PS II membranes (Tamura and Cheniae, 1987), although a small rate ( $20 \%$ maximum) of oxygen evolution is expected in the presence of $200 \mathrm{mM} \mathrm{Cl}^{-}$and $10 \mathrm{mM} \mathrm{Ca}^{2+}$ without adding the $33 \mathrm{kDa}$ protein (Miyao et al., 1987). Experiments using both of these preparations with preincubation of the PS II membranes with antibody will be explained in this chapter. For Tris-treated PS II membranes, the antibody incubation was followed by photoactivation in the presence or absence of added $33 \mathrm{kDa}$ protein. Then, the oxygen evolution rate was measured with or without the addition of purified $33 \mathrm{kDa}$ protein. For $\mathrm{NH}_{2} \mathrm{OH}$-treated PS II membranes, the antibody incubation was followed by photoactivation and then measurement of the oxygen evolution rate. The data from maximizing the yield of photoactivation while studying the antibody effects is consistent 
with the two reports (Miller and Brudvig, 1989; Tamura et al., 1989b) published after these experiments were done. Additionally, there were some effects of preincubation with antiD1-a on the yield of photoactivation. There was little or no effect indicated by preliminary results of preincubations with the other two antibodies, anti-D1-b and anti-D2-a.

\section{Procedures}

\section{PS II membrane preparation}

PS II membrane fragments were prepared from spinach leaves essentially as described by Berthold, et al. (1981), but including modifications from Ford and Evans (1983), Rutherford et al. (1984) and Dr. J.-L. Zimmermann (Service Biophysique, CENSaclay, France). The details of this preparation are presented in Chapter 4.

\section{Tris treatment of PS II membranes}

After thawing, spinach PS II membranes were depleted of $\mathrm{Mn}$ and all 3 extrinsic proteins by Tris-treatment as described by Tamura and Cheniae (1987). Afier centrifugation $(30,000 \times \mathrm{g}, 10 \mathrm{~min})$, the membranes were resuspended at $500 \mu \mathrm{g} \mathrm{Chl} / \mathrm{ml}$ in $0.8 \mathrm{M}$ Tris- $\mathrm{HCl} \mathrm{pH} 8.4,0.4 \mathrm{M}$ sucrose. The incubation was carried out for $40 \mathrm{~min}$ under room lights at $4^{\circ} \mathrm{C}$ with occasional mixing. The membranes were then collected by centrifugation $(30,000 \times \mathrm{g}, 10 \mathrm{~min})$, washed twice in SMN Buffer and resuspended in the same buffer. This procedure differs from the Tris treatments described in Chapters 4 and 7.

\section{$\mathrm{NH}_{2} \mathrm{OH}$ treatment of PS II membranes}

After thawing, spinach PS II membranes were diluted to $500 \mu \mathrm{g} \mathrm{Chl/ml} \mathrm{with} \mathrm{SMN}$ Buffer containing hydroxylamine (at $5 \mathrm{mM}$ final concentration). The membranes were 
treated for $1 \mathrm{~h}$ at $4^{\circ} \mathrm{C}$ in the dark with occasional mixing as described by Tamura and Cheniae (1987). The membranes were then collected by centrifugation $(30,000 \times \mathrm{g}, 10$ $\mathrm{min}$ ) and washed twice in SMN Buffer (at approx $500 \mu \mathrm{g} \mathrm{Chl} / \mathrm{ml}$ ) before resuspension in the sarne buffer. PS II membranes lose OEC Mn and the 17 and $24 \mathrm{kDa}$ proteins, but retain the $33 \mathrm{kDa}$ extrinsic protein, after this treatment, which is harsher than the hydroxylamine treatment described in Chapter 6.

\section{Isolation of $33 \mathrm{kDaprotein}$}

The $33 \mathrm{kDa}$ protein was isolated as described in Chapter 5 . The protein was stored frozen in SMN Buffer at $-70^{\circ} \mathrm{C}$.

\section{Photoactivation}

The procedures used here are modifications of the protocol for Mn photoactivation described by Tamura and Cheniae (1987). Mn-depleted (Tris- or hydroxylamine-treated) PS II membrane preparations were pelleted $(30,000 \times \mathrm{g}, 10 \mathrm{~min})$ and resuspended to $1 \mathrm{mg}$ $\mathrm{Chl} / \mathrm{ml}$ with 2x SMNC Buffer (40 mM MES-NaOH pH 6.5, 0.8 $\mathrm{M}$ sucrose, $30 \mathrm{mM} \mathrm{NaCl}$, $10 \mathrm{mM} \mathrm{MgCl} 2$ ). To portions of these samples, an equal volume of antibody or preimmune serum was added ( $1 \mu \mathrm{l}$ of serum per $\mathrm{mg}$ of $\mathrm{Chl}$ ). When testing different amounts of added serum, the serum was diluted with PBS before addition of an equal volume to the PS II membranes. These PS II membrane/antibody mixtures were incubated for 1 to $4 \mathrm{~h}$ in darkness at $4^{\circ} \mathrm{C}$ with occasional mixing. This mixture was then transferred to wells on a polystyrene cell culture plate (or petri dishes) containing an equal volume of $2 x$ freshly made photoactivation buffer $\left(2 \mathrm{mM} \mathrm{MnCl} 2,100 \mathrm{mM} \mathrm{CaCl}_{2}\right.$ and $2.00 \mu \mathrm{M}$ DCIP in SMN Buffer). The PS II membrane concentration at this point was $250 \mu \mathrm{g} \mathrm{ChV/ml}$. The PS II membranes were then photoactivated by incubation under low light (fluorescent lamps, approximately $1 \mathrm{~W} / \mathrm{m}^{2}$ at the sample) at room temperature $\left(21.23^{\circ} \mathrm{C}\right)$ for $40 \mathrm{~min}$. The samples were genty' swirled every 5 min to ensure mixing. After the photoactivation, the 
samples were transferred to darkness and kept on ice until measurement of oxygen evolution activity. Addition of purified $33 \mathrm{kDa}$ protein in SMN Buffer was at different points through the procedure and included a $30 \mathrm{~min}$ incubation in darkness at $4^{\circ} \mathrm{C}$ before continuation with the next step of the procedure. The controls for photoactivation were treated identically to the antibody samples except for addition of PBS instead of serum during the $1-4 \mathrm{~h}$ incubation.

\section{Oxygen evolution assays}

Each assay used $25 \mu \mathrm{g}$ of Chl per sample and was run as previously described (Chapter 5). Preparations lacking the $33 \mathrm{kDa}$ extrinsic protein were assayed with or without an additional incubation on ice with $35 \mu \mathrm{g}$ of purified $33 \mathrm{kDa}$ protein for $30 \mathrm{~min}$ to $1 \mathrm{~h}$ before the assay.

\section{Results and Discussion}

This chapter focuses on experiments aimed at characterizing possible antibody effects on PS II reaction centers by studying the Mn photoactivation protocol first applied to PS II-enriched membrane preparations by Tamura and Cheniae (1986). In Table 7-1, data from a representative preliminary experiment using Tris-treated PS II membranes without antibody incubation are presented. Next, in Tables 7-2 through 7-7, results from experiments using Tris-treated and hydroxylamine-treated PS II membranes to characterize the effects of anti-D1-a on the photoactivation process are given. Finally, in Tables 7-8 and 7-9, the results of a few preliminary experiments using Tris-treated and hydroxylaminetreated PS II membranes to study the effects of the other antibodies, anti-D1-b and anti-D2a, on the photoactivation process are given. 
The goal of the experiment whose results are presented in Table 7-1 was to reproduce the published experiments of Tamura and Cheniae (1987) using Tris-treated PS II membranes. The Tris-treated PS II membranes were photoactivated with or without the $33 \mathrm{kDa}$ extrinsic protein and the rate of oxygen evolution for each of these was then measured with or without the $33 \mathrm{kDa}$ protein. Tris treatment removes all three $(17,24$ and $33 \mathrm{kDa}$ ) extrinsic polypeptides along with the active $\mathrm{Mn}$, so addition of a slight molar excess of purified $33 \mathrm{kDa}$ protein and incubation on ice for 30-60 min was required for those samples which were to be photoactivated or assayed in the presence of $33 \mathrm{kDa}$ protein. All other samples were incubated under similar conditions with the addition of SMN Buffer to compensate for dilution. The amount of $33 \mathrm{kDa}$ protein required was described in Chapter 5 , where purified $33 \mathrm{kDa}$ protein was used to reconstitute the oxygen evolution of $\mathrm{CaCl}_{2}$-treated PS II membranes (which retain the active $\mathrm{Mn}$ but lack the three extrinsic proteins). Also, two illumination conditions which differed by a factor of 4-5 in light intensity (high light of $1 \mathrm{~W} / \mathrm{m}^{2}$ at the sample, which is approximately equal to the intensity described by Tamura and Cheniae, 1987) were used to examine the effects of light intensity on the photoactivation process.

The results shown in Table 7-1 give relative increases in oxygen evolution due to photoactivation for different samples which are comparable to those reported by Tamura and Cheniae (1987). The percentages for these samples which contain the $33 \mathrm{kDa}$ protein during assay for oxygen evolution are approximately $1 / 3$ to $1 / 2$ of the percentages calculated from their reported oxygen evolution rates, but the increases relative to control samples are in closer agreement. The main differences appear in the samples for which these results show very low oxygen evolution. These samples can be divided into twc groups. One group contains samples which were Tris-treated but received no illumination (first column of Table 7-1, but not including the untreated control). Tamura and Cheriae (1987) reported approximately $5 \%$ oxygen evolution for similarly treated samples. This 


\section{Table $7-1$}

Preliminary experiment of photoactivation of Tris-treated PS II membranes without antibody incubation. The photoactivation procedure used was similar to that described by Tamura and Cheniae (1987). The Tris-treated PS II membranes were photoactivated for 45 $\min$ (denoted as $\mathrm{hv}$ in the table) after an incubation with or without purified $33 \mathrm{kDa}$ extrinsic protein. The rate of oxygen evolution (denoted as $\mathrm{O}_{2}$ in the table) for each of these samples was then measured after an incubation with or without with purified $33 \mathrm{kDa}$ protein. The "low" and "high" light illuminations were both near the illumination intensity used by Tamura and Cheniae (1987).

Mlumination

Sample Type

None

Low

High

Control, untreated

Control, no illumination

hv without $33 ; \mathrm{O}_{2}$ without 33

hv without $33 ; \mathrm{O}_{2}$ with 33

hv with $33 ; \mathrm{O}_{2}$ with same 33
$555(100 \%)$

$\sim 0(\sim 0 \%)$

$$
\sim 0(-0 \%) \quad \sim 0(\sim 0 \%) \quad \sim 0(\sim 0 \%)
$$

$-0(\sim 0 \%) \quad 33(6 \%)$

$63(11 \%)$

$\sim 0(\sim 0 \%) \quad 81(15 \%) \quad 93(17 \%)$ 
may be due to more complete removal of the active $\mathrm{Mn}$ or of the $33 \mathrm{kDa}$ protein here than in their samples. The other group contains Tris-treated samples which were both photoactivated and assayed for oxygen evolution without addition of $33 \mathrm{kDa}$ protein (third row of Table 7-1). Tamura and Cheniae (1987) reported as high as 25\% oxygen evolution for similarly photoactivated and assayed samples. Their results can only be interpreted as residual $33 \mathrm{kDa}$ protein in their preparations, as shown by only a $5 \%$ increase in the oxygen evolution obtained by the addition of $33 \mathrm{kDa}$ protein after photoactivation but before the assay of oxygen evolution for their samples. These results are more consistent with the more recent data of Miller and Brudvig (1989) which showed a requirement for addition of purified $33 \mathrm{kDa}$ protein in order to measure appreciable oxygen evolution rates from Tris-treated PS II membranes photoactivated in the presence of $\mathrm{MnCl}_{2}$ and $\mathrm{CaCl}_{2}$. Finally, the two illuminations conditions which were used differed by a factor of 4-5 in light intensity, but gave relatively small differences in yield, indicating that the photoactivation process is not very sensitive to the exact light intensity in this weak light domain.

Table 7-2 shows the results of the first experiment addressing whether there were any effects of preincubation with anti-D1-a on the ability to photoactivate Tris-treated PS II membranes. Also, two illumination conditions which differed by a factor of 4.5 in light intensity (low light was $1 \mathrm{~W} / \mathrm{m}^{2}$ at the sample) were again used to confirm the insensitivity to these changes in light intensity of the photoactivation process. The yields of oxygen evolution after photoactivation were similar to those of the previous experiment (Table 71). Again, these results are more consistent with those of Miller and Brudvig (1989) than Tanura and Cheniae (1987) in that photoactivation occurs without the $33 \mathrm{kDa}$ protein and is detected only if oxygen evolution is measured with added $33 \mathrm{kDa}$ protein. As summarized in Table 7-2, each of the samples preincubated with $1 \mu$ l of anti-D1-a serum per $\mathrm{mg}$ of Chl shows slightly less yield of photoactivation than the corresponding sample 
Tabie 7-2

Photoactivation of Tris-treated PS II membranes following preincubations with anti-D1-a or pre-immune serum. After incubations with anti-D1-a or pre-immune serum, the Tristreated PS II membranes were photoactivated (hv) with different light intensities for $45 \mathrm{~min}$ after an incubation with or without purified $33 \mathrm{kDa}$ extrinsic protein. The rate of oxygen evolution $\left(\mathrm{O}_{2}\right)$ for each of these samples was then measured after an incubation with or without with purified $33 \mathrm{kDa}$ protein.

Preincubation

$\begin{array}{lccc} & & & \\ \text { Sample Type } & \text { Anti- } & \text { Non- } \\ \text { Preinc. } & \text { D1-a } & \text { Immune }\end{array}$

Control, untreated

$555(100 \%)$

Control, no illumination

$\sim 0(\sim 0 \%)$

hv without $33 ; \mathrm{O}_{2}$ with 33

low light

$76(14 \%) \quad 95(17 \%)$

hi light

$81(15 \%) \quad 92(17 \%)$

hv with $33 ; \mathrm{O}_{2}$ with same 33

low light

$92(17 \%) \quad 111(20 \%)$

hi light

$84(15 \%) \quad 95(17 \%)$ 
preincubated with $1 \mu$ of pre-immune serum per $\mathrm{mg}$ of $\mathrm{Chl}$. The differences are on the order of 2-3\% of the maximal photoactivation yield (which was assumed io be the rate of oxygen evolution prior to Tris treatment, as before). These differences represent a 12-20\% change of the rate of oxygen evolution for the anti-D1-a samples relative to the pre-immune samples. Finally, the light intensity again does not significantly alter the results, so illumination with $1 \mathrm{~W} / \mathrm{m}^{2}$ at the sample was used for the rest of the experiments.

The data presented in Table 7-3 is from an experiment to duplicate the results in Table 7-2 using illumination of $1 \mathrm{~W} / \mathrm{m}^{2}$ and to expand upon them. To confirm results indicating that no oxygen evolution is observed unless the $33 \mathrm{kDa}$ protein is added at some point prior to assay for oxygen evolution, this protein was again omitted for one series of samples. This observation was confirmed, as shown by the lack of photoactivation for all samples whose results are on the third, forth and fifth rows of Table 7-3. These results are again consistent with those reported by Miller and Brudvig (1989) while they contradict the earlier data of Tamura and Cheniae (1987). In order to quantitate the effect of anti-D1-a seen previously, the anount of serum used was as before for a given sample $(1 \mu \mathrm{l}$ of serum per $\mathrm{mg}$ of $\mathrm{Chl}$ ) and, additionally, it was increased by a factor of 10 for a matching sample (10 $\mu \mathrm{l}$ of serum per $\mathrm{mg}$ of $\mathrm{Chl}$ ). The results (Table 7-3) are approximately consistent with those of the previous experiment for the same amount of added serum. For the samples in which the amount of serum was increased 10-fold, an increase in the difference between the immune and pre-immune samples was expected. Surprisingly, the yield of photoactivation decreased for all samples in which the serum was increased. This effect was further investigated using hydroxylamine-treated PS II membrane preparations and the results are presented in the following tables.

As described thus far, Tris-treated PS II membranes gave little or no photoactivation unless the $33 \mathrm{kDa}$ protein was added before the measurement of oxygen 


\section{Table 7.3}

Photoactivation of Tris-treated PS II membranes following preincubations with different amounts of anti-D1-a or pre-immune serum. After incubations with anti-D1-a or preimmune serum, the Tris-treated PS II membranes were photoactivated (hv) by illumination at $1 \mathrm{~W} / \mathrm{m}^{2}$ for $45 \mathrm{~min}$ after an incubation with or without purified $33 \mathrm{kDa}$ extrinsic protein. The rate of oxygen evolution $\left(\mathrm{O}_{2}\right)$ for each of these samples was then measured after an incubation with or without with purified $33 \mathrm{kDa}$ protein.

\begin{tabular}{|c|c|c|c|}
\hline \multirow[b]{2}{*}{ Sample Type } & \multicolumn{3}{|c|}{ Preincubation } \\
\hline & $\begin{array}{c}\text { No } \\
\text { Preinc. }\end{array}$ & $\begin{array}{l}\text { Anti- } \\
\text { D1-a }\end{array}$ & $\begin{array}{l}\text { Non- } \\
\text { Immune }\end{array}$ \\
\hline Control, untreated & $555(100 \%)$ & & \\
\hline Control, no illumination & $\sim 0(\sim 0 \%)$ & & \\
\hline hv without $33 ; \mathrm{O}_{2}$ without 33 & $\sim 0(\sim 0 \%)$ & & \\
\hline and $1 x$ serum & & $\sim 0(\sim 0 \%)$ & $\sim 0(\sim 0 \%)$ \\
\hline and $10 x$ serum & & $\sim 0(\sim 0 \%)$ & $\sim 0(\sim 0 \%)$ \\
\hline hv without $33 ; \mathrm{O}_{2}$ with 33 & $40(7 \%)$ & & \\
\hline and $1 \mathrm{x}$ serum & & $49(9 \%)$ & $61(11 \%)$ \\
\hline and $10 \mathrm{x}$ serum & & $\sim 0(\sim 0 \%)$ & $\sim 0(\sim 0 \%)$ \\
\hline hv with $33 ; \mathrm{O}_{2}$ with same 33 & $81(15 \%)$ & & \\
\hline and $1 \mathrm{x}$ serum & & $76(14 \%)$ & $88(16 \%)$ \\
\hline and $10 x$ serum & & $\sim 0(\sim 0 \%)$ & $\sim 0(\sim 0 \%)$ \\
\hline
\end{tabular}


evolution. Additionally, when the $33 \mathrm{kDa}$ protein was added, Tris-treated PS II membranes gave generally low photoactivation yields (usually 15-20\%) and small differences for samples preincubated with immune serum relative to pre-immune serum. The results were quite similar whether the $33 \mathrm{kDa}$ protein was added before or after photoactivation, as long as it was added before the measurement of oxygen evolution. For these reasons, there was no advantage in using Tris-treated PS II membranes and, a series of experiments was performed using hydroxylamine-treated PS II membranes. Hydroxylamine treatment removes the active OEC Mn and most of the 17 and $24 \mathrm{kDa}$ proteins while retaining the $33 \mathrm{kDa}$ protein. These preparations give higher yields of photoactivation, reportedly up to 60\% (Tamura and Cheniae, 1987). Miller and Brudvig (1989) discussed their consistently attaining photoactivation yields of $40 \%$ for this type of sample.

The results of the first photoactivation experiment using hydroxylamine-treated PS II membranes are presented in Table 7-4. Again, the treatment of these samples removed all of their oxygen-evolving activity if no photoactivating illumination was performed. For photoactivations, two different illuminations were used as in Table 7-2, with the low light being $1 \mathrm{~W} / \mathrm{m}^{2}$ at the sample. The amount of added serum was as before ( $1 \mu \mathrm{l}$ of serum per $\mathrm{mg}$ of $\mathrm{Chl}$ ), and increased by a factor of 5 for a second sample of each treatment. Table 7 4 shows results which indicate that the samples preincubated with $1 \mu$ of serum gave good photoactivation, with yields in the range of $45-52 \%$. These samples showed a difference of $5-6 \%$ for the preincubation with immune vs pre-immune serum. Also, there is apparently little effect of light intensity on the yield of photoactivation, as was the case with Tris-treated PS II membranes. The 5-fold increase in serum gave large decreases in photoactivation for the samples incubated with both immune and pre-immune serum, as was seen for the 10-fold increase in serum used with the Tris-treated PS II membranes in Table 7-3. 


\section{Table 7.4}

Photoactivation of hydroxylamine-treated PS II membranes following preincubations with different amounts of anti-D1-a or pre-immune serum. After incubations with anti-D1-a or pre-immune serum, the hydroxylamine-treated PS II membranes were photoactivated (hv) with different light intensities for $45 \mathrm{~min}$.

Preincubation

$\begin{array}{lccc} & & & \\ \text { Sample Type } & \text { No } & \text { Anti- } & \text { Non- } \\ & \text { Preinc. } & \text { D1-a } & \text { Immune }\end{array}$

Control, untreated

Control, no illumination

High hv

High hv, 1x serum

High hv, $5 \mathrm{x}$ serum

Low hv

Low hv, 1x serum

Low hv, 5x serum
$585(100 \%)$

$-0(\sim 0 \%)$

$214(37 \%)$

$262(45 \%) \quad 295(50 \%)$

$77(13 \%) \quad 90(15 \%)$

$217(37 \%)$

$269(46 \%) \quad 302(52 \%)$

$81(14 \%) \quad 92(16 \%)$ 
The goals of the next experiment were to reproduce the previous results and test the yield of photoactivation for the same hydroxylamine-treated PS II membrane preparation used in the previous experiment (Table 7-4) after a $24 \mathrm{~h}$ frozen storage at $-80^{\circ} \mathrm{C}$. The results presented in Table 7-5 indicate that the yields of oxygen evolution for individual samples were diminished by approximately $10 \%$ relative to those shown in Table $7-4$. For this reason, further experiments utilized freshly prepared hydroxylamine-treated PS II membrane preparations from frozen PS II membrane aliquots. The sample preincubated with anti-D1-a ( $1 \mu \mathrm{l}$ of serum per $\mathrm{mg}$ of $\mathrm{Chl}$ ) still shows $5 \%$ less yield of oxygen evolution relative to the sample preincubated with pre-immune serum. The samples with 5-fold increase in serum again gave large decreases in photoactivation for the samples incubated with both immune and pre-immune serum, as was seen in the previous experiment.

The next experiment was intended to test a smaller range of serum to $\mathrm{Chl}$ ratios in order to see if there was a correlation between the amount of serum added and the yield of oxygen evolution following photoactivation. The results are shown in Table 7-6 for a series of added serum amounts representing 1/2,1,2 and 4 times the reference ratio added in previous experiments ( $1 \mu \mathrm{l}$ of serum per $\mathrm{mg}$ of $\mathrm{Chl})$. This experiment used freshly prepared hydroxylamine-treated PS II membrane preparations from frozen PS II membrane aliquots. However, the yields are all relatively low compared to the results in Table 7-4. These results are among those which show the inconsistency of the photoactivation procedure as described earlier and was also presented by Miller and Brudvig (1989). There is still a difference between the samples preincubated with anti-D1-a and those preincubated with pre-immune serum. The yield of oxygen evolution following photoactivation decreases with increasing amount of added serum for each pair of samples as had been previously observed. Surprisingly, the difference between samples preincubated with antiD1-a and those preincubated with pre-immune serum is greatest for the smallest amount of 
Table 7.5

Photoactivation of hydroxylamine-treated PS II membranes following preincubations with different amounts of anti-D1-a or pre-immune serum. After incubations with anti-D1-a or pre-immune serum, the hydroxylamine-treated PS II membranes were photoactivated (hv) by illumination at $1 \mathrm{~W} / \mathrm{m}^{2}$ for $45 \mathrm{~min}$.

Preincubation

\begin{tabular}{|c|c|c|c|}
\hline T. & No & Anti- & Non- \\
\hline e Type & & & Immune \\
\hline
\end{tabular}

Control, untreated

Control, no illumination

Photoactivated
Photoactivated, 1x serum

Photoactivated, $5 \mathrm{x}$ serum
$585(100 \%)$

$\sim 0(\sim 0 \%)$

$154(26 \%)$
$207(35 \%) \quad 235(40 \%)$

$63(11 \%) \quad 69(12 \%)$ 


\section{Table 7-6}

Photoactivation of hydroxylamine-treated PS II membranes following preincubations with different amounts of anti-D1-a or pre-immune serum. After incubations with anti-D1-a or pre-immune serum, the hydroxylamine-treated PS II membranes were photoactivated (hv) by illumination at $1 \mathrm{~W} / \mathrm{m}^{2}$ for $45 \mathrm{~min}$.

Preincubation

$\begin{array}{cccc} & & & \\ & \text { No } & \text { Ant- } & \text { Non- } \\ \text { Sample Type } & \text { Preinc. } & \text { D1-a } & \text { Immune }\end{array}$

Control, untreated

Control, no illumination

Photoactivated

Photoactivated, $1 / 2 \times$ serum

Photoactivated, 1 x serum

Photoactivated, $2 \times$ serum

Photoactivated, $4 \mathrm{x}$ serum
$585(100 \%)$

$\sim 0(\sim 0 \%)$

$188(32 \%)$

$118(20 \%) \quad 157(27 \%)$

$86(15 \%) \quad 118(20 \%)$

$25(4 \%) \quad 50(9 \%)$ 
serum and decreases as the amount of serum is increased. This may indicate effects of the added serum on these samples whose explanations are not as straight forward as expected.

The results shown in Table 7-7 are of a time course of illumination performed in order to see if the anti-D1-a effect had any dependance on the length of illumination. The illumination intensity was maintained constant at approximately $1 \mathrm{~W} / \mathrm{m}^{2}$. Again, somewhat low overall yields of photoactivation were obtained for these samples. The progression of yield with time was different for the samples preincubated with immune serum than for the other two sample types. For samples with no preincubation, the yields reach a maximum at $30 \mathrm{~min}$ and then decrease slightly with longer illuminations. The yields of samples preincubated with pre-immune serum also reach a maximum at $30 \mathrm{~min}$ and then plateau off or decrease slightly with longer illuminations. The yields of sampies preincubated with anti-D1-a serum, however, continue to increase all of the way out to the last time point, 60 min of illumination. The differences between immune and pre-immune samples also reach a maximum at $30 \mathrm{~min}$ and then decrease with longer illuminations. The differences at 30 and $45 \mathrm{~min}$ are similar to those previously observed for $45 \mathrm{~min}$ illuminations. These results indicate somewhat different effects of the lengths of illumination for the different sample types. The different time dependences may be explained by competing equilibria for the binding of $\mathrm{Mn}$ and antibody to sites important for the photoactivation process. Alternatively, there may be antibody protection against reaction center damage as was seen for oxygen evolution after prolonged incubations of $\mathrm{CaCl}_{2}$-treated $\mathrm{PS} \mathrm{II}$ membranes (Chapter 5).

Thus far, experiments focussing on the effects of anti-D1-a on the photoactivation process have been described. Table 7-8 presents preliminary data for the same process using preincubations of $\mathrm{NH}_{2} \mathrm{OH}$-treated PS II membranes with the other two antibodies, anti-D1-b and anti-D2-a. The different samples of each antibody were from three rabbits 
Table 7.7

Photoactivation time course of illumination of hydroxylamine-treated PS II mernbranes following preincubations with a constant amount of anti-Dl-a or pre-immune serum. After incubations with anti-D1-a or pre-immune serum, the hydroxylamine-treated PS II membranes were photoactivated (hv) by illumination at $1 \mathrm{~W} / \mathrm{m}^{2}$ for $0,15,30,45$ or 60 $\min$.

Preincubation

Control, untreated

Control, no illumination

Photoactivated, $0 \mathrm{~min}$

Photoactivated, 15 min

Photoactivated, $30 \mathrm{~min}$

Photoactivated, $45 \mathrm{~min}$

Photoactivated, $60 \mathrm{~min}$
$585(100 \%)$

$16(? ? \%)$

$\sim 0(? \%) \quad \sim 0(? \%) \quad \sim 0(? \%)$

$100(17 \%) \quad 99(17 \%) \quad 123(21 \%)$

$134(23 \%) \quad 145(25 \%) \quad 182(31 \%)$

$122(21 \%) \quad 160(27 \%) \quad 181(31 \%)$

$112(19 \%) \quad 164(28 \%) \quad 178(30 \%)$ 
Table $7-8$

Photoactivation of hydroxylamine-treated PS II membranes following preincubations with anti-D1-b, anti-D2-a or pre-immune serum. After the incubations with anti-D1-b, anti-D2-a or pre-immune serum, the hydroxylamine-treated PS II membranes were photoactivated (hv) by illumination at $1 \mathrm{~W} / \mathrm{m}^{2}$ for $45 \mathrm{~min}$.

Preincubation

$\begin{array}{lccc} & \text { No } & \text { Ant- } \\ \text { Sample Type } & \text { Preinc. } & \text { Non- } \\ \text { Immune }\end{array}$

Control, untreated

$585(100 \%)$

Control, no illumination

$29(5 \%)$

Photoactivated

$128(22 \%)$

Photoactivated, Anti-D1-b

$121(21 \%) \quad 69(12 \%)$

Photoactivated, Anti-D1-b

$103(18 \%) \quad 100(17 \%)$

Photoactivated, Anti-D1-b

$142(24 \%) \quad 126(22 \%)$

Photoactivated, Anti-D2-a

$137(23 \%) \quad 110(19 \%)$

Photoactivated, Anti-D2-a

$125(21 \%) \quad 101(17 \%)$

Photoactivated, Anti-D2-2

$132(23 \%) \quad 89(15 \%)$ 
which were producing antibody against the corresponding protein as screened by western blotting analysis (Chapter 4). The overall yields of oxygen evolution following photoactivation were again fairly low (15-25\%) for this type of sample (compare to Table 7-4). Although preliminary, the results seem to all show slightly greater yield for samples which were preincubated with immune sera relative to those samples which were preincubated with pre-immune sera. This is an interesting effect, which is the opposite of that observed when the preincubations used anti-Dl-a.

The results presented in Table 7-9 are from another preliminary experiment using anti-D1-b and anti-D2-a preincubations of Tris-treated PS II membranes. The purpose of this experiment was to determine if the increase in photoactivation yield seen in the previous experiment was due to a functional replacement of the $33 \mathrm{kDa}$ extrinsic protein by the binding of antibody. The results indicate that there is no such effect, as seen by the lack of photoactivation in samples treated with antibody without additional $33 \mathrm{kDa}$ protein for the assay of oxygen evolution. When purified $33 \mathrm{kDa}$ protein was added prior to assay for oxygen evolution, reasonable yields were obtained (compare to Table 7-2). Again, the yields for samples which were preincubated with immune sera were slightly higher than those for samples which were preincubated with pre-immune sera. This slight variation was not further investigated.

In summary, the experiments described in this chapter were aimed at characterizing possible antibody effects on PS II reaction centers by studying the Mn photoactivation protocol. As described in several publications (best explained by Miller and Brudvig, 1989), the photoactivation procedure is not easily reproducible. The results vary from one experiment to the next and the yields of oxygen evolution depend on factors not fully characterized. However, the results in this chapter indicate that the first antibody produced, anti-D1-a. may inhibit the photoactivation process. Small decreases in yield of oxygen 


\section{Table $7 m 9$}

Photoactivation of Tris-treated PS II membranes following preincubations with anti-D1-b, anti-D2-a or pre-immune serum. After the incubations with anti-D1-b, anti-D2-a or preimmune serum, the Tris-treated PS II membranes were photoactivated (hv) by illurnination at $1 \mathrm{~W} / \mathrm{m}^{2}$ for $45 \mathrm{~min}$ after an incubation with or without purified $33 \mathrm{kDa}$ extrinsic protein. The rate of oxygen evolution $\left(\mathrm{O}_{2}\right)$ for each of these samples was then measured after an incubation with or without with purified $33 \mathrm{kDa}$ protein.

\begin{tabular}{lccc}
\hline & \multicolumn{3}{c}{ Preincubation } \\
\cline { 2 - 4 } Sample Type & $\begin{array}{c}\text { No } \\
\text { Preinc. }\end{array}$ & $\begin{array}{c}\text { Anti- } \\
\text { serum }\end{array}$ & $\begin{array}{c}\text { Non- } \\
\text { Immune }\end{array}$ \\
\hline Control, untreated & $555(100 \%)$ & \\
Control, no illumination & $\sim 0(\sim 0 \%)$ & & \\
hv without 33; O2 without 33 & $\sim 0(\sim 0 \%)$ & & \\
Anti-D1-b & & $\sim 0(\sim 0 \%)$ & $\sim 0(\sim 0 \%)$ \\
Anti-D1-b & & $\sim 0(\sim 0 \%)$ & $\sim 0(\sim 0 \%)$ \\
Anti-D1-b & & $\sim 0(\sim 0 \%)$ & $\sim 0(\sim 0 \%)$ \\
Anti-D2-a & & $\sim 0(\sim 0 \%)$ & $\sim 0(\sim 0 \%)$ \\
Anti-D2-a & & $\sim 0(\sim 0 \%)$ & $\sim 0(\sim 0 \%)$ \\
Anti-D2-a & & $\sim 0(\sim 0 \%)$ & $\sim 0(\sim 0 \%)$ \\
hv without 33; O2 with 33 & & \\
Anti-D1-b & $85(15 \%)$ & & \\
Anti-D1-b & & $79(14 \%)$ & $56(10 \%)$ \\
Anti-D1-b & & $67(12 \%)$ & $65(12 \%)$ \\
Anti-D2-a & & $93(17 \%)$ & $82(15 \%)$ \\
Anti-D2-a & & $89(16 \%)$ & $73(13 \%)$ \\
Anti-D2-a & & $81(15 \%)$ & $65(12 \%)$ \\
& & $86(15 \%)$ & $57(10 \%)$ \\
\hline
\end{tabular}


evolution due to incubation with anti-Di-a before photoactivation were observed when using Tris-treated PS II membranes. Somewhat greater decreases in yield were observed with hydroxylamine-treated PS II membranes. The effect was influenced by the amount of added antiserum and the duration of illumination. Results for preincubation with the other two antibodies, anti-D1-b and anti-D2-a, are preliminary, but seem to indicate little or no effect on the yields of oxygen evolution after photoactivation. 


\section{ASSAY OF HIGH-AFFINITY Mn-BINDING SITES}

\section{Introduction}

In this chapter, experiments that examine antibody effects on the high-affinity $\mathrm{Mn}$ binding sites of PS II are presented. The antibodies used were those previously described which were raised against the peptides corresponding to two overlapping segments of the carboxyl end of the D1 protein and one antibody against the C-terminus of the D2 protein. The $\mathrm{Mn}^{2+} / \mathrm{DPC}$ competition for DCIP photoreduction assay was developed by Hsu et al. (1987) and subsequently used by the groups of Seibert (at SERI, in Colorado) and Inoue (at RIKEN, in Japan). A summary of each major contribution, along with the relevant conclusions and the remaining questions, are presented in order to explain this complicated assay and shed some light on the advances it has provided to the knowledge of $\mathrm{Mn}$-binding in PS II.

Hsu et al. (1987) examined the effect of exogenous electron donors on the oxidizing side of PS II by measuring light-induced electron transport through PS II. The electron transport was followed by monitoring the exogenous electron acceptor DCIP whose $590 \mathrm{~nm}$ absorption is quenched upon reduction by PS II. The initial slope of the DCIP quenching reaction was used to calculate the rate of electron transport through the photosystem. For intact PS II, where endogenous $\mathrm{Mn}$ is still bound, $\mathrm{H}_{2} \mathrm{O}$ acts as the ultimate electron donor by way of the Mn cluster of the OEC. After removal of Mn by Tris or hydroxylamine treatment, exogenous electron donors must be added in order to observe electron transport. Two such donors are $\mathrm{Mn}^{2+}$ (at mM concentrations) and DPC (at $\mu \mathrm{M}$ concentrations). Hsu et al. (1987) observed that when they used DPC as the donor to Tristreated PS II particles, $\mathrm{Mn}^{2+}$ at $0.1-10 \mu \mathrm{M}$ acts as an inhibitor of DPC photooxidation. 
They studied this competition between $\mathrm{Mn}^{2+}$ and DPC in detail and suggested that the "highly specific Mn(II) binding site on the oxidizing side of Photosystem II... is the site for the endogenous Mn in the O2-evolving complex of PS II." (Hsu et al. 1987). They based this conclusion on the following observations: 1) the presence of endogenous Mn blocks DPC donation to PS II, 2) Mn removal by Tris treatment stimulates electron transport with DPC as donor, 3) $\mathrm{Mn}^{2+}$ in low concentrations acts as a competitive inhibitor of DPC electron donation (but, see discussion of Preston and Seibert, 1991a, below), 4) $\mathrm{Mn}^{2+}$ binds to a site with high specificity and dissociation constant of about $0.15 \mu \mathrm{M}, 5) \mathrm{Mn}$ binding decreases with increasing ionic strength, indicating an electrostatic interaction, 6) the affinity of $\mathrm{Mn}$ binding also depends on the anions present with an ordering of effectiveness resembling the requirement for reactivation of oxygen evolution from $\mathrm{Cl}^{-}$depleted PS II (Critchley et al., 1982) and 7) the binding affinity of $\mathrm{Mn}^{2+}$ decreased as the $\mathrm{pH}$ was shifted from 6.1 to 7.7, consistent with the behavior of endogenous $\mathrm{Mn}$ which is destabilized at high $\mathrm{pH}$ and the observation that $\mathrm{OH}^{-}$reversibly inhibits oxygen evolution competitively with $\mathrm{Cl}^{-}$(Critchley et al., 1982; Homann, 1985).

The model proposed by Hsu et al. (1987), competitive $\mathrm{Mn}^{2+}$ inhibition of DPCsupported DCIP photoreduction at the same binding site for $\mathrm{Mn}^{2+}$ and DPC, and their conclusion that the highly specific Mn-binding site could correspond to the site for active OEC Mn on the intrinsic membrane proteins of PS II seem reasonable. The experimental evidence, however, is only circumstantial, although consistent, with their assertions. One of the main criticisms lies in the single $\mathrm{Mn}$ site postulated (along with one dissociation constant) while it is accepted that the active OEC contains four Mn per reaction center (reviewed by Amesz, 1983; Dismukes, 1986). Another question left unanswered was why the maximum inhibition by $\mathrm{Mn}^{2+}$ of DPC electron donation was only $50-70 \%$. Given that DPC does not alter the DCIP photoreduction rate measured when the $\mathrm{OEC}$ is intact $\left(\mathrm{H}_{2} \mathrm{O}\right.$ donates electrons through the endogenous $\mathrm{Mn}$ ) one would expect $\mathrm{Mn}^{2}+$ to reach $100 \%$ 
inhibition. As mentioned before, $\mathrm{Mn}^{2+}$ can also donate electrons to PS II (at approximately half the DPC rate) although at high concentrations compared to the $\mu \mathrm{M}$ levels where inhibition of DPC donation is observed. Also, side reactions, including direct redox reactions between $\mathrm{Mn}^{2+}, \mathrm{DPC}, \mathrm{DCIP}$ and their corresponding oxidized or reduced species, could also be influencing the observed changes in rates. Finally, Hoganson et al. (1989) reported measurements of rates of $\mathrm{YZ}^{+}$reduction where $\mathrm{Mn}^{2+}$ binding appeared to be weaker at $\mathrm{pH} 6$ than at $\mathrm{pH} 7.5$, in contrast to the results of Hsu et al. (1987) described above.

Preston and Seibert (1991a; 1991b) have recently addressed many of the problems explained above by investigating the mechanism of $\mathrm{Mn}^{2+}$ inhibition of DPC-supported DCIP photoreduction further and proposing a more complete model of the interactions. The interaction between $\mathrm{Mn}^{2+}$ and DPC appeared to have different mechanisms at different DPC concentration ranges. At the "high" concentration used for $\mathrm{Mn}^{2+/ D P C}$ competition assays, the mechanism was shown to be non-competitive, consistent with their results which had indicated different binding sites for $\mathrm{Mn}^{2+}$ and DPC (Preston and Seibert, 1991a). They also proposed a different mechanism in the "low DPC concentration range" where the electron donation from the two species seemed to be additive. Incorporating the evidence of electron donation by DPC to two different sites, probably $\mathrm{YZ}_{\mathrm{Z}}$ and $\mathrm{YD}$ (Blubaugh and Cheniae, 1990; Tamura et al., 1990), they proposed that Mn blocks access by DPC to only one of these, probably YZ. The second site of DPC electron donation was not well characterized and may also involve direct donation to P680 or donation to P680 through Cyt $b-559$. Also, they combined calculations with experimental results and explained why they believe that the side reactions explained above do not influence the initial rate of DCIP photoreduction measured in this assay. Finally, the photoactivation of Mn depleted preparations was proposed to require several sequential binding and oxidation steps (Tamura and Cheniae, 1987) and has been recently shown to require the binding of 
only one $\mathrm{Mn}^{2+}$ and its oxidation to $\mathrm{Mn}^{3+}$ before the second $\mathrm{Mn}^{2+}$ ion can bind and be oxidized, which then allows the last two $\mathrm{Mn}^{2+}$ ions to bind (Miller and Brudvig, 1990). The $\mathrm{Mn}^{2+}$ competition of DPC photooxidation is proposed by Preston and Seibert (1991b) to measure four different "Mn-binding sites" (these may provide four ligands to anywhere from one to four Mn ions). In the same report, they provide measurements of $\mathrm{Mn}$ content which show 1.0 Mn bound per reaction center (photoactivation conditions) and 3.2 $\mathrm{Mn}$ bound per reaction center ( $\mathrm{Mn}^{2+} / \mathrm{DPC}$ assay conditions). This result is most consistent with the assignment of four high-affinity Mn-binding sites being measured by the $\mathrm{Mn}^{2}+\mathrm{DPC}$ assay and explains the difference in $\mathrm{pH}$ dependence reported by Hoganson et al. (1989), under whose photoactivation conditions only one $\mathrm{Mn}^{2+}$ is expected to bind.

Tamura et al. (1989a) showed the connections between photoligation of $\mathrm{Mn}$ as described in Chapter 7, chemical modification by DEPC, the involvement of histidine residues on the D1 protein (and possibly the D2 protein) and the $\mathrm{Mn}^{2+} / \mathrm{DPC}$ competition assay developed by Hsu et al. (1987). They described the following results: 1) oxygen evolution activity of PS II membranes was not changed by DEPC treatment, but the capability to photoligate $\mathrm{Mn}$ to $\mathrm{NH}_{2} \mathrm{OH}$-treated PS II membranes (as measured by $\mathrm{Mn}$ quantitation) was lost after incubation with DEPC, 2) photoreduction of DCIP with either DPC or $\mathrm{Mn}^{2+}$ as the electron donor was reduced, but at a much slower rate than the loss of photoactivation activity, 3) the specific modification of histidine residues by DEPC was shown by the $\mathrm{pH}$ dependence with $\mathrm{pK}_{\mathrm{a}}$ of 6.9 and the $\mathrm{NH}_{2} \mathrm{OH}$ reversibility of the DEPC effect on photoactivation, 4) previously photoligated $\mathrm{Mn}$ inhibited the modification by DEPC, 5) treatment with DEPC greatly decreased Mn-binding affinity as shown by the $\mathrm{Mn}^{2+} / \mathrm{DPC}$ photooxidation assay and also decreased the rate of photoactivation and 6) many PS II proteins were radioactively labeled by [14C]-DEPC, but labeling of the D1 protein and the D1/D2 protein dimer were suppressed by photoligated Mn (involvement of the D2 protein was not confirmed due to heavy labeling in the corresponding region of the 
gel). Of main importance to this section are the demonstration that DEPC modification alters the amount of $\mathrm{Mn}^{2}+$ inhibition of DPC electron donation as measured by DCIP photoreduction, that modification by DEPC is specific for histidine residues and labels the D1 protein (and possibly the D2 protein) and that DEPC treatment prevents the photoligation of Mn. Also, the authors speculated that possible residues involved in the DEPC modification (and, therefore, also Mn-binding) include: His-190 and/or His-337 on at least the D1 protein. They cannot, however, exclude His-92 and His-332 of the D1 protein as possible Mn ligands for which the symmetrical amino acids on the D2 protein are no. histidines.

Seibert et al. (1989) proposed that the high-affinity Mn-binding site measured by the $\mathrm{Mn}^{2+}$ inhibition of DPC-stimulated DCIP photoreduction described by Hsu et al. (1987) can be divided into at least two different components. They showed that PS IIenriched membranes from the LF-1 mutant of Scenedesmus obliquus apparently contain half of the Mn-binding site measured for WT Scenedesmus preparations. Using DEPC (the histidine chemical modifier described above) they showed that half of the Mn-binding site of WT Scenedesmus (or spinach or wheat) preparations is blocked after modification. This component is not available in the LF-1 Scenedesmus preparation, as indicated by no change in $\mathrm{Mn}^{2+}$ inhibition after DEPC modification. They also showed that LF-1 membranes cannot be photoactivated, consistent with the requirement of the full highaffinity $\mathrm{Mn}$-binding site for photoactivation described by Tamura et al. (1989b). Another important result was the demonstration that the full high-affinity Mn-binding site is present in the isolated reaction centers complex (D1/D2/Cyt $b-559 / 4.2 \mathrm{kDa}$ proteins), limiting the possible proteins which might provide these ligands to Mn. Finally, they too speculated on the possible residues responsible for the observed DEPC modification. They considered His-332 and His-337 of the D1 protein to be the primary candidates based on the proposed steric hindrance of this component of the Mn-binding site in the LF-1 mutant. They could 
not eliminate His-92 of the D1 protein or possible involvement of the D2 protein, on which they proposed His-190 could also be considered.

Preston and Seibert (1989) regenerated the blocked component of the high-affinity Mn-binding site of membranes (but not thylakoids) from the L.F-1 mutant of Scenedesmus obliquus by mild protease treatment with papain, subtilisin or carboxypeptidase $\mathbb{A}$. They performed DEPC modification of the protease-treated LF-1 membranes for which they observed the same results as with WT Scenedesmus or spinach and concluded the native site had become accessible. Finally, they were unsuccessful in photoactivating the protease-treated membranes, indicating that the product was still unable to perform this function, probably because the protease cleavages were not identical to the processing which occurs upon insertion of the D1 protein into the thylakoid membrane. This observation is consistent with the indication that the $-\mathrm{COOH}$ group of Ala-344 of the Cterminus of the processed D1 protein provides a ligand to OEC Mn (B. Diner, Du Pont, Wilmington, DE, unpublished results), but it would be a ligand not detected by the $\mathrm{Mn}^{2+} / \mathrm{DPC}$ assay.

In a preliminary report, Preston and Seibert (1990) proposed that the high-affinity Mn-binding site consists of four separately identifiable components, "corresponding to the four Mn required for functional $\mathrm{O}_{2}$ evolution." They based this conclusion on studies using combinations of proteases and amino acid chemical modifiers to alter the amount of $\mathrm{Mn}^{2+}$ inhibition of DPC-stimulated DCIP photoreduction in the assay described by Hsu et al. (1987). The results of protease and amino acid chemical modifier studies, along with studies of the mechanism of the Mn2+/DPC assay discussed above, were explored further by Preston and Seibert (1991a, 1991b). In Preston and Seibert (1991a), they used EDC (a carboxyl group modifier) and found that it blocks all of the high-affinity Mn-binding site available in the LF-1 mutant of Scenedesmus obliquus and half of the Mn site in spinach or WT Scenedesmus, the half insensitive to DEPC (the histidine modifier previously used). 
Again, $\mathrm{MnCl}_{2}(2 \mathrm{mM})$ provides complete protection from EDC modification, while six other divalent ions were ineffective. They also showed the EDC and DEPC effects to be mutually exclusive and specific to the lumenal side of the thylakoid membrane. An important result was that the removal of the two more loosely bound of the four OEC Mn by aging $\mathrm{CaCl}_{2}$-treated membranes in low $\mathrm{NaCl}$ buffer (Ono and Inoue, 1985; Cole et al., 1987; Seibert et al., 1988) uncovers the EDC-sensitive half of the Mn site and not the DEPC-sensitive half of the site. This result is strong evidence that the $\mathrm{Mn}^{2+} / \mathrm{DPC}$ assay is detecting ligands which correlate to at least two functional Mn and, possibly, all four.

In their most recent publication, Preston and Seibert (1991b) combined the amino acid chemical modifiers described above with protease treatments in order to better define the high-affinity $\mathrm{Mn}$-binding site using the $\mathrm{DPC} / \mathrm{Mn}^{2+}$ non-competitive inhibition assay for DCIP photoreduction (Preston and Seibert, 1991a). In Table 8-1, a summary of their results, which they used as proof in dividing the site into four independent components, is presented. Basically, their data indicate that the DEPC-sensitive and EDC-sensitive halves of the high-affinity site can each be divided into two components which demonstrate differential sensitivity to the proteases used (see Table 8-2 for interpretation of their results). The two DEPC-sensitive components (histidine residues) are most exposed to proteases, one of them removable by three of the enzymes used, and both accessible in the presence of the extrinsic polypeptides. The two EDC-sensitive components (carboxylcontaining residues) are more protected, neither of them being accessible when the $33 \mathrm{kDa}$ protein is present, and one becoming available to one of the enzymes upon its removal while the other was not sensitive to any of the proteases used. They proposed the following as likely residues for the location of the DEPC-sensitive components of the highaffinity site: His-92, His-332 and His-337 on the D1 protein along with His-62, His-88 and His-337 on the D2 protein. The strongest possibilities for residues of the EDCsensitive components are given as any carboxyl-containing residue on the C-terminal ends 


\section{Table 8-1}

Combination of treatments with amino acid chemical modifiers and proteases in order to define the high-affinity Mn-binding site using the $\mathrm{Mn}^{2+} / \mathrm{DPC}$ competition assay for DCIP photoreduction (Preston and Seibert, 1991a, 1991b and unpublished results). For a single sample, the rate of DCIP photoreduction in the presence of $10 \mu \mathrm{M} \mathrm{MnCl} 2$ divided by the rate in the absence of $\mathrm{MnCl}_{2}$ gives a fractional rate of DCIP photoreduction. As this number increases, the number of components of the $\mathrm{Mn}$-binding site available to $\mathrm{Mn}^{2+}$ decreases. Loss of $0,1,2,3$ or 4 components would ideally correspond to fractional rates of $0.50,0.625,0.75,0.875$ and 1.00 , respectively. Comparing data from simultaneous treatments (with amino acid chemical modifiers and proteases) against data from separate treatments allows for the identification of the amino acids involved (see Table 8-2).

\begin{tabular}{lccc}
\hline Enzyme & Enz. only & $\begin{array}{c}\text { Enzyme } \\
+ \text { DEPC }\end{array}$ & $\begin{array}{c}\text { Enzyme } \\
+ \text { EDC }\end{array}$ \\
\hline none & 0.50 & 0.75 & 0.75 \\
Carboxypeptidase A & 0.63 & 0.75 & 0.87 \\
Subtilisin & 0.62 & 0.75 & \\
CPase A + Subtilisin & 0.76 & & 0.87 \\
Trypsin (Tris-PS II) & 0.77 & & \\
Trypsin (NH2OH-PS II) & 0.63 & 0.75 & 0.88 \\
Staph. aureus V8 protease & 0.63 & & \\
CPase A + CPase B & 0.75 & 0.75 & \\
\hline
\end{tabular}




\section{Table 8-2}

Interpretation of data presented in Table 8-1. Comparing data from simultaneous treatments (with amino acid chemical modifiers and proteases) against data from separate treatments allows for the identification of the amino acids involved. Different protease or amino acid chemical modifier treatments affect various combinations of histidine and/or carboxyl-containing (Glu or Asp) residues. The high-affinity Mn-binding site as measured by the $\mathrm{Mn}^{2+} / \mathrm{DPC}$ non-competitive assay can be divided in this way into four discrete components (Preston and Seibert, 1991b).

\begin{tabular}{lcc}
\hline Enzyme or chem. modifier & $\begin{array}{c}\text { Missing \# of } \\
\text { Components }\end{array}$ & $\begin{array}{c}\text { Type of } \\
\text { Residue }\end{array}$ \\
\hline none & 0 & \\
DEPC & 2 & His, His \\
EDC & 2 & COOH, COOH \\
Carboxypeptidase A & 1 & His \\
Subtilisin & 1 & His \\
CPase A + Subtilisin & 2 & His, His \\
Trypsin (Tris-PS II) & 2 & His, COOH \\
Trypsin (NH2OH-PS II) & 1 & His \\
Staph. aureus V8 protease & 1 & COOH \\
CPase A + CPase B & 2 & His, His \\
\hline
\end{tabular}


of the D1 and D2 proteins. Of all these, they proposed only His-337 of the D1 protein as being a prime candidate for a ligand of the $\mathrm{Mn}$-binding site. Although they proposed the four components located by the Mn2+/DPC assay to be sites involved in photoligation of Mn during photoactivation and/or binding the functional OEC $\mathrm{Mn}$, they also provided some altemative explanations. These explanations include the possibility that protease and chemical modifier action at sites other than those directly ligating $\mathrm{Mn}$ could induce conformational changes and allosteric effects which could be mistaken as direct ligands to $\mathrm{Mn}$. Also, they pointed out that the Mn $2+/ \mathrm{DPC}$ components may, in fact, be any of two to four terninal ligands to each of the four $\mathrm{Mn}$ and that there is no certainty as to the actual number of Mn detected (any number from one to four being possible).

Recently, Seibert has investigated the components of the high-affinity Mn-binding site using the $\mathrm{DPC} / \mathrm{Mn}^{2+}$ non-competitive inhibition assay for $\mathrm{DCIP}$ photoreduction (Preston and Seibert, 1991a) on membrane preparations from site-specific mutants of amino acids on the D1 and D2 proteins provided to him by other investigators. One of these mutants in which His-337 of the D2 protein was replaced by tyrosine, has been characterized as still containing all four components of the Mn-binding site, but with an interesting decrease in affinity for the binding of $\mathrm{Mn}^{2+}(\mathrm{M}$. Seibert, SERI, Golden, $\mathrm{CO}$, personal communication). This could be explained as a removal of a strong ligand to Mn (His) and its replacement with a residue acting as a ligand, but more weakly (Tyr). In this case, one ligand to $\mathrm{Mn}$ has been changed but $\mathrm{Mn}^{2+}$ is still able to bind, in contrast with arnino acid chemical modification and protease treatment which seem to "remove" components of the Mn site as measured by a decrease in Mn ${ }^{2+}$ inhibition of DPC electron donation to PS II. The residue changed in the mutant, His-337 of the D2 protein, is also one of two possible histidine residues involved as a DEPC-sensitive component as shown by other recent experiments (M. Seibert, personal cornmunication). The second histidine residue was removed by treatment with both carboxypeptidase $\mathrm{A}$ (which cleaves $\mathrm{C}$-terminal 
amino acids, stops at Arg residues and, by itself, removes only one histidine component) and carboxypeptidase B (which digests away C-terminal Arg residues, allowing CPase A to continue digesting past Arg residues). The combination of these two proteases removes a second DEPC-sensitive component of the Mn-binding site, being either His-337 of the D2 protein or His-332 of the D1 protein.

In summary, this is a complex assay, and as has been described above, there ane many models and possible explanations consistent with the experimental data. The simplest model (M. Seibert, personal communication), however, which is consistent with all of the current data, is useful as a starting point for further predictions and experiments. The high-affinity $\mathrm{Mn}$-binding site as measured by the $\mathrm{Mn}^{2}+\mathrm{DPC}$ non-competitive assay can be divided into four discrete components (Preston and Seiber, 1991b). Probably only one of these components corresponds to the first Mn-binding site detected during photoactivation (see Chapter 7). Of these four components, two are histidine and the other two carboxyl-containing (Glu or Asp) residues. These amino acid residues are proposed to be four (of 12-16 total) terminal ligands to one, two, three or four Mn ions functional in the OEC of PS II. Each of these four components has the same binding affinity (KD of 0.3$0.4 \mu \mathrm{M})$ and, modification or removal of any number of components does not alter the binding affinity of the remaining components (M. Seibert, personal communication). If one modifies or removes one ligand to a specific $\mathrm{Mn}$, a decrease in affinity would be expected for binding of $\mathrm{Mn}$ to any other of its terminal ligands (as was observed with the mutant in which His-337 of the D2 protein was replaced by tyrosine, see above) because binding affinity is an additive phenomenon. This information from binding affinities, in cornbination with Mn quantitation studies and the appearance of two components upon aging and loss of two $\mathrm{Mn}$, is most consistent with the explanation of the four components as ligands to four separate $\mathrm{Mn}$ ions. 
In this chapter, the use of antibodies raised against the peptides corresponding to the two overlapping segments of the carboxyl end of the DI protein and one against the Cterminus of the D2 protein to test whether there is any effect of these antibodies on the four components of the high-affinity Mn-binding site as measured by the $\mathrm{Mn}^{2+} / \mathrm{DPC}$ noncompetitive assay (Preston and Seibert, 1991b) are explained. The experiments described in this chapter were done in collaboration with Christopher Preston and Michael Seibert of the Photoconversion Research Branch, Solar Energy Research Institute, Golden, CO and have been submitted for publication (Dalmasso et al., 1992). Only one of the three antibodies produced (anti-D1-a) had any effect on the Mn-binding site, an effect consistent with the rendering of one of the four components of the Mn-binding site inaccessible to $\mathrm{Mn}^{2+}$. This component was shown to be one of the two DEPC-sensitive (histidine) residues. The other two antibodies (anti-D1-b and anti-D2-a) and pre-immune serum from all three rabbits had no effect on the assay. These results, in combination with western blotting analysis (Chapter 4) and solution binding assays (Chapter 6), decrease the likelihood of the corresponding regions of peptides D1-b and D2-a as involved in $\mathrm{Mn}$ ligation and are most consistent with the proposal that His-337 on the D1 protein is a ligand in one of the high-affinity Mn-binding sites of PS II as described by Presion and Seibert (199lb).

\section{Procedures}

\section{PS Il membrane oreparation}

PS II membrane fragments were prepared from spinach leaves essentially as described by Berthold, et al. (1981), but including modifications from Ford and Evans (1983), Rutherford et al. (1984) and Dr. J.-L. Zimmermann (Service Biophysique, CENSaclay, France). The details of this preparation are presented in Chapter 4. 
Tris treatment of PS IImernbranes

Spinach PS II membranes were Mn-depleted by Tris-treatment as described in Chapter 4. This treatment, which is harsher than that presented in Chapter 7, was shown to be occasionally necessary for complete removal of $\mathrm{Mn}$ from spinach PS II membranes as measured by the Mn2+/DPC assay (Preston and Seibert, 1991a).

\section{Antibody incubations}

PS II membranes were incubated with antibody or with the appropriate pre-immune serum on ice at about $1 \mathrm{mg} \mathrm{Chl} / \mathrm{ml}$ for $4 \mathrm{~h}$. To a sample of $300 \mu \mathrm{g} \mathrm{Chl}, 100 \mu \mathrm{l}$ of either Buffer A, antibody or pre-immune serum was added. Samples were assayed for DPCsupported DCIP photoreduction immediately upon completion of the incubation without removing excess antibody.

\section{DEPC modification}

Histidine residues were modified with DEPC as described by Tamura et al. (1989a) prior to exposure to the antibodies. In addition to histidine, DEPC can, under various conditions, also modify cysteine, tyrosine, lysine, serine, arginine and the alpha-amino group of amino acids (Miles, 1977). Tamura et al. (1989a) concluded that under their conditions, which were reproduced here, DEPC specifically modifies histidine residues. They showed this by studying the $\mathrm{pH}$ dependence of reaction, chemical reversal using $\mathrm{NH}_{2} \mathrm{OH}$, rates of inactivation and examining the labeling of control extrinsic proteins. Spinach PS II membranes were incubated at $100 \mu \mathrm{g} \mathrm{Chl} / \mathrm{ml}$ with $500 \mu \mathrm{M} \mathrm{DEPC} \mathrm{(from} 100$ $\mathrm{mM}$ stock dissolved in ethanol) in SMN Buffer (0.4 M sucrose, $50 \mathrm{mM}$ MES-NaOH pH $6.5,20 \mathrm{mM} \mathrm{NaOH}$ ) for $60 \mathrm{~min}$ at $20^{\circ} \mathrm{C}$ in the dark. The reaction was stopped by addition of a 5-fold volume of $4^{\circ} \mathrm{C} 10 \mathrm{mM}$ histidine in SMN Buffer and pelleted by centrifugation $(30,000 \times \mathrm{g}, 10 \mathrm{~min})$. The pellet was resuspended in the previous final volume of SMN 
Buffer and washed twice. The final pellet was resuspended in $1 / 10$ the original incubation volume of SMN Buffer. Untreated controls were incubated and washed under the same conditions, but without DEPC, in parallel with the treated samples.

\section{High-affinity manganese assays}

DPC-stirnulated DCIP photoreduction was measured using an Aminco DW2a spectrophotometer in the splitbeam mode as described by Preston and Seibert (1991a). Samples consisted of $5 \mu \mathrm{g} \mathrm{Chl/ml} \mathrm{in} \mathrm{buffer} \mathrm{containing} 0.4 \mathrm{M}$ sucrose, $50 \mathrm{mM} \mathrm{MES}-\mathrm{NaOH}$ (pH 6.5), $20 \mathrm{mM} \mathrm{NaCl}, 200 \mu \mathrm{M}$ DPC and $30 \mu \mathrm{M}$ DCIP and the indicated amounts of $\mathrm{MnCl}_{2}$ added from $100 \mu \mathrm{M}$ or $5 \mathrm{mM}$ stocks prepared in assay buffer. Continuous, saturating red light was passed through a heat filter (Melles Griot 03MHG007) and a 630 nm cut-off filter (Schott RG630) and focused on the sample cuvette at a $90^{\circ}$ angle to the spectrophotometer beam. DCIP reduction was monitored at $600 \mathrm{~nm}$ with the photomultiplier protected from the sample illumination light by a $600 \mathrm{~nm}$ narrow bandpass filter (Melles Griot 03FIV045). The pathlength was $1 \mathrm{~cm}$ and an extinction coefficient of 13 per $\mathrm{mM}$ per crn (Armstrong, 1964) was used to calculate the rates of DCIP photoreduction from the initial slope of quenching of absorption after providing light.

\section{Results and Discussion}

The high-affinity Mn-binding assay was first published by Hsu et al. (1987) and its Mn2+/DPC non-competitive mechanism was later described by Preston and Seibert (1991a). This assay was used here to determine the effects of the three antibodies to the carboxyl ends of the D1 and D2 proteins (see Chapter 3) on the components of the highaffinity Mn-binding site of PS II. The arnino acid chemical modifier DEPC shown by Tamura et al. (1989a) to specifically modify histidine residues was used later in conjunction 
with the antibodies in order to define which of the four components of the high-affinity Mn-binding site described by Preston and Seibert (1991b) was altered by interaction with antibody.

Figure 8-1 shows the profile of a typical assay for $\mathrm{MnCl}_{2}$ inhibition of DPCstimulated DCIP photoreduction using Tris-treated PS II membranes. The PS II membranes for the experiments described in this chapter were Tris-treated as previously described in order to remove all the functional OEC Mn. Along with removal of the intrinsic $\mathrm{Mn}$, the 17,24 and $33 \mathrm{kDa}$ extrinsic polypeptides of PS II are also removed by Tris treatment. The maximum rates of DCIP photoreduction for these preparations with no added $\mathrm{MnCl}_{2}$ were generally $300-500 \mu$ moles DCIP reduced/mg Chl per $\mathrm{h}$. Under the conditions used in these experiments $(0.4 \mathrm{M}$ sucrose, $50 \mathrm{mM}$ MES- $\mathrm{NaOH}$ pH $6.5,20 \mathrm{mM}$ $\mathrm{NaCl}, 200 \mu \mathrm{M} \mathrm{DPC}$ and $30 \mu \mathrm{M}$ DCIP), $\mathrm{MnCl}_{2}$ inhibits DPC to DCIP photoreduction by about $50 \%$ (usually to within $2 \%$ ). This corresponds to a fractional rate of 0.50 as explained in Table 8-1. Maximum inhibition is seen between 2 and $5 \mu \mathrm{M} \mathrm{MnCl} 2$ with no further inhibition occurring at higher concentrations of $\mathrm{MnCl}_{2}$ up to $100 \mu \mathrm{M}$ (at this high $\mathrm{MnCl} 2$ concentration, a slight increase in rate is routinely observed, possibly due to electron donation from $\mathrm{Mn}^{2+}$ ). The average binding affinity of $\mathrm{Mn}^{2+}$ to the components of the high-affinity $\mathrm{Mn}$-binding site present in a given assay can be estimated as the $\mathrm{MnCl}_{2}$ concentration required to induce half of the maximum amount of inhibition (Tamura et al., 1989a). In the assay shown in Figure 8-1, the half-inhibition occurs at approximately 0.25 $\mu \mathrm{M} \mathrm{MnCl} 2$. This value is consistent with previously published values (estimated from this type of assay) which range from $0.15 \mu \mathrm{M}$ to $0.40 \mu \mathrm{M}$ (Hsu et al., 1987; Tamura et al., $1989 \mathrm{~b}$; Seibert et al., 1989).

Incubation of PS II membranes with serum containing antibodies to the carboxylterminal end of the D1 protein (anti-D1-a) for $4 \mathrm{~h}$ resulted in one of the four components of the high-affinity $\mathrm{Mn}$-binding site becoming unavailable for $\mathrm{Mn}^{2+}$ binding. This can be 


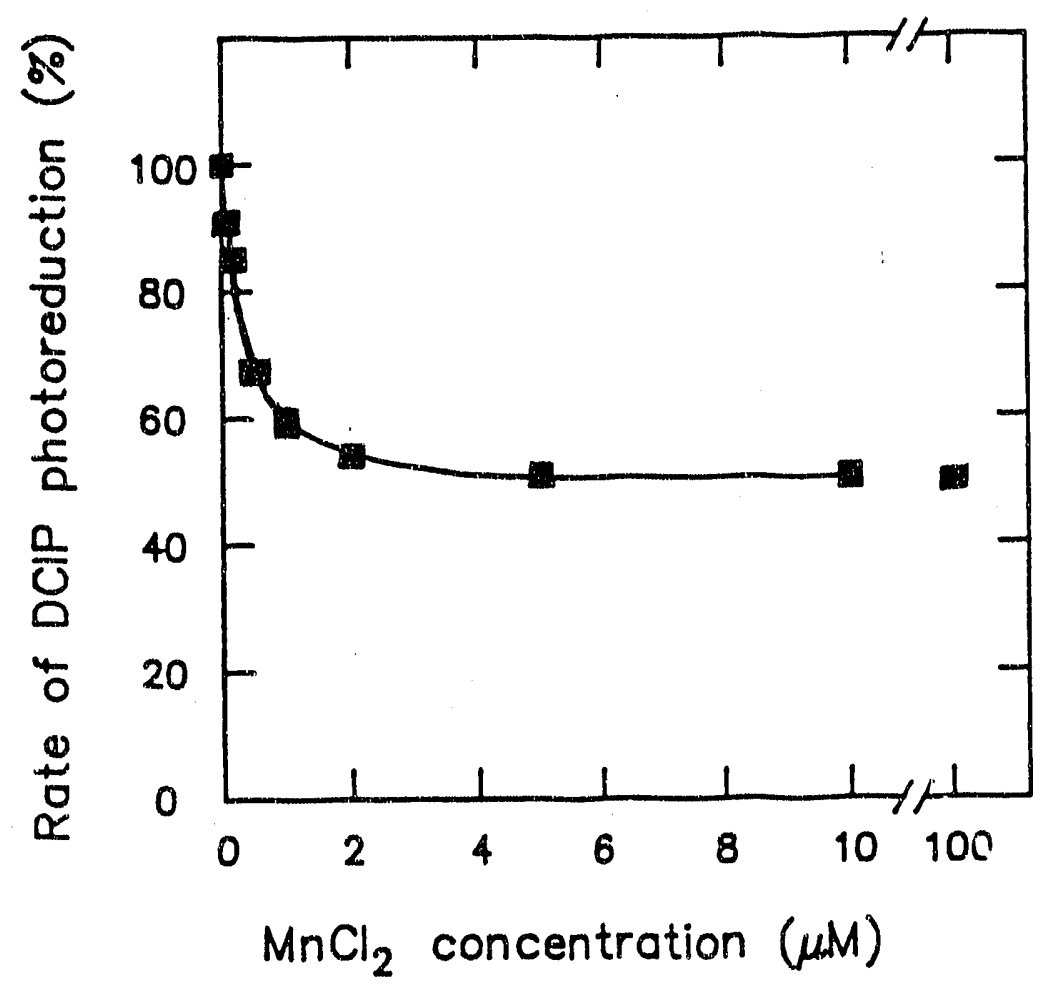

Figure 8.1: Example of $\mathrm{Mn}^{2}+/ \mathrm{DPC}$ assay using Tris-treated PS II membranes

Profile of a typical assay for $\mathrm{MnCl}_{2}$ inhibition of DPC-stimulated DCIP photoreduction using Tris-treated PS II membranes. The rate of DCIP photoreduction at a given $\mathrm{MnCl}_{2}$ concentration relative to the control rate with no $\mathrm{MnCl}_{2}$ is plotted against the $\mathrm{MnCl}_{2}$ concentration. The maximum rates of DCIP photoreduction for these preparations with no added $\mathrm{MnCl}_{2}$ were generally $300-500 \mu$ moles DCIP reduced/mg Chl per h. Maximum inhibition of $50 \%$ is seen between 2 and $5 \mu \mathrm{M} \mathrm{MnCl} 2$ with no further inhibition occurring at higher concentrations of $\mathrm{MnCl}_{2}$ up to $100 \mu \mathrm{M}$. 
seen as a reduction of the maximum $\mathrm{MnCl}_{2}$ inhibition of DPC to DCIP activity from $50 \%$ to $37 \%$ (Figure 8-2). This can also be expressed as a change in fractional rate from 0.50 to 0.63 as explained in Table 8-1. In contrast, incubation for the same period of time with the pre-immune serum from the same rabbit did not alter the number of binding sites available (a maximum of 50\% inhibition is still measured). The maximum inhibition is shown on the right side of this and subsequent figures, divided into a scale of four components, labeled to indicate the number of high-affinity Mn-binding components detectable in the sample as described by Preston and Seibert (1991b). The control PS II membranes used in this experiment had been incubated on ice in Buffer $\mathrm{A}$ for $4 \mathrm{~h}$ and show the same results as the incubation with pre-immune serum with all four components present. Increasing the incubation time for either the anti-D1-a serum or the pre-immune serum to $16 \mathrm{~h}$ did not alter the results (data not shown). Note that the half-inhibition occurs at approximately the same $\mathrm{Mn}^{2+}$ concentration for all three treatments, consistent with anti-D1-a affecting one component from each reaction center as opposed to totally inhibiting $1 / 4$ of all the centers.

Incubation of PS II membranes with the other antibodies (anti-D1-b or anti-D2-a), did not affect the number of high-affinity Mn-binding sites present (Figures 8-3 and 8-4). Their pre-immune serums likewise had no-effect. These results were not changed by increasing the incubation time to $16 \mathrm{~h}$ (data not shown). Although the actual binding sites for these two antibodies are not well characterized, they have been shown to bind to Tristreated PS II membranes in solution binding assays (see Chapter 6). Combining the solution binding data with the lack of effect on the $\mathrm{Mn}^{2}+/ \mathrm{DPC}$ assay decreases, but does not eliminate, the likelihood that these regions of the D1 and D2 proteins are involved in providing ligands for high-affinity $\mathrm{Mn}$.

It has been previously suggested that the carboxyl end of the D1 protein contains one of the two DEPC-sensitive components of the high-affinity Mn-binding site that are presumably histidine residues (Preston and Seibert 1991b). To determine whether the 


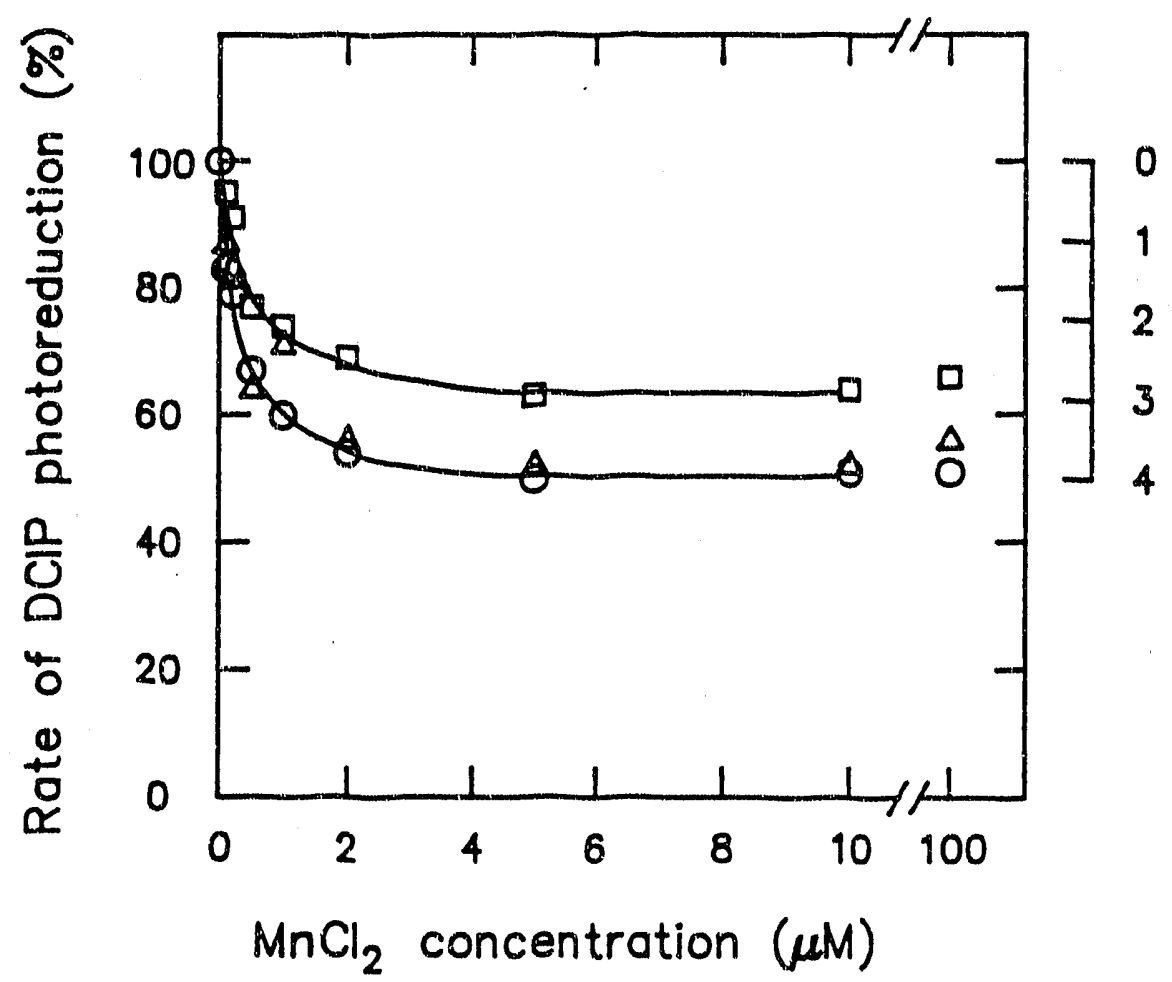

Figure 8-2: Results of $\mathrm{Mn}^{2+} / \mathrm{DPC}$ assay using Tris-treated PS II membranes and anti-D1-a

Inhibition of one component of the high-affinity Mn-binding site in PS II in the presence of anti-D1-a. Tris-treated PS II membranes were incubated for $4 \mathrm{~h}$ with SMN Buffer (O), anti-D1-a $(\square)$ or pre-immune serum $(\Delta) .100 \%$ activities were 449,379 and $451 \mu$ moles DCIP reduced/mg Chl per $h$ for SMN Buffer, anti-Dl-a and pre-immune serum treatments, respectively. The maximum inhibition is shown on the right side of this and subsequent figures, divided into a scale of four components, labeled to indicate the number of highaffinity Mn-binding components detectable in the sample as described by Preston and Seibert (1991b). 


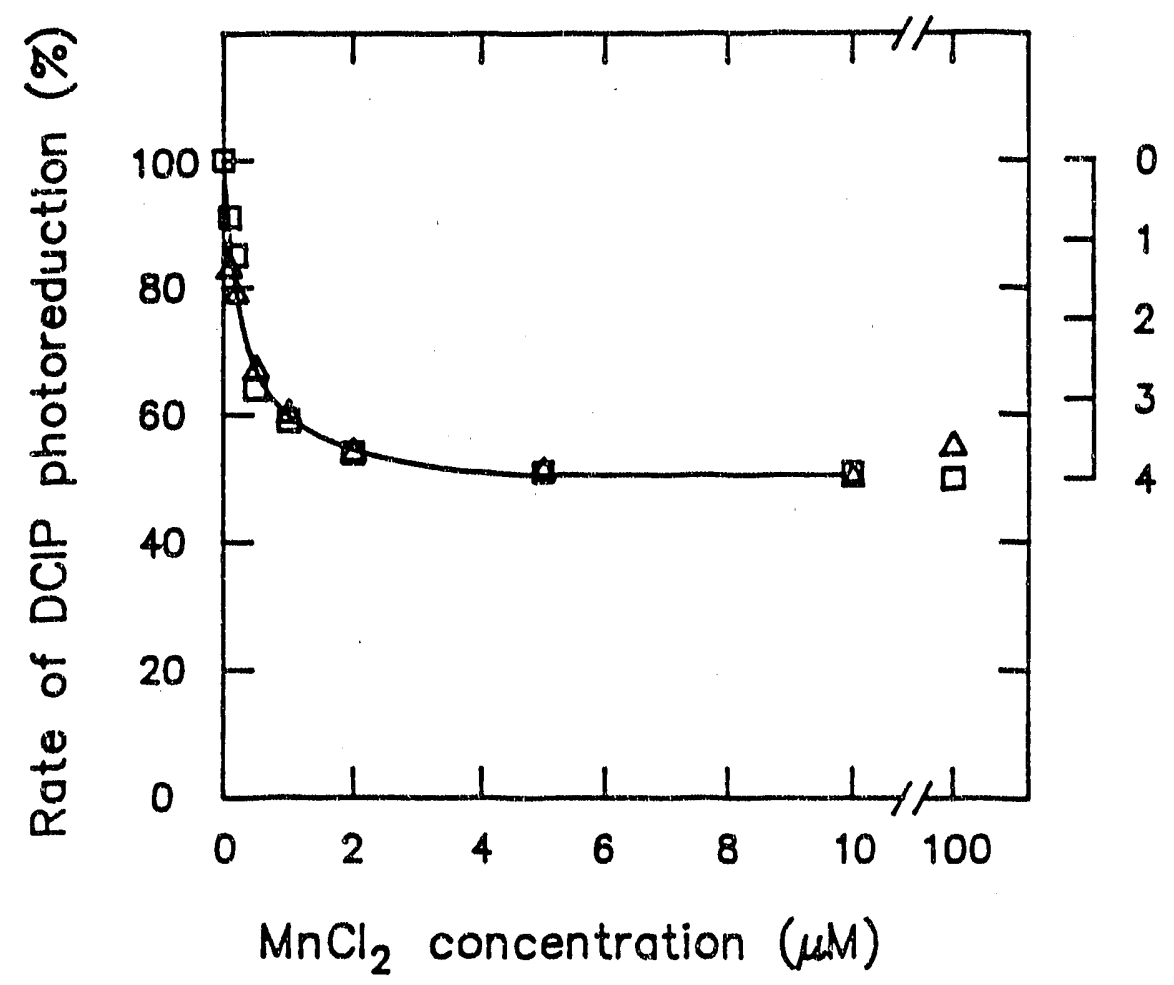

\section{Figure 8-3; Results of $\mathrm{Mn}^{2+} / \mathrm{DPC}$ assay using Tris-treated PS II membranes and anti-D1-b}

Lack of inhibition of the high-affinity Mn-binding site in PS II in the presence of anti-D1-b. Tris-treated PS II membranes were incubated for $4 \mathrm{~h}$ with the anti-D1-b ( $\square$ ) or preimmune serum $(\Delta) .100 \%$ activities were 469 and $538 \mu$ moles DCIP reduced/mg Chl per h for the anti-D1-b and pre-immune serum treatments, respectively. The maximum inhibition is shown on the right side, divided to show the number of high-affinity $\mathrm{Mn}$-binding components detectable in the sample, as described in Figure 8-2. 


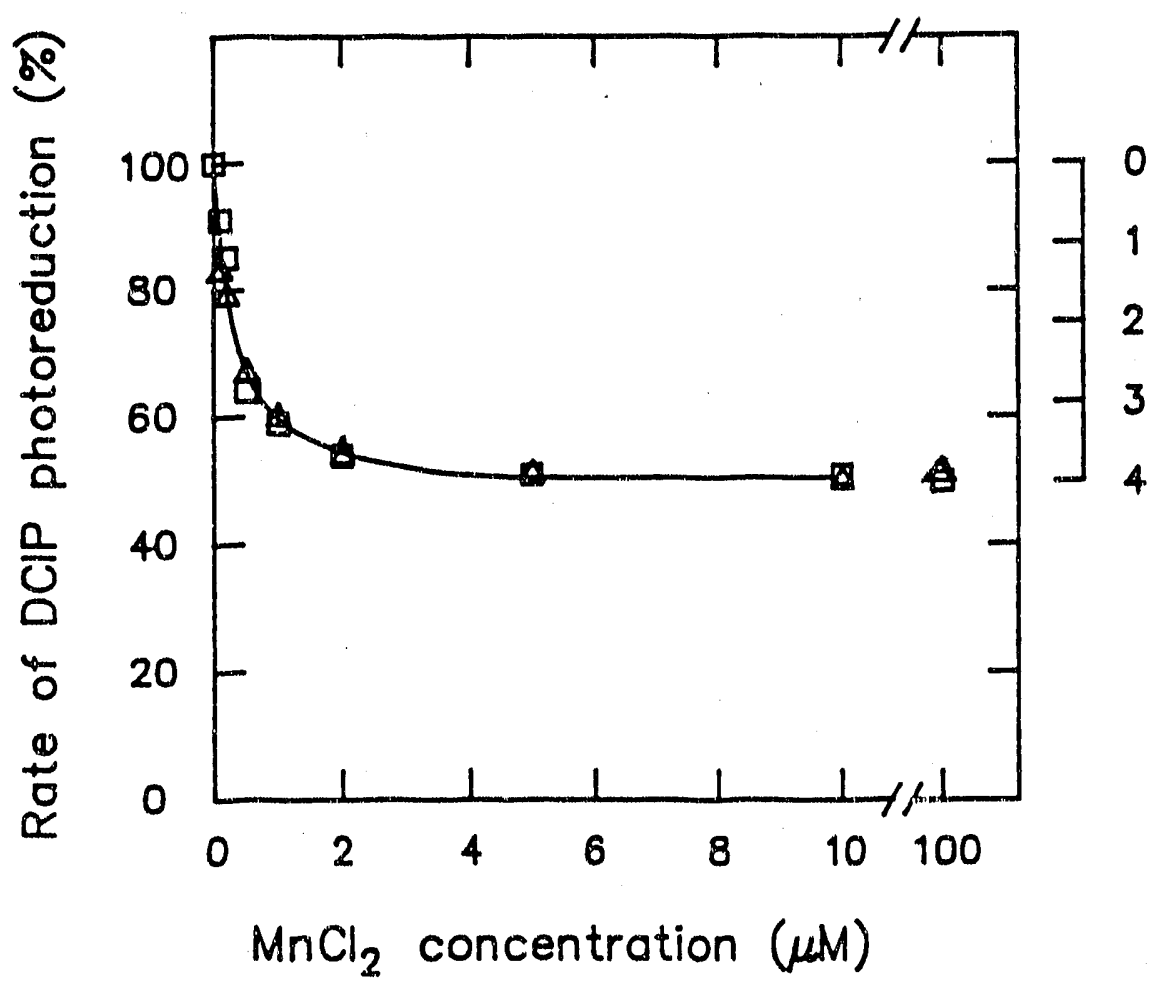

Figure 8-4: Results of $\mathrm{Mn}^{2+} / \mathrm{DPC}$ assay using Tris-treated PS II membranes and anti-D2-a

Lack of inhibition of the high-affinity Mn-binding site in PS II in the presence of anti-D2-a. Tris-treated PS II membranes were incubated for $4 \mathrm{~h}$ with the anti-D2-a (口) or pre-immune serum $(\Delta) .100 \%$ activities were 385 and $416 \mu$ moles DCIP reduced/mg $\mathrm{Chl}$ per $\mathrm{h}$ for the anti-D2-a and pre-immune serum treatments, respectively. The maximum inhibition is shown on the right side, divided to show the number of high-aftinity Mn-binding components detectable in the sample, as described in Figure 8-2. 
component of the high-affinity Mn-binding site affected by anti-D1-a was this component, Tris-treated PS II membranes were first modified with DEPC and then incubated with the serum. Modification of PS II membranes with DEPC affected two components as shown by reduction of $\mathrm{MnCl}_{2}$ inhibition of DPC to DCIP activity from $50 \%$ to $25 \%$ (Figure 8-5). This can also be expressed as a change in fractional rate from 0.50 to 0.75 as explained in Table 8-3 (see Table 8-3 for summary of results). This result contrasts to only one componeni being affected by anti-D1-a serum as discussed above (in this set of experiments, all control samples were treated as in the DEPC procedures, but in the absence of DEPC, in order to control for any artifacts during the incubations or washes as described in the procedures section). Incubation of DEPC-treated PS II membranes with anti-D1-a serum failed to further decrease the $\mathrm{MnCl}_{2}$ inhibition of DPC to DCIP activity. It has been previously shown that the four components of the high-affinity Mn-binding site affect the Mn-binding assay in a discrete manner (Preston and Seibert 1991b). Therefore, from the results shown in Figure 8-5, one can conclude that the component of the highaffinity Mn-binding site affected by anti-D1-a is one of the two blocked by modification of histidine residues by DEPC (see Table $8-4$ for interpretation of these results). These data, in combination with solution binding assay (Chapter 6) and western blotting assay results (Chapter 4), is further evidence that a DEPC-sensitive component of the high-affinity Mnbinding site is located on the carboxyl end of the D1 protein. This histidine would be located on the portion of D1-a which does not overlap with D1-b, making His-337 of the D1 protein a prime candidate for providing a ligand to high-affinity Mn.

In Figure 8-6, a schematic diagram of the reaction center core proteins, D1 and D2, is shown with the results of this chapter graphically depicted and combined with information from western blotting assays (Chapter 4) and solution binding assays (Chapter 6). The topology of the proteins in the membrane was adapted from that proposed by Trebst (1986) and later verified by Sayre et al. (1986), as described earlier. This fciding 


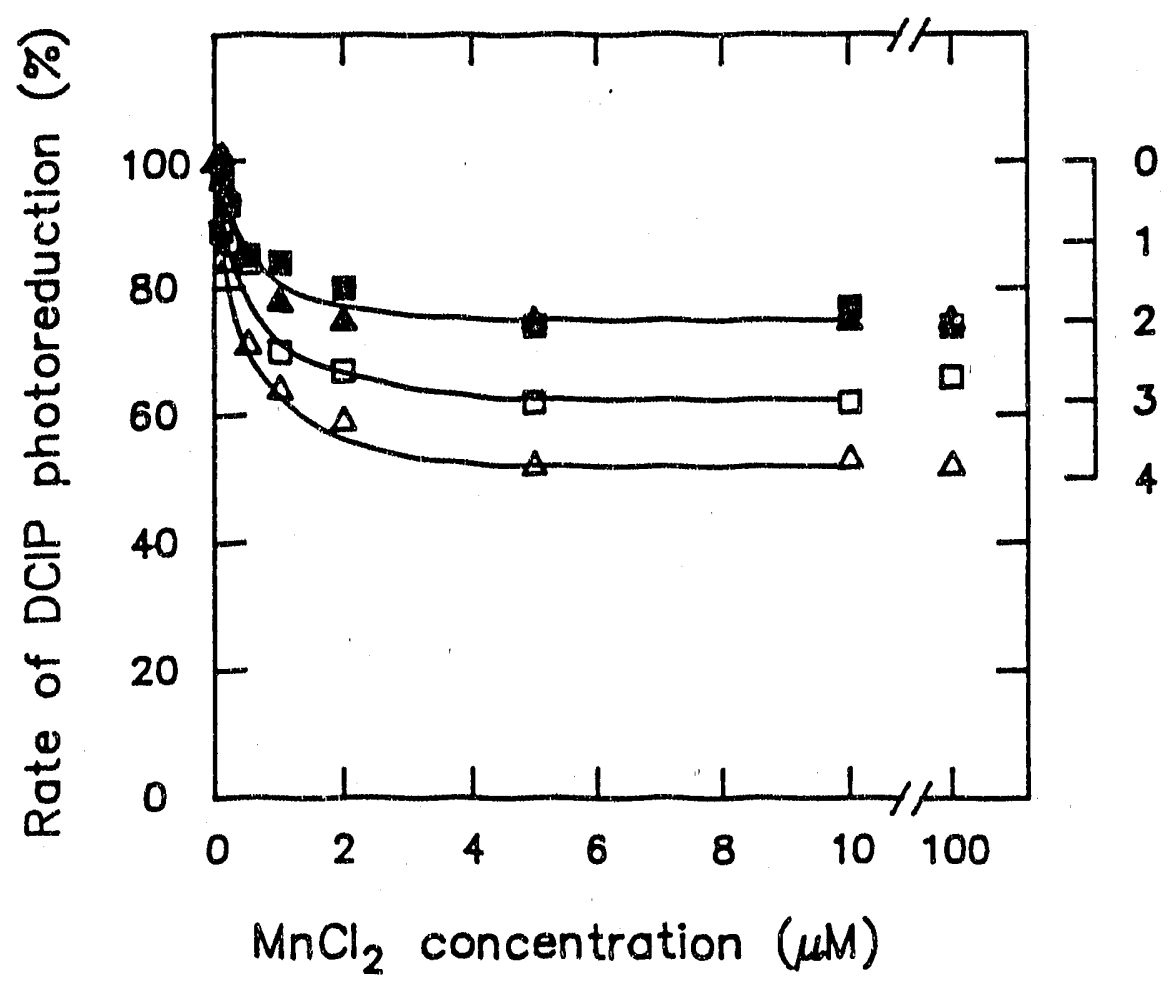

Figure 8-5: Results of $\mathrm{Mn}^{2+} / \mathrm{DPC}$ assay using Tris-treated PS II membranes, anti-D1-a and DEPC-modification

Anti-D1-a inhibits a DEPC-sensitive, high-affinity Mn-binding site. Tris-treated PS II membranes were incubated for $4 \mathrm{~h}$ with anti-D1-a $(\square, \square)$ or pre-immune serum $(\Delta, \Delta)$. Open symbols are control samples and closed symbols are samples modified with $500 \mu \mathrm{M}$ DEPC prior to incubation with the antibodies. $100 \%$ activities were 332, 222, 403 and 216 $\mu$ moles DCIP reduced/mg Chl per $h$ for the anti-D1-a, DEPC then anti-D1-a, pre-immune serum and DEPC then pre-immune serum treatments, respectively. The maximum inhibition is shown on the right side, divided to show the number of high-affinity Mnbinding components detectable in the sample, as described in Figure 8-2. 


\section{Table 8-3}

Use of the $\mathrm{Mn}^{2+} / \mathrm{DPC}$ competition assay for DCIP photoreduction and a combination of treatments with anti-D1-a, anti-D1-b or anti-D2-a sera and DEPC. Complete Mn $2+/ D P C$ competition assays are shown in Figures 8-2 through 8-5. For a single sample, the rate of DCIP photoreduction in the presence of $10 \mu \mathrm{M} \mathrm{MnCl}_{2}$ divided by the rate in the absence of $\mathrm{MnCl}_{2}$ gives a fractional rate of DCIP photoreduction. As this number increases, the number of components of the $\mathrm{Mn}$-binding site available to $\mathrm{Mn}^{2+}$ decreases. Loss of 0,1 , 2,3 or 4 components would ideally correspond to fractional rates of $0.50,0.625,0.75$, 0.875 and 1.00 , respectively. Comparing data from simultaneous treatments (with antisera and DEPC) against data from separate treatments allows for the identification of the amino acids involved (see Table 8-4).

\begin{tabular}{ccc}
$\begin{array}{c}\text { Spinach PS II } \\
+ \text { Antibody }\end{array}$ & $\begin{array}{c}\text { No chemical } \\
\text { treatment }\end{array}$ & + DEPC \\
\hline None* & 0.50 & 0.75 \\
anti-D1-a & 0.63 & 0.75 \\
anti-D1-b & 0.50 & \\
anti-D2-2 & 0.50 & \\
\hline
\end{tabular}

*Approximately the same for all corresponding control incubations (with pre-immune serum or Buffer A) 
Table 8-4

Interpretation of data presented in Table 8-3. Comparing data from simultaneous treatment (with antisera and DEPC) against data from separate treatments allows for the identification of the amino acids involved. Modification of PS II membranes with DEPC affects two histidine components as shown by a change in fractional rates of $\mathrm{MnCl}_{2}$ inhibition of DPC to DCIP activity from 0.50 to 0.75 . This result contrasts to only one component being affected by anti-D1-a serum as shown by a change in fractional rates from 0.50 to 0.63 . Incubation of DEPC-treated PS II membranes with anti-D1-a serum failed to further decrease the $\mathrm{MnCl}_{2}$ inhibition of DPC to DCIP activity. Therefore it can be concluded that the component of the high-affinity Mn-binding site affected by anti-D1-a is one of the two blocked by modification of histidine residues by DEPC.

\begin{tabular}{ccc}
$\begin{array}{c}\text { Preparation } \\
\text { and Treaunent }\end{array}$ & $\begin{array}{c}\text { Missing \# of } \\
\text { Components }\end{array}$ & $\begin{array}{c}\text { Type of } \\
\text { Residue }\end{array}$ \\
\hline Tris-PS II & 0 & none \\
+ DEPC & 2 & His, His \\
+ anti-D1-a & 1 & His* \\
\hline
\end{tabular}

*Concluded from sequential treatment with troth DEPC and anti-D1-a giving the same resuit as treatment with DEPC alone. 


\section{Figure 8-6: Diagram of D1 and $\mathrm{D} 2$ showing results of $\mathrm{Mn}^{2+} / \mathrm{DPC}$ assay combined with previous results}

Diagrammatic representation of the five transmembrane helix models showing the results of this chapter combined with information from westem blotting assays (Chapter 4) and solution binding assays (Chapter 6). The topology of the proteins in the membrane was adapted from that proposed by Trebst (1986) and later verified by Sayre et al. (1986), as explained earlier. As described in Figure 2-5, only lumenal histidine and carboxylcontaining amino acids (aspartic and glutamic acids) are shown, with the position number of histidines labeled explicitly. The two regions corresponding to the D1-b and D2-a peptides appear to not contain any of the components of the high-affinity $\mathrm{Mn}$-binding site and are therefore shaded. The region of the Dl-a peptide which does not overlap with the D1-b peptide contains one of the four components detected by the $\mathrm{Mn}^{2+}$ competition for DPC-stimulated DCIP photoreduction assay and is circled. 


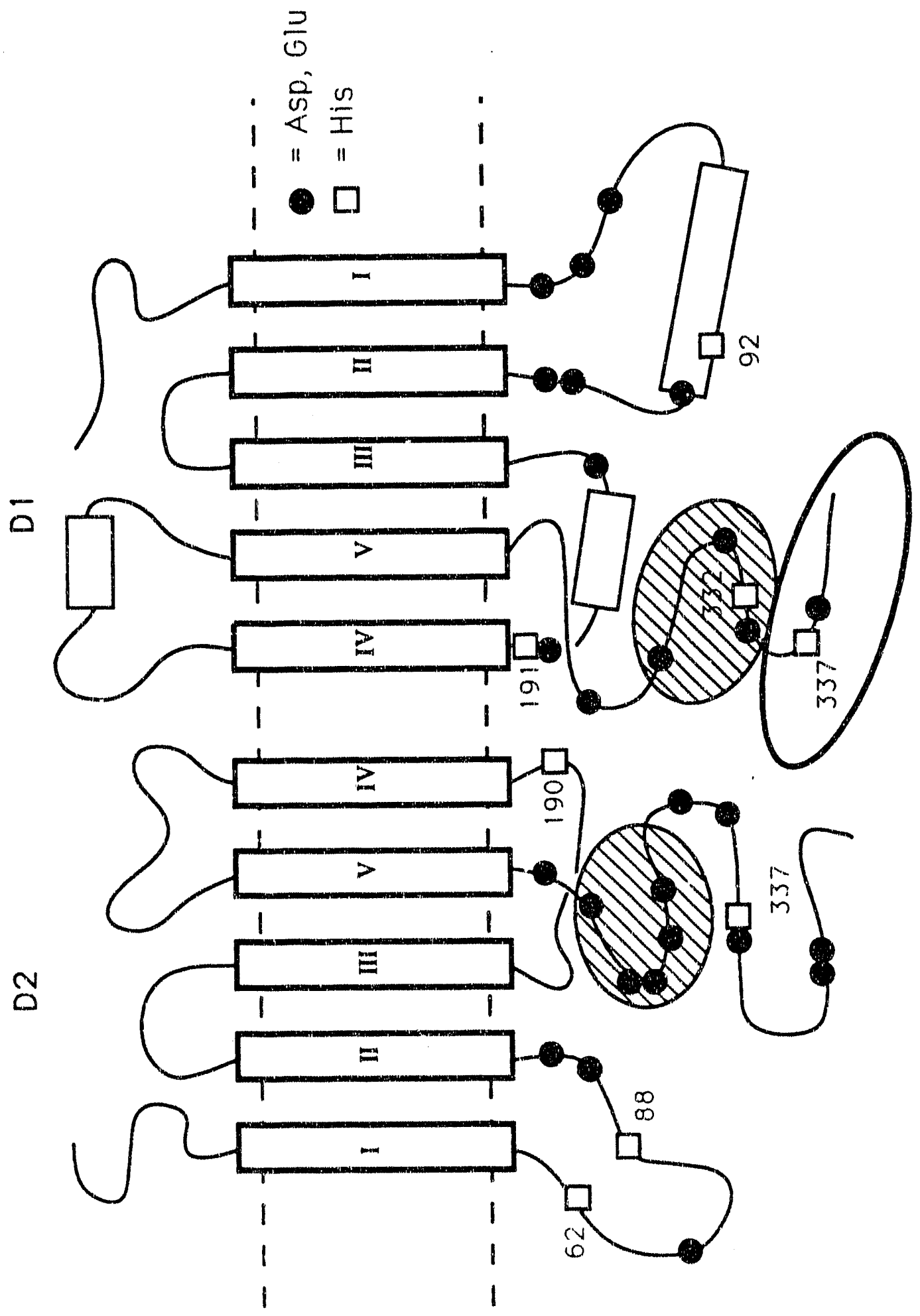


model is described in more detail in the first 2 chapters. To summarize, the two regions corresponding to the D1-b and D2-a peptides appear to not contain any of the components of the high-affinity Mn-binding site detected by the assay of $\mathrm{Mn}^{2+}$ competition for DPCstimulated DCIP photoreduction and are therefore shaded in Figure 8-6. The region of the D1-a peptide which does not overlap with the D1-b peptide contains one of the four components detected by the $\mathrm{Mn}^{2+}$ competition for DPC-stimulated DCIP photoreduction assay and is circled in Figure 8-6. Because of the results of the study which combined incubation with anti-D1-a and modification with DEPC, it is quite probable that His-337 of the $\mathrm{D} 1$ protein provides the $\mathrm{Mn}$ ligand which is detected by the $\mathrm{Mn}^{2+} / \mathrm{DPC}$ competition assay. 


\section{Appendix 1: List of Abbreviations}

\begin{tabular}{|c|c|}
\hline ATP & adenosine triphosphate \\
\hline $\mathrm{BCIP}$ & 5-bromo-4-chloro-3-indolyl phosphate \\
\hline BSA & bovine serum albumin \\
\hline Chl & chlorophyll \\
\hline CPase A & carboxypeptidase A \\
\hline CPase B & carboxypeptidase B \\
\hline Cyt & cytochrome \\
\hline $\mathrm{D}$ & Tyr 160 of the $D 2$ protein ( $D^{+}$is the source of EPR signal II) \\
\hline D1 & $32 \mathrm{kDa}$ (herbicide-tinding) PS II reaction center protein \\
\hline $\mathrm{D} 2$ & $34 \mathrm{kDa}$ PS II reaction center protein \\
\hline DCBQ & 2,6-dichloro-p-benzoquinone \\
\hline DCIP & 2,6-dichlorophenol indophenol \\
\hline DEPC & diethylpyrocarbonate \\
\hline DMSO & dimethyl sulfoxide \\
\hline $\mathrm{DPC}$ & diphenylcarbazide \\
\hline DTT & dithiothreitol \\
\hline EDTA & ethylenediaminetetraacetic acid \\
\hline ELISA & enzyme-linked immuno-sorbent assay \\
\hline EPR & electron paramagnetic resonance \\
\hline
\end{tabular}


ESEEM electron spin echo envelope modulation

EXAFS extended X-ray absorption fine structure

FAB

fast atom bombardment

Fab

binding fragment of IgG

Fc

constant fragment of $\operatorname{lgG}$

Hepes

4-(2-hydroxyethyl)-1-piperazineethanesulfonic acid

HPLC

high performance liquid chromatography

$\mathrm{kDa}$

kilodaltons

MES

4-morpholineethanesulfonic acid

NADP+

nicotinamide-adenine dinucleotide phosphate, oxidized form

NADPH

nicotinamide-adenine dinucleotide phosphate, reduced form

NB'T

nitroblue tetrazolium

OEC

oxygen-evolving complex

P680

PS II reaction center chlorophyll a complex (primary electron donor in PS II)

PAGE polyacrylamide gel ele trphoresis

PBS phosphate buffered saline

PPD purified protein derivative of tuberculin bacillus

PS 1 photosystem I

PS II photosystem II

SDS Sodium dodecyl sulfate 
SMN

SMNC

TFA

TPB

Tris

Tween-20

XANES

XAS

YD

YZ

Z
$0.4 \mathrm{M}$ sucrose, $20 \mathrm{mM}$ MES-NaOH pH 6.5, $15 \mathrm{mM} \mathrm{NaCl}, 10 \mathrm{mM}$ $\mathrm{MgCl}_{2}$

$0.4 \mathrm{M}$ sucrose, $50 \mathrm{mM}$ MES- $\mathrm{NaOH}$ pH $6.5,50 \mathrm{mM} \mathrm{NaCl}, 50 \mathrm{mM}$ $\mathrm{CaCl}_{2}$

trifluoroacetic acid

tetraphenylboron

tris(hydroxymethyl)aminomethane

polyoxyethylenesorbitan monolaurate

X-ray absorption near-edge structure

X-ray absorption spectroscopy

Tyr-160 of the D2 protein (same as D)

Tyr-161 of the D1 protein (same as Z)

Tyr-161 of the D1 protein (intermediate electron donor between the OEC Mn and P680) 
Appendix 2: List of Amino Acid 3 and 1 Letter Codes

$\begin{array}{lll}\text { Alanine } & \text { Ala } & \text { A } \\ \text { Arginine } & \text { Arg } & \text { R } \\ \text { Asparagine } & \text { Asn } & \text { N } \\ \text { Aspartic acid } & \text { Asp } & \text { D } \\ \text { Cysteine } & \text { Cys } & \text { C } \\ \text { Glutamine } & \text { Gln } & \text { Q } \\ \text { Glutamic acid } & \text { Glu } & \text { E } \\ \text { Glycine } & \text { Gly } & \text { G } \\ \text { Histidine } & \text { His } & \text { H } \\ \text { Isoleucine } & \text { Ile } & \text { I } \\ \text { Leucine } & \text { Leu } & \text { L } \\ \text { Lysine } & \text { Lys } & \text { K } \\ \text { Methionine } & \text { Met } & \text { M } \\ \text { Phenylalanine } & \text { Phe } & \text { F } \\ \text { Proline } & \text { Pro } & \text { P } \\ \text { Serine } & \text { Ser } & \text { S } \\ \text { Threonine } & \text { Thr } & \text { T } \\ \text { Tryptophan } & \text { Trp } & \text { W } \\ \text { Tyrosine } & \text { Val } & \text { Y } \\ \text { Valine } & \text { V }\end{array}$




\section{Appendix 3: List of Figures}

page

Fig. 1-1: $\quad$ Photosynthetic Z-scheme 3

Fig. 1-2: $\quad$ Schematic of PS II proteins 7

Fig. 1-3: $\quad$ S-state scheme 15

Fig. 2-1: $\quad$ Folding pattern of the D1 and D2 proteins 34

Fig. 2-2: $\quad$ Sequence comparison of D1 to L subunit 36

Fig. 2-3: $\quad$ Sequence comparison of D2 to M subunit 38

Fig. 2-4: $\quad$ Diagram of D1 and D2 with all possible Mn ligands labeled $\quad 42$

Fig. 2-5: $\quad$ Diagram of D1 and D2 showing regions to be synthesized 45

Fig. 2-6: $\quad$ Sequences of peptides synthesized 50

Fig. 2-7: $\quad$ Diagram of D1 and D2 showing synthesized peptide regions $\quad 52$

$\begin{array}{lll}\text { Fig. 2-8: } & \text { Possible peptide fragmentation patterns }\end{array}$

Fig. 4-1: $\quad$ PAGE of various PS II preparations $\quad 74$

Fig. 4-2: $\quad$ Western blot of gel in Fig. 4-1 using anti-D1-a 80

Fig. 4-3: $\quad$ Darker exposure of western blot of gel in Fig. 4-1 using anti-

D1-a $\quad 82$

Fig. 4-4: $\quad$ PAGE examples of the best resolution for the D1 and D2

proteins $\quad 86$ 
Fig. 4-5: Western blots using enzymatic detection

Fig. 4-6: Western blots of PS III and carboxypeptidase A-treated PS II preparations

Fig. 8-1: $\quad$ Example of $\mathrm{Mn}^{2}+/ \mathrm{DPC}$ assay using Tris-treated PS II membranes

Fig. 8-2: $\quad$ Results of $\mathrm{Mn}^{2+} / \mathrm{DPC}$ assay using Tris-treated PS II membranes and anti-D1-a

Fig. 8-3: $\quad$ Results of $\mathrm{Mn}^{2}+/ \mathrm{DPC}$ assay using Tris-treated PS II membranes and anti-Dl-b

Fig. 8-4: $\quad$ Results of $\mathrm{Mn}^{2+} / \mathrm{DPC}$ assay using Tris-treated PS II membranes and anti-D2-a

Fig. 8-5: $\quad$ Results of $M n^{2+}$ /DPC assay using Tris-treated PS II membranes, anti-D1-a and DEPC-modification

Fig. 8-6: $\quad$ Diagram of $D 1$ and D2 showing results of $M n^{2+} / D P C$ assay combined with previous results 


\section{REFERENCES}

Åkerlund, H.-E., Jansson, C. and Andersson, B. (1982) Biochim. Biophys. Acta 681, 110.

Alt, J., Morris, J., Westhoff, P. and Herrmann, R. (1984) Curr. Genet. 8, 597-606.

Amesz, J. (1983) Biochim. Biophys. Acta 726, 1-12.

Armstrong, J. McD. (1964) Biochim. Biophys. Acta 86, 194-197.

Arnon, D. I. (1949) Plant Physiol. 24, 1-15.

Babcock, G. T. (1987) in New Comprehensive Biochemistry, Vol. 15, Photosynthesis (Amesz, J., ed.) pp. 125-158, Elsevier, Amsterdam.

Berthold, D. A., Babcock, G. T. and Yocum, C. F. (1981) FEBS Lett. 134, 231-234.

Blankenship, R. E., Babcock, G. T. and Sauer, K. (1975) Biochim. Biophys. Acta 387, 165-175.

Blankenship, R. E. and Prince, R. C. (1985) Trends Biol. Sci. 10, 383.

Blubaugh, D. J. and Cheniae, G. (1990) Biochemistry 29, 5109-5118.

Brudvig, G. W., Beck, W. F. and de Paula, J. C. (1989) Annu. Rev. Biophys. Biophys. Chem 18, 25-46.

Chapman, D. J., Gounaris, K. and Barber, J. (1988) Biochim. Biophys. Acta 933, 423431.

Critchley, C., Baianu, I. C., Govindjee and Gutowsky, H. S. (1982) Biochim. Biophys. Acta 682, 436-445.

Cole, J. L., Yachandra, V. K., McDermott, A. E., Guiles, R. D., Britt, R. D., Dexheimer, S. L., Sauer, K. and Klein, M. P. (1987) Biochemistry 26, 59675973. 
Cooper, S. R., Dismukes, G. C., Klein, M. P. and Calvin, M. C. (1978) J. Amer. Chem. Soc. $100,7248-7252$.

Dalmasşo, E. A., Preston, C., Sauer, K., Hearst, J. E. and Seibert, M., (1992) Biochim. Biophys. Acta (submitted).

Debus, R. J., Barry, B. A., Babcock, G. T. and McIntosh, L. (1988a) Proc. Natl. Acad. Sci. USA 85, 427-430.

Debus, R. J., Barry, B. A., Sithole, I., Babcock, G. T. and McIntosh, L. (1988b) Biochemistry 27, 9071-9074.

Deisenhofer, J., Epp, O., Miki, K., Huber, R. and Michel, H. (1984) J. Biol. Chem. 259, 3900-3908.

Deisenhofer, J., Epp, D., Miki, K., Huber, R. and Michel, H. (1985) J. Mol. Biol. 180, 385-398.

Dekker, J. P., van Gorkom, H. J., Brok, M. and Ouwehand, L. (1984) Biochim. Biophys. Acta 764, 301-309.

DeRose, V. J. (1990) Ph.D Thesis, Lawrence Berkeley Laboratory, University of California, Berkeley, Lawrence Berkeley Laboratory Report LBL-30077.

DeRose, V. J., Yachandra, V. K., McDermott, A. E., Britt, R. D., Sauer, K. and Klein, M. P. (1991) Biochemistry 30, 1335-1341.

Diner, B. A., Ries, D. F., Cohen, B. N. and Metz, J. G. (1988) Nature 318, 618-624.

Dismukes, G. C. (1986) Photochem. Photobiol. 43, 99-115.

Dismukes, G. C. (1988) Chemica Scripta 28A, 99-104.

Dismukes, G. C. and Siderer, Y. (1981) Proc. Natl. Acad. Sci. USA 78, 274-278.

Edelman, M. and Reisfeld, A. (1978) in Chloroplast Development (Akoyunoglou, G. and Argyroudi-Akoyunoglou, J. H., eds.) pp. 641-652, Elsevier Biomedical Press, Amsterdam. 
Erickson, J. M., Rahire, M., Malnoë, P., Girard-Bascou, J., Pierre, Y., Bennoun, P. and Rochaix, J.-D. (1986) EMBO J. 5, 1745-1754.

Evelo, R. G., Styring, S., Rutherford, A. W. and Hoff. A. J. (1989) Biochim. Biophys. Acta 973, 428-442.

Ford, R. C. and Evans, M. C. W. (1983) FEBS Lett. 160, 159-164.

Frank, H. A., Hansson, Ö. and Mathis, P. (1989) Photosynth. Res. 20, 279-289.

Fukuhara, Y., Ise, Y. and Kakinuma, K. (1988) FEBS Lett. 229, 150-156.

Ghanotakis, D. F., Babcock, G. T. and Yocum, C. F. (1984a) Biochim. Biophys. Acta 765, 388-398.

Ghanotakis, D. F., Babcock, G. T. and Yocum, C. F. (1984b) FEBS Lett. 167, 127-130.

Ghanotakis, D. F., de Paula, J. C., Demetriou, D. M., Bowlby, N. R., Petersen, J., Babcock, G. T. and Yocum, C. F. (1989) Biochim. Biophys. Acta 974, 44-53.

Gingrich, J. C., Buzby, J. S., Stirewalt, V. L. and Bryant, D. A. (1988) Photosynth. Res. 16, 83-99.

Gingrich, J. C., Gasparich, G. E., Sauer, K. and Bryant, D. A. (1990) Photosynth. Res. $24,137-150$.

Goodin, D. B., Yachandra, V. K., Britt, R. D., Sauer, K. and Klein, M. P. (1984) Biochim. Biophys. Acta 767, 209-216.

Greenberg, B. M., Gaba, V., Mattoo, A. K. and Edelman, M. (1987) EMBO J 6, 2865 2869.

Guengerich, F. P., Wang, P. and Mason, P. S. (1981) Biochemistry 20, 2379-2385.

Guiles, R. D., Yachandra, V. K., McDermott, A. E., Cole, J. L., Dexheimer, S. L., Britt, R. D., Sauer, K. and Klein, M. P. (1990a) Biochemistry 29, 486-496.

Guiles, R. D., Zimmermann, J.-L., McDermott, A. E., Yachandra, V. K., Cole, J. L.., Dexheimer, S. L., Britt, R. D., Weighardt, K., Bossek, U., Sauer, K. and Klein, M. P. (1990b) Biochemistry 29, 471-485. 
Hansson, Ö., Andréasson, L.-E. and Vänngård, T. (1986) FEBS Lett. 195, 151-154.

Hearst, J. E. (1986) in Encyclopedia of Plant Physiology, New Series, Vol. 19, Photosynthesis II (Staehlin, L. A. and Arntzen, C. J., eds.) pp. 382-389, Springer-Verlag, Berlin.

Hearst, J. E. and Sauer, K. (1983) in Proc. $6^{\text {th }}$ Int. Congr. Photosynthesis, Vol. II, (Sybesma, C., ed.) pp. 355-359, S. Nijhoff/Junk, The Hague.

Hearst, J.:E. and Sauer, K. (1984) Z Naturforsch. 39C, 421-424.

Hoganson, C. W. and Babcock, G. T. (1988) Biochemistry 27, 5848-5855.

Hoganson, C. W. and Babcock, G. T. (1989) Biochemistry 28, 1448-1454.

Hoganson, C. W., Ghanotakis, D. F., Babcock, (j. T. and Yocum, C. F. (1989) Photosynth. Res. 22, 285-293.

Holschuh, K., Bottomley, W. and Whitfeld, P. R. (1984) Nucl. Acids Res. 12, 88198834.

Homann, P. H. (1985) Biochim. Biophys. Acta 809, 311-319.

Hsu, B-D., Lee, J-Y. and Pan, R-L. (1987) Biochim. Biophys. Acta 890, 89-96.

Hundal, T., Virgin, I, Styring, S. and Andersson, B. (1990) Biochim. Biophys. Acta $1017,235-241$.

Ikeuchi, M. and Inoue, Y. (1987) FEBS Lett. 210, 71-76.

Ikeuchi, M. and Inoue, Y. (1988) FEBS Lett. 241, 99.104.

Ikeuchi, M., Koike, H. and Inoue, Y. (1988) Biochim. Biophys. Acta 932, 160-169.

Innes, J. B. and Brudvig, G. W. (1989) Biochemistry 28, 1116-1125.

Joliot, P., Barbieri, G. and Chabaud, R. (1969) Photochem. Photobiol. 10, 309-329.

Kent, S. and Clark-Lewis, I. (1985) in Synthetic Peptides in Biology and Medicine

(Alitalo, K., Partanen, P. and Vaheri, A. eds.) Elsevier, Amsterdam. 
Kim, D. H., Brith, R. D., Klein, M. P. and Sauer, K. (1990) J. Amer. Chem. Soc. 112, 9389-9391.

Kok, B., Forbush, B. and McGiloin, M. (1970) Photochem Photobiol. 11, 457-476.

Kuwabara, T. and Murata, N. (1982) Plant Cell Physiol. 23, 533-539.

L.achmann, P. J., Strangeways, L., Vyakarnam, A. and Evan, G. (1986) in Synthetic Peptides as Antigens (Ciba Foundation S, "mposium 119) pp. 25-57, Wiley, Chichester.

Laemmli, U. K. (1970) Nature (Lond.) 227, 680-685.

Ljungberg, U., Åkerlund, H.-E. and Andersson, B. (1986) Eur. J. Biochem. 158, 477 482.

Marder, J. B., Goloubinoff, P. and Edelman, M. (1984) J. Biol. Chem. 259, 3900-3908.

Mattoo, A. K., Hoffrnan-Falk, H., Marder, J. B. and Edelman, M. (1984) Proc. Natl. Acad. Sci. USA 81, 1380-1384.

Merrifield, R. B. (1963) J. Amer. Chem. Soc. 85, 2149.

Metz., J. G. and Bishop, N. I. (1980) Biochem. Biophys. Res. Commun. 94, 560-566.

Metz, J. G., Wong, J. and Bishop, N. I. (1980) FEBS Lett. 114, 61-66.

Metz, J. G., Bricker, T. M. and Seibert, M. (1985) FEBS Lett. 185, 191-196.

Metz, J. G., Pakrasi, H. B., Seibert, M. and Amtzen, C. J. (1986) FEBS Lett. 205, $269-$ 274.

Michel, H. and Deisenhofer, J. (1986) in Encyclopedia of Plant Physiology, New Series, Vol. 19, Photosynthesis II (Staehlin, L. A. and Arntzen, C. J., eds.) pp. 371-381, Springer-Vtilag, Berlin.

Michel, H. and Deisenhofer, J. (1988) Biochemistry 27, 1-7.

Miles, E. W. (1977) Methods Enzymol. 47, 431-442.

Miller, A.-F. and Brudvig, G. W. (1989) Biochemistry 28, 8181-8190. 
Miller, A. F. and Brudvig, G. W. (1990) Biochemistry 29, 1385-1392.

Mimuro, M., Yamazaki, I., Itoh, S., Tamai, N. and Satoh, K. (1988) Biochim. Biophys. Acta 933, 478-486.

Miyao, M., Murata, N., Lavorel, J., Maison-Peteri, B., Boussac, A. and Etienne, A.-L. (1987) Biochim. Biophys. Acta 890, 151-159.

Miyao, M. and Murata, N. (1984) FEBS Lett. 170, 350-354.

Miyao, M. and Murata, N. (1985) FEBS Lett. 180, 303-308.

Murata, N. et al. (1984) Biochim. Biophys. Acta 765, 363-369.

Nakatani, H. Y.. Ke, B., Dolan, E. and Amtzen, C. J. (1984) Biochim. Biophys. Acta 765, 347-352.

Nanba, O. and Satoh, K. (1987) Proc. Natl. Acad Sci. USA 84, 109.112.

Newell, W. R., van Amerongen, H., van Gror.islle, R., Aalberts, J. W., Drake, A. F., Udvarhelyi, P. and Barber, J. (1988) FEBS Lett. 228, 162-166.

Nisirnoto, Y., Yamashita, J. and Horio, T. (1973) J. Biochem. 73, 515-521.

Ohad, 1., Kyle, D. J. and Hirshberg, J. (1985) Embo J. 4, 1655-1659

Ohba, M., Sato, R., Yoshida, Y., Bieglmayer, C. and Ruis, H. (1979) Biochim. Biophys. Acta 572, 352-362.

Ono, T.-A. and Inoue, Y. (1983a) Biochim. Biophys. Acta 723, 191-201.

Ono, T.-A. and Inoue, Y. (1983b) FEBS Letr. 164, 255-260.

Ono, T.-A. and Inoue, Y. (1985) Biochim Biophys. Acta 806, 331-340.

Pecoraro, V. L. (1988) Photochem Photobial. 48, 249-264.

Pickering, M. V. and Newton, P. (1990) LC-GC 8, 778-781.

Preston, C. and Seibert, M. (1989) Photosynth. Res. 22, $101-113$. 
Preston, C. and Seibert, M. (1990) in Current Research in Photosynthesis, Vol. 1 (Baltscheffsky, M., ed.) pp. 925-928, Kluwer Academic Publishers, Dordrecht.

Preston, C. and Seibert, M. (1991a) Biochemistry 30, 9615-9624.

Preston, C. and Seibert, M. (1991b) Biochemistry 30, 9625-9633.

Rao, J. K. M., Hargrove, P. A. and Argos, P. (1983) FEBS Lett. 156, 165-169.

Rasmussen, O. F., Bookjans, G., Stummann, B. M. and Henningsen, K. W. (1984) Plant Mol. Biol. 3, 191-199.

Reichlin, M. (1980) Methods Enzymol. 70, 159-165.

Renger, G. and Weiss, W. (1986) Biochim. Biophys. Acta 850, 184-196.

Rivier, J., McClintock, R., Galyean, R. and Anderson, H. (1984) J. Chrom. 288, 303328.

Rochaix, J.-D., Dron, M., Rahire, M. and Malnoe, P. (1984) Plant Mol. Biol. 3. 363370.

Rogers, S., Wells, R. and Rechsteiner, M. (1986) Science 234, 364.368.

Rutherford, A. W., Seibert, M. and Metz, J. G. (1988) Biochim Biophys. Acta 932, 171176.

Rutherford, A. W., Zimmerman, J. L. and Mathis, P. (1984) FEBS Lett. 165, 156-162.

Sauer, K., Yachandra, V. K., Britt, R. D. and Klein, M. P. (1991) in Manganese Redox Enzymes (Pecoraro, V. L., ed.), VCH Publishers, New York (in press).

Saygin, O. and Witt, H. T. (1987) Biochim. Biophys. Acta 893, 452-469.

Sayre, R. T., Andersson, B. and Bogorad, L. (1986) Cell 47, 601-608.

Seibert, M., DeWit, M. and Stzehlin, L. A. (1987) J. Cell Biol. 105, 2257-2265.

Seibert, M.. Cotton, T. M. and Metz, J. G. (1988) Biochim. Biophys. Acta 934, 235-246.

Seiber, M., Tamura, N. and Inoue, Y. (1989) Biochim Biophys. Acta 974, 185-191. 
Sigel, M. B., Sinha, Y. N. and VanderLaan, W. P. (1983) Methods Enzymol. 93, 3-12.

Silverthome, J. and Ellis, R. J. (1980) Biochim Biophys. Acta 607, 319-330.

Sivaraja, M. and Dismukes, G. C. (1988) Biochemistry 27, 3467-3475.

Styring, S. A. and Rutherford, A. W. (1988) Biochemistry 27, 4915-4923.

Takahashi, Y. and Satoh, K. (1989) Biochim. Biophys. Acta 973, 138-146.

Takahashi, M., Shiraishi, T. and Asada, K. (1988) FEBS Lett. 240, 6-8.

Takayama, H., Iwaki, S., Tamoto, K. and Koyama, J. (1984) Biochim Biophys. Acta 799, 151-157.

Tam, J. P., Heath, W. F. and Merrifield, R. B. (1983) J. Amer. Chem. Soc. 105, $6442-$ 6455.

Tamura, N. and Cheniae, G. (1985) Biochim. Biophys. Acta 809, 245-259.

Tamura, N. and Cheniae, G. (1986) FEBS Lett. 200, 231-236.

Tamura, N. and Cheniae, G. (1987) Biochim. Biophys. Acta 890, 179-194.

Tamura, N., Ikeuchi, M. and Inoue, Y. (1989a) Biochim Biophys. Acta 973, 281-289.

Tamura, N., Inoue, Y. and Cheniae, G. (1989b) Biochim. Biophys. Acta 976, 173-181.

Tamura, N., Inoue, H. and Inoue, Y. (1990) Plant Cell Physiol. 31, 469-477.

Taylor, M. A., Nixon, P. A., Todd, C. M., Barbe;, J. and Bowyer, J. R. (1988) FEBS Lett. 235, 109-116.

Telfer, A., Barber, J. and Evans, M. C. W. (1988) FEBS Lett. 232, 209-213.

Tetenkin, V. L., Gulyaev, B. A., Seibert, M. and Rubin, A. B. (1989) FEBS Lett. 250, 459.463 .

Towbin, H., Staehelin, T and Cordon, J. (1979) Proc. Natl. Acad. Sci. USA 76, 43504353.

Trebst, A. (1986) Z. Naturforsch. 41C, 240-245. 
Virgin, 1, Styring, S. and Andersson, B. (1988) FEBS Lett. 233, 408-412.

Webber A. N., Packham, L., Chapman, D. J., Barber, J. and Gray, J. C. (1989) FEBS Lett. 242, 259-262.

Yachandra, V. K., Guiles, R. D., McDermoth, A. E., Britt, R. D., Dexheimer, S. L., Sauer, K. and Klein, M. P. (1986) Biochim. Biophys. Acta 850, 324-332.

Yachandra, V. K., Guiles, R. D., McDermott, A. E., Cole, J. L., Brith, R. D., Dexheimer, S. L., Sauer, K. and Klein, M. P. (1987) Biochemistry 26, 59745981.

Yamashita, T., Tsuji, J. and Tomita, G. (1971) Plant Cell Physiol. 12, 117-126.

Yocum, C. F., Yerkes, C. T., Blankenship, R. E., Sharp, R. R. and Babcock, G. T. (1981) Proc. Natl. Acad. Sci. USA 78, 7507-7511.

Youvan D. C., Bylina, E. J., Alberti, M., Begusch, H. and Hearst, J. E. (1984) Cell 37, 949-957.

Zurawski, G., Bohnert, H., Whitfeld, P. and Bottomley, W. (1982) Proc. Natl. Acad. Sci. USA 79, 7699-7703. 
